Portland State University

PDXScholar

Spring 6-8-2017

\title{
Wolbachia-Host Interactions and the Implications to Insect Conservation and Management
}

Amy Michelle Truitt

Portland State University

Follow this and additional works at: https://pdxscholar.library.pdx.edu/open_access_etds

Part of the Microbiology Commons

Let us know how access to this document benefits you.

\section{Recommended Citation}

Truitt, Amy Michelle, "Wolbachia-Host Interactions and the Implications to Insect Conservation and Management" (2017). Dissertations and Theses. Paper 3643.

https://doi.org/10.15760/etd.5527

This Dissertation is brought to you for free and open access. It has been accepted for inclusion in Dissertations and Theses by an authorized administrator of PDXScholar. Please contact us if we can make this document more accessible: pdxscholar@pdx.edu. 
Wolbachia- Host Interactions and the Implications to Insect

Conservation and Management

by

Amy Michelle Truitt

A dissertation submitted in partial fulfillment of the requirements for the degree of

\author{
Doctor of Philosophy \\ in \\ Environmental Sciences and Resources
}

Dissertation Committee:

Catherine E. de Rivera, Chair

Daniel Ballhorn

Anne Duplouy

Joseph Maser

Michael Murphy

Portland State University

2017 
C 2017 Amy Michelle Truitt 


\section{ABSTRACT}

Parasitic reproductive endosymbionts are emerging as formidable threats to insect biodiversity. Wolbachia are prevalent maternally inherited intra-cellular bacteria found in $>50 \%$ of arthropod species. These symbiotic bacteria interact with their hosts in diverse ways, most often they alter host reproduction causing four conditions that all selectively favor infected females: feminization, male killing, parthenogenesis, and cytoplasmic incompatibility (CI). Furthermore, depending on strain-type and host genetic background, Wolbachia are known to affect insect behavior, expand or shift host thermal tolerance ranges, and confer anti-viral protection to their hosts. Because Wolbachia both reside in and are transmitted with host cell cytoplasm, mitochondria and other cytoplasmically inherited genetic elements become linked with the bacteria. Thus, by enhancing their own transmission, Wolbachia-induced phenotypes can lead to mitochondrial selective sweeps, which may have profound impacts on vulnerable and small insect populations. Elucidating the extent to which endosymbionts influence biological and ecological functions is pivotal to making management decisions regarding imperiled insect species.

My dissertation investigates biological and ecological impacts of hostendosymbiont interactions by examining Wolbachia infections in three different host systems. First, I used the federally threatened butterfly species Speyeria zerene hippolyta to determine whether the general reproductive success of local populations was affected by the introduction of CI-inducing Wolbachia-infected butterflies through implemented species recovery programs. Next, by characterizing the Wolbachia infections of parasitoids associated with the Eurema butterfly clade, I analyzed whether host-parasitoid interactions provide a path for interspecies horizontal transmission. Finally, I conducted a 
laboratory experiment using an isogenic Drosophila melanogaster line to determine whether Wolbachia influence host temperature preference. Together, my research examines how the individual level effects of host-endosymbiont interactions can expand into populations, have broader impacts on insect communities, and potentially impede the conservation and management of insects in nature.

In chapter one, I screened S. z. hippolyta samples from three extant populations for Wolbachia infection. To examine the impacts of Wolbachia on small populations, I analyzed and compared infected and uninfected $S . z$. hippolyta reproductive data and showed that, in a population composed of infected and uninfected S. z. hippolyta, uninfected butterflies had reduced reproductive success (GLMM z $=-8.067, \mathrm{P}<0.0001$ ). I then developed a single-population demographic theoretical model using these same reproductive data to simulate and analyze different potential dynamics of small populations resulting from population supplementation with uninfected, CI-Wolbachia infected, or combined uninfected and infected butterflies. Analysis of model simulations revealed that supplementation with CI-inducing butterflies significantly suppressed hostpopulation size (ANOVA F5,593 $=3349, \mathrm{P}<0.0001)$. A population with 300 uninfected individuals can be reduced by $88.7 \%$ from a single introduction of 50 Wolbachia-infected individuals (Tukey's post-hoc test $\mathrm{P}<0.0001$ ). In addition, supplementation by multiple releases using a combination of 50 infected and 300 uninfected butterflies has a less severe suppression effect, reducing the population by $75.8 \%$, but the reduction occurs 42.6\% faster than with the single release of 50 Wolbachia-infected butterflies (Tukey's post-doc test $\mathrm{P}<0.0001)$.

Parasitoid-host interactions have emerged as probable ecological relationships to 
facilitate horizontal transmission of Wolbachia. In chapter two, I addressed horizontal transmission using Eurema butterflies and their associated parasitoids. From four locations in Northern Queensland, Australia, I collected a total of 404 Eurema hecabe butterfly larvae. Twenty-three parasitoids emerged from the larvae of which 21 were Diptera and two were Hymenoptera. I amplified COI loci fragments from each parasitoid for BLAST query searches and found that 20 individual Diptera parasitoids matched to the genus Exorista and one to the genus Senometopia. One of the Hymenoptera parasitoids matched to the genus Microoplitis and the other to the genus Cotesia. To characterize Wolbachia infections, I used Wolbachia Multi Locus Sequencing Technique (MLST) and discovered that all 20 Exorista parasitoids were infected with an identical Wolbachia strain (ST-41), which is the same strain infecting their Eurema hecabe butterfly hosts. Although, further experiments are necessary to definitively determine that ST-41 Wolbachia are incorporated into germline cells of the parasitoids, this is the first study to provide ecological evidence for inter-ordinal Wolbachia transmission between Lepidoptera and Diptera. Furthermore, this discovery exposes the risk of population augmentation programs that move insects, potentially facilitating the spread of Wolbachia between species within a community through the accidental introduction of new Wolbachia-infected parasitoids.

Finally, both Wolbachia and their insect hosts are temperature sensitive organisms. Wolbachia's replication behavior in their hosts is positively-temperature dependent, while environmental variation can have profound effects on insect's immune function, fitness, and fecundity. In chapter three, I conducted a laboratory experiment using a thermal gradient choice assay and an isogenic Drosophila melanogaster line with 
four different Wolbachia infection statuses - uninfected, $w \mathrm{Mel}, w \mathrm{MelCS}$, and $w \mathrm{MelPop}$ to assess whether a relationship existed between Wolbachia infection and host temperature preference. Results from my laboratory experiment revealed that Wolbachiainfected flies preferred cooler temperatures compared to uninfected flies. Moreover, $D$. melanogaster temperature preferences varied depending on the Wolbachia strain variant with which they were infected; flies infected with the $w$ Mel strain had temperature preferences $2{ }^{\circ} \mathrm{C}$ cooler compared to uninfected flies; flies infected with either $w \mathrm{MelCS}$ or $w$ MelPop strains had preferred temperatures $8^{\circ} \mathrm{C}$ cooler compared to uninfected flies. Wolbachia-associated temperature preference variation within a species can lead to conspecifics occupying different microclimates, genetically adapting to different sets of specific environmental conditions, and may eventually result in ecological and reproductive isolation. While, reproduction isolation is recognized as one of the first stages in speciation, in small populations of endangered and threatened species, the inability to reproduce between conspecifics can drive species to extirpation or extinction.

Collectively, the three chapters of my dissertation set precedent for future integration of host-endosymbiont research prior to implementing population supplementation or translocation programs for the conservation of imperiled insects. 
Dedicated to my mom and dad, my wife, and to the loving memories of Mike Barline and Victor Andres Vargas. 


\section{ACKNOWLEDGEMENTS}

First, thank you to my advisor, Catherine de Rivera. I am forever grateful that, despite my research subject differing from hers, she accepted me into her lab. She inspired me, offered guidance, support, patience, and always took the time to listen.

Thank you to my committee members - Daniel Ballhorn, Anne Duplouy, Joseph Maser, and Michael Murphy. I very much appreciate Daniel Ballhorn's support and for graciously allowing me to conduct my research in his lab. I am eternally grateful to Anne Duplouy for translating French to English for me at my first Wolbachia conference, sharing with me her wisdom and enthusiasm for butterflies and Wolbachia, for always answering my questions, no matter how off-the-wall they may have been, for reminding me to focus, and, most of all, for her friendship. I express my gratitude to Joseph Maser for always having his office door open, for his excitement for and knowledge of science, and for helping me to the finish line. I thank Michael Murphy for his positive influence starting when I was an undergrad, for his population biology class, infectious positive attitude, and for inspiring me by once telling me that he reads a journal article every day.

I was extremely lucky to have traveled extensively for my research and to have had the most exceptional hosts along the way, many with whom I have formed life-long friendships. In Costa Rica, Paola Vargas generously hosted me, translated Spanish for me, and welcomed me into her family. For this, I am deeply thankful. I extend a very warm thank you to Markus Riegler and Cameron Palmer for hosting me and taking me hiking during my research trip in Australia. The advice and help Markus has given me throughout this process is invaluable. Also, thank you to Wolfgang Miller for hosting me in Vienna and providing a vibrant lab filled with exciting discussions. 
For the lab meeting critiques, support, and kindness, thank you to my de Rivera lab mates past and present: Sydney Gonsalves, Brian Turner, Leslie Bliss-Ketchum, Sara Henderson, Jalene Littlejohn, Whitney McClees, Tim Davidson, Erin Kincaid, Aileen Miller, Louisa Pless, and Inez Lawson.

I thank Peter Kern for always keeping it real, texting me back at all hours of the day and night, visiting me in Vienna, being the most amazing tour guide, and for continuing to be my dear friend. For stabbing bazillions of flies for me, talking with me about science, showing me all about the Vienna trains, and for her friendship, thank you, Rupinder Karr. To both Peter and Rupinder, I have two words: Pizza Mafioso.

For always being my loyal and honest friends despite my long absences and constantly canceling plans, thank you to Kateri Spinelli, Jason Deignan, Jill Kuehler, Brett Younginger, Rachel Wagner, Tessa and Mike Boccongelle, and Chris Mongeon. I would never have made it without you.

Thank you to my funding sources for their generous financial support of my research: The National Science Foundation’s GK-12 Program (\#0948041), the Bushby Travel and Graduate scholarship program, the Dunnette Foundation grants, Scion Natural Sciences, Future for Wildlife grant, Butterfly Conservation Grant, and to everyone who backed my crowd funding project "Did you know that butterflies have STDs?" through Sci-Fund challenge and Rockethub.

I am endlessly thankful and grateful for my loving, caring, encouraging, and supportive parents, Linda and CR Truitt. Without their support and late night pep-talks when I called them from all over the world, I would have never made it. All my love. To 
my brother, sister, nieces and nephews, cousins, and aunts and uncles: thank you for always believing that I would succeed.

Finally, thank you to my wife, Erin Beery, for her strength, love, patience, and support. She always kept her sense of humor and believed in me when I doubted myself. She proof-read countless documents and listened to many of my practice talks. I am extremely grateful and thankful for her always staying by my side. 


\section{Table of Contents}

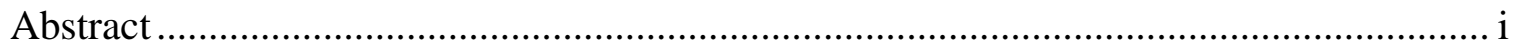

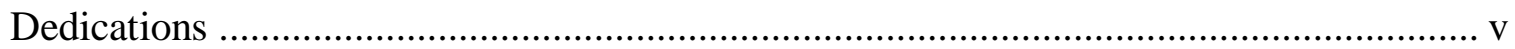

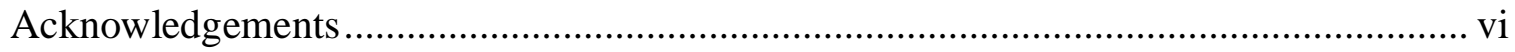

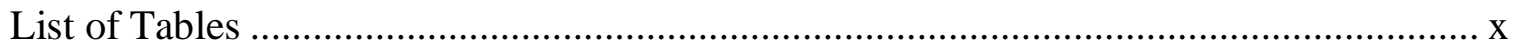

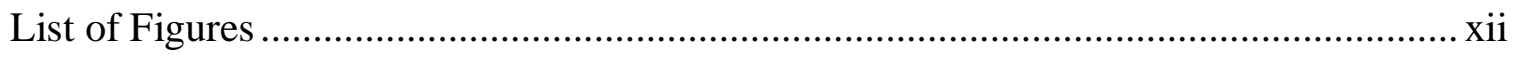

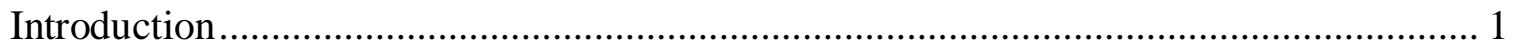

Chapter 1: Wolbachia's butterfly effect: An emerging adversary to the conservation of

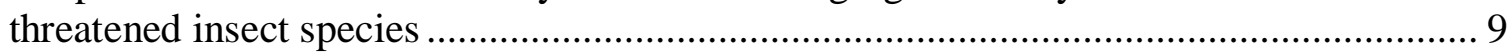

Chapter 2: Eurema butterflies are quite hospitable: characterization of their parasitoids revealed some sharing of identical Wolbachia strains

Chapter 3: Chill out: Wolbachia associated cooling off of Drosophila melanogaster in thermal gradient temperature preference choice assays.

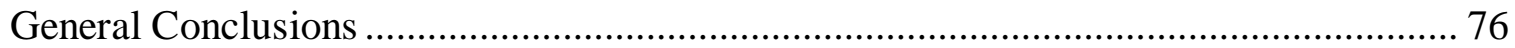

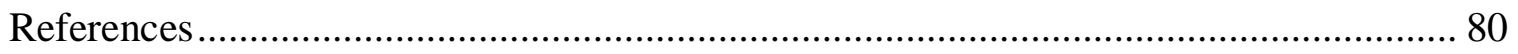

Appendix A: Chapter 1 supplemental tables and figures.......................................... 107

Appendix B: Chapter 3 supplemental tables and figures ......................................... 113

Appendix C: Cascades to Coast GK-12 Curriculum .............................................. 119 


\section{List of Tables}

Table 1.1: List of primers used for PCR amplification of loci, targeted genome, and

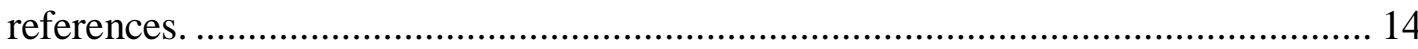

Table 1.2: Thermocycler conditions for PCR of each loci. .............................................. 15

Table 1.3: Model conditions for simulating different population supplementation

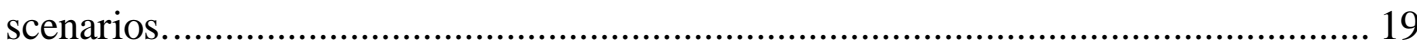

Table 1.4: Definition of parameters and symbols used in the model............................... 20

Table 2.1: Australia field collection site locations, coordinates, and altitudes.

Table 2.2: List of primers used for PCR amplification of loci, targeted genome, and references.

Table 2.3: Annealing temperatures specific to primers sets

Table 2.4: Thermocycler conditions for PCR of each loci.

Table 2.5: Lists the number of larvae and parasitoids collected at each site.

Table 2.6: Results showing alleles from PCR and sequencing analysis of the five Wolbachia MLST loci from each parasitoid collected. Parasitoids morphotypes are listed as: D stands for Diptera and $\mathrm{H}$ for Hymenoptera, D1 = Tachinid fly $(\mathrm{N}=17)$, $\mathrm{D} 2=$ Tachind unique from the others $(\mathrm{N}=3), \mathrm{H} 1=$ small Braconids, larvae yielded six small wasps, but they were pooled for DNA extraction $(\mathrm{N}=1)$. Parasitoids from Mt. Sophia are highlighted in grey. Samples that had unique strains are listed in bold text

Table 2.7: Allelic profiles at the five Wolbachia MLST loci from each Eurema butterfly tested. Butterflies collected at Mt. Sophia are highlighted in grey. The life stage listed for each Eurema is the stage from which we sampled tissues for DNA extractions. Eurema that survived adult the stage are listed in bold text

Table 2.8: Results from BLAST search using COI sequences of parastioids. Species listed were the closest match in the NCBI database where $\mathrm{N}$ indicates the number of samples

Table 3.1: List of primers used for PCR amplification of loci, targeted genome, and references.

Table 3.2: Thermocycler conditions for PCR of each loci. 
Table 3.3: Results from two-way ANOVA examining the effects of Wolbachia-infection, strain-variant, and temperature on Drosophila melanogaster temperature preference.

Table 3.4: Results from Tukey's post hoc multiple comparison test comparing the temperature preference values (the temperature at which the $w \mathrm{Mel}$ - variant had the highest proportion of flies) to the proportion of flies at all of the other available temperatures for each of the four infection treatment options, showing that, for each Wolbachia-variant, its temperature preference was significantly different from the proportion of flies at the seven other temperature ranges for that variant

Table 3.5: Results from Tukey's post hoc multiple comparison test comparing the temperature preference values of each Wolbachia infection treatment (w(uninfected) D. melanogaster and $w \mathrm{Mel}, w \mathrm{MelCS}$, and $w$ MelPop-infected $D$. melanogaster). The temperature where most of the flies landed varied based on their infection: the temperature preference of $\mathrm{w}$ - flies significantly differed from that of $w \mathrm{Mel}$ infected flies and both were significantly different from those of $w \mathrm{MelCS}$ and

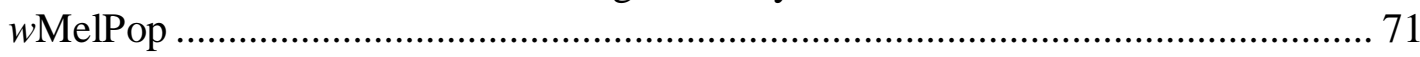




\section{List of Figures}

Figure 1.1: Proportion of Wolbachia-infected female Speyeria zerene hippolyta for each year. Numbers above bars represent the number of combined sampled females from three populations, Cascade Head, Rock Creek, and Mt. Hebo for years 1999 and 2001-2011.

Figure 1.2: Comparison of the number of eggs laid by uninfected $(\mathrm{N}=70)$ versus Wolbachia-infected $(\mathrm{N}=135)$ female $S$. $z$. hippolyta butterflies. Uninfected butterflies laid fewer eggs than infected butterflies. Bars represent SE.

Figure 1.3: Average proportion of eggs that developed into larvae a) from uninfected female butterflies, b) from Wolbachia-infected female butterflies, and c) as a ratio of uninfected to infected butterflies, each as a function of the proportion of Wolbachiainfected butterflies in the population.

Figure 1.4: Simulation results from 100 iteration averages of single populations with nonoverlapping generations under different single release at time point five supplementation scenarios. Graphs illustrate the dynamics of a butterfly population (a) without supplementation, (b) supplementation with 300 uninfected butterflies, (c) supplementation with 1000 uninfected butterflies, (4) supplementation with 50 Wolbachia-infected butterflies, (5) supplementation with 300 Wolbachia-infected butterflies, (6) supplementation with 1000 Wolbachia-infected butterflies.

Figure 1.5: Simulation results from 100 iteration averages of single populations with nonoverlapping generations under different multiple release at eight different time point (odd time points from t5 to 19) supplementation scenarios. Graphs illustrate the dynamics of a butterfly population (a) without supplementation, (b) supplementation with 300 uninfected butterflies, (c) supplementation with 300 Wolbachia-infected butterflies, (4) supplementation with 300 uninfected 300 and 50 Wolbachia-infected butterflies, (d) supplementation with 50 uninfected and 300 Wolbachia-infected butterflies

Figure 1.6: Confidence intervals for model comparisons of (a) single release lowest population sizes, (b) single release population sizes at year 50, (c) multiple release population lowest population sizes, and (d) multiple releases population sizes at year 50

Figure 2.1: Schematic of a phylogeny tree that depicts the relationship between Australian Eurema butterfly species and their associated Wolbachia strain types (STs) as listed below each species. Green plus signs below a species indicates the species is infected and the red minus sign below E. smilax indicates the species is uninfected. Eurema laeta, E. brigitta, E. alitha, and E. hecabe are infected with ST25. Eurema brigitta is infected with a second strain, ST-125, which is the same strain type with which $E$. herla is infected 
Figure 2.2: Inferred phylogenetic tree based on COI sequence framents (544bp) of Eurema constructed by maximum likelihood method (Model T92+G). Eurema hecabe samples from this study are shaded in grey boxes, with dark grey boxes highlight E. hecabe samples collected at Mt. Sophia. Outgroups from other Eurema species retrieved from the NCBI database. Numbers at nodes represent bootstrap balues (1000 replicates) > 50\% and scale bar represents number of nucleotip substitutions per site.

Figure 2.3: Phylogenetic tree based on COI sequence fragments (523bp) constructed by maximum likelihood method (Model T93+G+I). Parasitoid samples from this study are shaded in grey boxes, with dark grey boxes highlighting parasitoids collected from Mt. Sophia..

Figure 2.4: Phylogenetic tree based on concatenated MLST genes (2079bp) constructed by maximum likelihood method (Model T93+G). Outgroups from other known Wolbachia ST and supergroups, listed by ID, host name, and sequence type, were retrieved from the Wolbachia MLST database.

Figure 3.1: $1 \%$ agarose gel with $1 \mathrm{~kb}$ DNA ladder on the far left and PCR amplification products of VNTR-141 loci from: wMel in lane 1, wMelCS in lane 2, wMelPop in lane $3, \mathrm{w}$ - in lane 4 , and blank quality control in lane 5 .

Figure 3.2: Plots showing linearity of temperature change for the different surfaces (a. aluminum rod, b. top, c. bottom, and mid-point of the polycarbonate tube) as measured with K-type thermocouples at regular intervals along the length of apparatus from the hottest end (H3) to the coldest (C3).....

Figure 3.3: Results from temperature preference assays with standard error bars; Y-Axis in each graph is the proportion of flies and the $\mathrm{X}$-Axis represents range of the temperature where flies congregated. Two-way ANOVA results revealed a significant relationship between Wolbachia-infection and the temperature preference of D. melanogaster. 


\section{INTRODUCTION}

Ecosystems are composed of complex ecological relationships among and between species, populations, and communities (Levin 1998; Christian et al. 2015). The nature of these relationships is primarily determined by how organisms adapt on evolutionary timescales to environmental pressures (Levin 1998; Margulis 2004; Moran 2006; Moran et al. 2008). Symbiosis is arguably the most important inter-organismal interaction from which all major life forms have emerged (Margulis 2004). In its simplest form, a symbiotic relationship is defined as different species living together in long-term close associations (de Bary 1879). The constituents of symbiotic relationships have varying effects depending on the association they have formed: mutualism, parasitism, or commensalism (Moran 2006). These associations can be obligate, where the survival of one or both organisms depends on the survival of the other, or facultative, when neither organism relies on the other for their own survival (Moran et al. 2008; Oliver et al. 2010).

In the past several decades, and with the advent of relatively affordable sophisticated molecular biology techniques, ecologists and evolutionary biologists have increasingly appreciated the incredible bacterial diversity on our planet and the critical roles that microorganisms play in biological and ecological processes (Hurst \& Werren 2001; Bordenstein 2003; Telschow et al. 2007; Siozios et al. 2008; Brucker \& Bordenstein 2012; Chrostek et al. 2013; Kern et al. 2015; van Nouhuys et al. 2016). Some of the most interesting and complex symbiotic relationships discovered are between endosymbiotic bacteria and insects (Moran 2006; Mouton et al. 2007; Werren et al. 2008). Endosymbiotic bacteria live inside the cells of insect hosts and are passed to offspring in the cytoplasm of maternal germ line cells (Werren 1997; Margulis 2004). 
Wolbachia, one of many insect endosymbionts, are the most prevalent and well-studied group of endosymbiotic bacteria. Endosymbionts belonging to the genus Wolbachia receive significant attention because they are ubiquitous - estimated to infect 53\% of terrestrial arthropods (Zug \& Hammerstein 2012; Weinert et al. 2015) and 52\% of aquatic insects (Sazama et al. 2017) - and have a wide range of phenotypic effects on their hosts including altering their hosts' reproduction and conferring anti-viral protection against insect-vector borne diseases (Werren 1997; Dobson et al. 2002; Teixeira et al. 2008; Hedges et al. 2008; Werren et al. 2008; Werren 2011; Chrostek et al. 2013; Zug \& Hammerstein 2014; Kern et al. 2015). These bacteria are estimated to have invaded arthropods approximately 200 million y.a. (Gerth \& Bleidorn 2016). Differing distinctly in their host distribution and biology, the primary evolutionary Wolbachia lineages are designated into 16 "supergroups" labeled A-H, except for G (Comandatore et al. 2015).

Parasitic strains of Wolbachia have developed four ways to manipulate their host's reproduction that selectively favor infected females, ensuring their intergenerational transmission and persistence in populations (Werren et al. 2008). Three of these reproductive manipulations, male killing, feminization, and parthenogenesis, selectively favor infected females over males and result in female-biased sex ratio distortions in host populations (Werren et al. 2008). The fourth phenotype, cytoplasmic incompatibility (CI), induces cytoplasmic factors in host gamete cells that cause embryonic death when an egg from an uninfected female is fertilized by a sperm from an infected male (Werren et al. 2008). Unidirectional CI occurs when a host population is infected with a single Wolbachia CI-inducing strain. Several insect taxa including parasitic wasps (Breeuwer et al. 1992), fruit flies (Rousset \& Solignac 1995), leafcutter 
ants (Van Borm et al. 2001), and bruchid beetles (Kondo et al. 2002) are known to be infected with two CI-inducing Wolbachia strains. Bidirectional CI occurs when a doubly infected egg is fertilized by a sperm from a male infected with a different and incompatible Wolbachia strain (Werren et al. 2008). Whether unidirectional or bidirectional, CI results in decreased fitness of uninfected females compared to infected females (Werren et al. 2008). Furthermore, because Wolbachia are transmitted in the cytoplasm of their host's cells, reproductive phenotypes that selectively favor Wolbachiainfected females have the consequence of indirectly selecting for other genetic elements sharing host cytoplasm, most notably mitochondria. Hence, mitochondria "hitch-hike" and spread with Wolbachia, resulting in mtDNA linkage disequilibrium with the Wolbachia strain (Turelli et al. 1992). Indirect selection and linkage disequilibrium can result in a selective sweep of the Wolbachia associated mtDNA haplotypes and reduced mtDNA diversity in host populations (Turelli et al. 1992; Hurst \& Jiggins 2000; Jiggins 2003; Hurst \& Jiggins 2005). Like other heritable selfish genetic elements, Wolbachia can impact genetic diversity of their host populations in ways that may lead to extinction or trigger the beginning stages of speciation (Orgel \& Crick 1980; Hatcher 2000; Hurst \& Werren 2001; Werren 2011).

Genetic diversity, including mtDNA haplotype diversity, is important in small populations that experience geographic isolation from source populations and restricted gene flow, particularly populations of imperiled insect species (Moritz 1994; Crandall et al. 2000; DeSalle \& Amato 2004). Recent studies that examined Wolbachia prevalence in butterflies and moths estimated that up to $80 \%$ of all butterflies and moths (Ahmed et al. $2015)$ and 19 of $22(86 \%)$ butterfly species of conservation concern are infected with 
Wolbachia (Hamm et al. 2014). Emerging diseases are universally acknowledged as a serious threat to biodiversity, exceptionally so for vulnerable species (Daszak et al. 2000). Concerns were first raised about Wolbachia in endangered and threatened butterflies in regard to the endangered Lycaeides melissa samuelis and the possibility that future population supplementation efforts could introduce a novel CI-inducing Wolbachia strain from an infected donor population into an uninfected recipient population (Nice et al. 2009).

Imperiled butterfly conservation efforts that include population supplementation are frequently employed as a method to stimulate population growth while addressing genetic diversity (Crone et al. 2007). However, inter-population transfer of conspecifics can remarkably increase risk of novel disease emergence, which can devastate small populations (Brower 1995; Daszak, 2001; Crone et al. 2007; Altizer \& de Roode 2010). Certainly, these programs employ disease-screening protocols prior to releasing individuals into new areas, but Wolbachia could easily evade detection as they do not produce visible morphological aberrations to their hosts. Moreover, it may take several generations for the effects of a newly introduced Wolbachia infection to become apparent in a population. Male-eliminating phenotypes are recognizable by distorted female to male sex ratios in populations (Hurst \& Jiggins 2000; Jiggins 2003; Duplouy et al. 2010). In contrast, cytoplasmic incompatibility is more difficult to detect and, in large populations where only a few infected individuals are introduced, Wolbachia could potentially remain unnoticed. However, in small populations CI can cause population suppression due to mating incompatibilities between conspecifics (Zabalou et al. 2004; Perlman et al. 2008; Hancock et al. 2011). This suppression effect of Wolbachia strains 
that induce CI was first identified as potential biological control agents by Laven (1967) to suppress pest insect populations. Subsequent research showed that when male hosts were artificially infected with CI-inducing Wolbachia they became effectively "sterile" because they did not produce viable offspring when they mated with uninfected females (Laven 1967; Dobson et al. 2002; Zabalou et al. 2004; Bourtzis 2008). Theoretical models predict that, depending on the size of a population and the number of Wolbachiainfected individuals released, population suppression can be successful after only a single exposure to a novel CI-inducing Wolbachia strain (Dobson et al. 2002; Gebiola et al. 2016).

Although Wolbachia are primarily vertically transmitted, their prevalence among insect species suggests they may occasionally transfer horizontally between individuals and diverged taxa (Riegler et al. 2005; Schuler et al. 2013; Morrow et al. 2014; Ahmed et al. 2016; Schuler et al. 2016). The exact mechanisms responsible for horizontal transmission have not yet been discovered; however, research indicates that close ecological interactions appear to be fundamental to interspecies transfer, including hostparasitoid interactions and shared resources (Heath et al. 1999; Huigens et al. 2004; Morrow et al. 2014; Raychoudhury et al. 2014; Ahmed et al. 2015a; Li et al. 2016). The opportunity for interspecies Wolbachia transmission is presented when insect parasitoid larvae develop on or within the body of their arthropod hosts (Maure et al. 2014). The most likely direction of Wolbachia transmission is from parasitoid-host to the parasitoid because parasitoids most often kill their hosts. However, some hosts do survive and even reproduce following the emergence of a parasitoid (DeVries 1984; Shaw \& Huddleston 1991). Wolbachia could possibly be transferred from parasitoid to their host if the host 
survives emergence of a parasitoid and reproduces. Population supplementation and translocation programs likely present more opportunities for species to species Wolbachia transfer than would otherwise be possible, including transfer to vulnerable insect species (Snyder et al. 1996; Daszak et al. 2001) as introduced individuals may carry Wolbachia that will later transfer into and affect a new host's population dynamics.

The effects of Wolbachia on insect populations expand beyond theoretical bottlenecking via reproductive manipulations and may also include strong effects due to host-endosymbiont conflicts. Wolbachia, like their insect hosts, are also extremely sensitive to temperature and have positive temperature-dependent replication behavior (Mouton et al. 2006; Mouton et al. 2007; Chrostek et al. 2013; Strunov et al. 2013a). Overlapping host and symbiont thermal tolerance ranges may be narrow and independent organismal physiological requirements may disagree (Mouton et al. 2007). Several scenarios could emerge from host-symbiont temperature preference conflicts: 1 ) uninfected and infected conspecifics might experience genetic differentiation as they adapt to different sets of specific environmental conditions (Martin \& Huey 2008; Hoffmann \& Sgrò 2011; Huey et al. 2012; Rajpurohit \& Schmidt 2016), 2) over- or under-replication of Wolbachia under different temperatures could induce various costs or benefits to the host (Chrostek et al. 2013), or 3) Wolbachia could be selected against and lost from the host population as observed by Chrostek et al. (2013). Theory predicts that with global climate change, temperature will be the principal factor affecting insects, forcing them to either perish or migrate to suitable habitats (Bale et al. 2002). Studies addressing the importance of Wolbachia on host temperature preference and host response to climate change, which could have significant impacts on endangered and 
threatened species, remain unrepresented in the literature.

To date, despite the growing list of endangered and threatened species, few studies have addressed the biological and ecological impacts of extremely common reproductive endosymbionts like Wolbachia on their respective hosts. My overall research goals were to elucidate ways in which Wolbachia impact their host's biology and ecology. I was particularly interested in investigating the impact of spillovers into populations and communities and the implications to the conservation and management of endangered and threatened insects. In this context, in chapter 1, I provide the first empirical investigation of Wolbachia infection in a federally listed insect species, the butterfly Speyeria zerene hippolyta. Importantly, this species has a population supplementation program as part of its species recovery plan. I developed a singlepopulation demographic model to demonstrate the Wolbachia-driven dynamics of different supplementation scenarios by using multiple years of empirical reproductive data.

In chapter two, I address the lack of ecological studies to empirically support phylogenetic analyses indicating horizontal transmission of Wolbachia by examining parasitoids that afflict butterfly species from the genus Eurema in Australia. Previous studies have revealed an identical CI-inducing Wolbachia strain in two Japanese Eurema species, E. hecabe and E. mandarin (Hiroki et al. 2004; Narita et al. 2007a) and five Australian Eurema species (Kern et al. unpublished). I hypothesized that if parasitoid interactions are a route for interspecies horizontal transmission of Wolbachia, Eurema butterfly species and their associated parasitoids would be infected with identical Wolbachia strains. Using multi-locus sequencing technique (MLST) (Baldo et al. 2006), I 
characterized the Wolbachia strains of Australian Eurema butterflies and their parasitoids.

Finally, in chapter 3, I explore endosymbiont-host conflict that may arise from divergent physiological needs of each organism by testing whether a relationship exists between Wolbachia and host temperature preference. I developed a three-dimensional thermal gradient chamber apparatus and conducted a laboratory experiment comparing temperature preferences of uninfected and Wolbachia-infected fruit flies (Drosophila melanogaster). This study is the first to employ thermal choice assays to address Wolbachia associated temperature-dependent behavioral phenotypes. Results from my experiment begin to fill the knowledge gap regarding Wolbachia's influence on host physiology and ways in which temperature preference disparities of conspecifics may affect a species ecology.

This dissertation introduces a new approach, rooted in empirical data, to better understand how Wolbachia-host interactions behave in natural and laboratory conditions, and discusses ways in which this endosymbiont could profoundly affect population trajectories. In addition, these field- and experiment-informed studies fills crucial gaps of knowledge in the Wolbachia field and provides platforms from which future research can build. My research indicates that understanding the population trajectories of species given their endosymbionts is imperative prior to implementation of population supplementation or translocation programs. 


\section{Chapter 1: Wolbachia's butterfly effect: An emerging adversary to the conservation of threatened insect species}

\section{INTRODUCTION}

Ecologists and natural resource managers have developed various population management programs, including population supplementation, that are aimed at mitigating some of the risks associated with small populations of endangered and threatened species (Snyder et al. 1996; Crone et al. 2007). Population supplementation aims to enhance populations that are at risk of extinction while maintaining or increasing genetic diversity. Small unstable populations are supplemented with individuals of the same species from the same population or from a larger, more stable population (Crone et al. 2007). The latter type of supplementation brings populations together that otherwise may have lacked gene flow. In the United States, at least 10 programs breed and release butterflies as a conservation method for threatened and endangered species, some of which are considered important pollinators (Schultz et al. 2008). While supplementation programs are diligent about not releasing visibly infected butterflies into recipient populations, movement between populations has the potential to spread less obvious hitchhiking microbes such as endosymbiotic bacteria like Wolbachia.

Widespread in terrestrial insects, Wolbachia comprise a diverse group of heritable endosymbiotic bacteria, some of which are characterized as parasitic as they manipulate their host's reproductive system in one of four ways: feminization, male killing, parthenogenesis, or cytoplasmic incompatibility (CI) (Werren et al. 2008; Zug \& Hammerstein 2012; Kern et al. 2015; Weinert et al. 2015). Each of these phenotypes favors selection for infected females, ensuring Wolbachia's persistence through 
intergenerational transmission. Cytoplasmic incompatibility is the most extensively found reproductive manipulation in insects. Cytoplasmic incompatibility does not cause a female biased sex ratio distortion in their host's population, but rather embryo mortality, which ranges from barely detectable to complete, when an egg from an uninfected female is fertilized by a sperm from an infected male, or when an infected egg is fertilized by a sperm from a male infected with a different and incompatible Wolbachia strain (Yen \& Barr 1973; Werren 1997; Zabalou et al. 2004; Werren et al. 2008). The consequences of $\mathrm{CI}$ are reduced fitness of uninfected females and a reproductive advantage to infected females (Werren et al. 2008). Such reproductive manipulation can cause reproductive isolation and lead to speciation (Brucker \& Bordenstein 2012).

Cytoplasmic incompatibility-inducing Wolbachia were first identified as potential biological control agents by Laven (1967) to suppress pest insect populations. Subsequent research showed that when male hosts were artificially infected with CI-inducing Wolbachia they became effectively "sterile" because they did not produce viable offspring when they mated with uninfected females (Laven 1967; Dobson et al. 2002; Zabalou et al. 2004; Bourtzis 2008). Theoretical models predict that population suppression can be successful after only a single exposure to a novel CI-inducing Wolbachia strain (Dobson et al. 2002).

Wolbachia was recently detected in 19 Lepidoptera species of conservation concern, including one species spotlighted for captive rearing efforts (Neonympha mitchelli mitchelli) (Tolson 2008; Hamm et al. 2014). Accidental exposure of CIinducing Wolbachia to threatened or endangered insect populations through a population supplementation program may unintentionally have similar suppression effects on 
recipient populations (Nice et al. 2009). Thus, the nature of population supplementation programs and the ubiquity of Wolbachia in butterflies of conservation concern prompted me to investigate the prevalence of Wolbachia in populations of the threatened butterfly species Speyeria zerene hippolyta, (common name: Oregon silverspot butterfly). Here I examined the potential consequences that endosymbiotic bacteria Wolbachia might have had on several isolated populations of S. z. hippolyta, which carry Wolbachia and are managed by a population supplementation program. The goal of this study was to assess whether accidental introduction of Wolbachia could have negative impacts on small, at risk populations of insects.

I hypothesized that if Wolbachia had been accidently introduced and spread through S. z. hippolyta populations, the proportion of infected butterflies would increase over time. If the Wolbachia strain type induced CI, it would decrease reproductive output of uninfected females and may confer a positive frequency dependent fitness advantage to Wolbachia-infected female butterflies. I further hypothesized that CI-inducing Wolbachia could cause a temporary or permanent reduction in S. z. hippolyta population sizes due to offspring mortality. To address these hypotheses, I sampled female $S$. $z$. hippolyta butterflies that had been used in a population supplementation program, screened them for Wolbachia, and collected and analyzed their reproductive output data. Furthermore, I developed a single-population demographic model to simulate different potential dynamics of small populations resulting from population supplementation with uninfected, CI-Wolbachia infected, or combined uninfected and infected butterflies.

The infection dynamics of CI-inducing Wolbachia invasion into naïve host populations have previously been described for single populations, parapatric 
populations, and populations with a mainland-island structure (Caspari \& Watson 1959;

Fine 1978; Hoffmann et al. 1990; Hurst 1991; Turelli 1994; Telschow et al. 2007; Flor et al. 2007; Turelli 2010). Extensions of these models have been used to describe the release of CI-inducing Wolbachia-infected hosts into large populations with the goal of either successful population suppression of pest insects or identifying population replacement strategies for mosquitoes that carry insect-vector borne diseases that affect humans (Dobson et al. 2002; Zabalou et al. 2004; Jansen et al. 2008; Hancock et al. 2011). In contrast, my model aims to build on previous models by describing the population dynamics when CI-inducing Wolbachia is released into small populations of endangered insect species.

This study is the first, to my knowledge, to use reproductive data from threatened or endangered insects to show that the spread of Wolbachia in a natural population is associated with reduced fertility of uninfected hosts in the population and that this fitness reduction is positively frequency dependent. My results have important implications not only for S. z. hippolyta conservation, but for the conservation of all imperiled insect species, including some key pollinators.

\section{MATERIALS AND METHODS}

\section{Butterfly populations}

Reduced to five geographically isolated populations, the federally threatened $S . z$. hippolyta (Family: Nymphalidae) historically inhabited coastal prairies and grasslands from southern Washington to northern California. Three of the five extant populations, Bray Point, Cascade Head, and Rock Creek, all of which are located in Oregon, are 
supplemented by the captive rearing and release program as dictated by the S. z. hippolyta Recovery Plan (US Fish \& Wildlife Service 2001). Cascade Head (4503’24”N

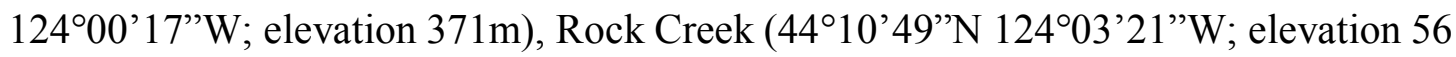

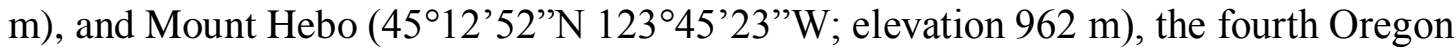
population, have all been used as source populations at some time during the program, though the most stable population, Mount Hebo, has been the primary source population.

\section{Measurement, tissue collection, Wolbachia screen, and reproductive data}

Individual leg tissue samples were taken from 234 S. z. hippolyta female specimens used in the population supplementation program from 1999 and 2001-2011(no butterflies were collected in 2000) at the Oregon Zoo (Portland, Oregon) and Woodland Park Zoo (Seattle, Washington). Because S. z. hippolyta is a federally listed threatened species, I had limited tissue available for use in my study. Therefore, I extracted DNA from only a portion of each tissue sample and preserved the remaining portion in case a second DNA extraction was required. All tissue samples were stored individually at $20^{\circ} \mathrm{C}$ in $1.5 \mathrm{ml}$ microcentrifuge tubes that contained absolute ethanol. Three of the sampled butterflies were males, and thus were included in the Wolbachia screen but excluded from analyses on reproduction data. Individual tissues were homogenized in $1.5 \mathrm{ml}$ microcentrifuge tubes using liquid nitrogen and microtube pestles (Scientific Specialties Inc., Lodi, CA). All DNA extractions were performed using the Qiagen DNeasy Blood and Tissue kit, following the manufacturer's protocol (Qiagen, Valencia, CA, USA). Diagnostic PCR amplification of $28 S \mathrm{rDNA}$ was performed to test the quality of DNA using universal arthropod primer sets (Werren et al. 1995a). For samples that 
failed to detect $28 S$ rDNA or that yielded light bands, I performed a second DNA extraction.

I screened individual S. z. hippolyta for Wolbachia by performing PCR amplification using Wolbachia specific $16 S$ rDNA primer sets and thermocycling conditions as described by Werren \& Windsor (2000). Polymerase chain reactions were each a total of $25 \mu 1$ comprised of $12.5 \mu 12 X$ Phusion High-Fidelity PCR Master Mix (New England BioLabs Inc.), 2-4 $\mu 1$ template DNA, and nuclease-free molecular grade water to $25 \mu 1$. All PCR products were visualized with ethidium bromide on $1 \%$ agarose gels. For samples from which arthropod $28 S$ was successfully amplified, but indicated a negative result for Wolbachia-infection, PCR amplification of $16 S$ rDNA was repeated with a higher concentration of genomic DNA template. Primers and thermocycler conditions are listed in Tables 1.1 and 1.2.

Table 1.1: List of primers used for PCR amplification of loci, targeted genome, and references.

\begin{tabular}{|c|c|c|c|c|}
\hline Loci & Primers & $\begin{array}{l}\text { Target } \\
\text { genomes }\end{array}$ & Sequences ( $\left(5^{\prime}-3^{\prime}\right)$ & References \\
\hline \multirow[t]{2}{*}{$16 S$} & $16 \mathrm{SW}$ spec $\mathrm{F}$ & Mitochondria & CATACCTATTCGAAGGGATAG & $\begin{array}{l}\text { Werren \& } \\
\text { Windsor }\end{array}$ \\
\hline & $16 \mathrm{SW}$ spec $\mathrm{R}$ & & AGCTTCGAGTGAAACCAATTC & 2000 \\
\hline \multirow[t]{2}{*}{$28 S$} & 28SF & Nuclear & CCCTGTTGAGCTTGACTCTAGTCTGGC & $\begin{array}{l}\text { Werren et } \\
\text { al. } 1995 \text { a }\end{array}$ \\
\hline & 28SR & & AAGAGCCGACATCGAAGGATC & \\
\hline
\end{tabular}


Table 1.2: Thermocycler conditions for PCR of each loci.

\begin{tabular}{|c|c|c|}
\hline & $\begin{array}{l}\text { Mitochondrial loci } \\
16 S \text { and } C O I\end{array}$ & $\begin{array}{l}\text { Nuclear loci } \\
28 S\end{array}$ \\
\hline Denaturation & $98^{\circ} \mathrm{C}$ for $4 \mathrm{~min}$ & $98^{\circ} \mathrm{C}$ for $2 \mathrm{~min}$ \\
\hline \multirow[t]{9}{*}{ Cycling } & 5 cycles: & 1 cycle: \\
\hline & $98^{\circ} \mathrm{C}$ for $2 \mathrm{~min}$ & $98^{\circ} \mathrm{C}$ for $1 \mathrm{~min}$ \\
\hline & $\begin{array}{l}60^{\circ} \mathrm{C} \text { for } 1 \mathrm{~min} \text {, } \\
\text { and } 72^{\circ} \mathrm{C} \text { for } 1 \mathrm{~min}\end{array}$ & $\begin{array}{l}56^{\circ} \mathrm{C} \text { for } 1 \mathrm{~min}, \\
\text { and } 72^{\circ} \mathrm{C} \text { for } 2 \mathrm{~min}\end{array}$ \\
\hline & 35 cycles: & 35 cycles: \\
\hline & $98^{\circ} \mathrm{C}$ for $30 \mathrm{sec}$ & $98^{\circ} \mathrm{C}$ for $15 \mathrm{sec}$ \\
\hline & $\begin{array}{l}60^{\circ} \mathrm{C} \text { for } 45 \mathrm{sec}, \\
\text { and } 72^{\circ} \mathrm{C} \text { for } 1 \mathrm{~min}\end{array}$ & $\begin{array}{l}56^{\circ} \mathrm{C} \text { for } 1 \mathrm{~min}, \\
\text { and } 72^{\circ} \mathrm{C} \text { for } 2 \mathrm{~min}\end{array}$ \\
\hline & & 1 cycle: \\
\hline & & $94^{\circ} \mathrm{C}$ for $15 \mathrm{sec}$ \\
\hline & & $56^{\circ} \mathrm{C}$ for $1 \mathrm{~min}$ \\
\hline Final elongation & $72^{\circ} \mathrm{C}$ for $10 \mathrm{~min}$ & $72^{\circ} \mathrm{C}$ for $7 \mathrm{~min}$ \\
\hline
\end{tabular}

Both zoos collected fertility data for every female butterfly used in the captive rearing and release program during the years 2003-2011 (N=205). Before looking at the infection status of the butterflies, I used these fertility data to determine three measures of fertility: 1) whether butterflies laid eggs, 2) the number of eggs laid by females that did lay eggs, and 3) the number of eggs that successfully developed into larvae (hatched) compared to the number that did not hatch. I also employed these data in the demographic model. To determine if butterfly size affected their reproductive output, 
expired butterflies were placed onto Cartesian graph paper next to a centimeter ruler aligned with their abdomen, thorax, and head. I used a Panasonic Lumix DMC-FZ18 camera that was stationed above the butterflies to capture images. Images were scaled and butterflies were measured using ImageJ software (National Institute of Health, Bethesda, MD, USA).

\section{Data analysis}

For each Year and Site from which S. z. hippolyta were used in the captive rearing and release program, I determined the number of Wolbachia-infected butterflies versus the number of butterflies that were uninfected. To determine whether body sizes were associated with reproductive output, I used linear regression and compared slopes of the regression lines describing the relationships between body sizes and number of eggs laid by uninfected and infected butterflies. I repeated the previous described statistical test for comparison using proportion of eggs that hatched instead of number of eggs laid for uninfected and infected butterflies. In addition, a t-test was used to determine whether uninfected and Wolbachia-infected butterflies body sizes were significantly different. A Mann-Whitney test was used to compare the number of eggs laid by uninfected and Wolbachia-infected female butterflies.

Using R statistical software version 3.3.2 (R Development Core Team 2016) and linear-mixed model package "Ime4" (Bates 2014), I created a general linear mixed effects model (GLMM) to compare Hatch Success (the number of laid eggs that hatched compared to the number that did not hatch) between butterflies of two different Infection Statuses: uninfected female butterflies and Wolbachia-infected female butterflies. The 
predictor variable in my model was Wolbachia Infection Status and had a binomial distribution of the number hatched given the number of eggs that did not hatch (using column bind). A GLMM was used for this analysis because 1) it allows for the use of binomial data and 2) it allows for the inclusion of random effects. The random effects in my model were Year and Site, with Site (Cascade Head, Rock Creek, and Mt. Hebo) nested within Year (2003-2011). Finally, my GLMM model used a binomial error distribution and logit link function. The R code used and GLMM model outputs are in Appendix A.

I created a scatterplot of the proportion of eggs that hatched (number of hatched eggs from the total number of eggs laid) from uninfected female butterflies against the frequency of Wolbachia-infected butterflies among my specimens to visually assess the relationship between the frequency of Wolbachia-infection among my specimens and the fertility of uninfected butterflies. To avoid creating a multiplicity issue, I used these plots to visualize trends, but did not perform statistical analyses on them.

I also used the reproductive data and the systems dynamics modeling software STELLA v. 10.0.6 (ISEE systems 2014) to develop a demographic population model (model description below).

\section{Population demographic model}

I referenced Hoffman et al. (1990) and Dobson et al. (2002) and used an extension of the logistic growth equation to develop a model describing the population dynamics of a single panmictic butterfly population with discrete and non-overlapping generations under four different scenarios (Table 1.3). My model assumed that all 
butterflies mated only once. Additionally, my model assumed a 1:1 female to male sex ratio in all populations, as a sex ratio distortion in $S$. z. hippolyta has not been detected. I first modeled a control population to describe the population dynamics of a completely uninfected butterfly population without supplementation and an initial population size of 300. Let $u_{t}$ denote the number of uninfected butterflies, $w_{t}$ denote number of Wolbachiainfected butterflies, and $N_{t}$ denote the total number of butterflies in the population at time $t$. Then I described the intergenerational changes in the number of uninfected butterflies by

(1) $u_{t+1}=u_{t} r\left(1-\frac{u_{t}}{K}\right) p$, where $r$ denotes the population growth rate and is calculated as the product of the number of eggs laid and the proportion of eggs that hatch, $p$ denotes adult survival, and $K$ denotes carrying capacity of the population. The number of eggs laid per female butterfly was set to 162 ; a value derived from previously collected $S$. z. hippolyta reproductive data. I included stochasticity in the model by randomizing larval survival rates yearly between 0.015 and 0.023 , which represents seasonal variation in butterfly abundance (US Fish \& Wildlife Service). Carrying capacity $K$ was set at 500 butterflies, but can be as low as 200-500 in some of the S. z. hippolyta populations (McCorkel et al. 1980). Adult butterfly survival was set to $65 \%$ based on the best available data, adult survival during release events. Model symbols and definitions are listed in Table 1.4. 
Table 1.3: Model conditions for simulating different population supplementation scenarios.

\begin{tabular}{|c|c|c|c|}
\hline $\begin{array}{l}\text { Model numbers and } \\
\text { description }\end{array}$ & $\begin{array}{l}\text { Number of times } \\
\text { butterflies were } \\
\text { released }\end{array}$ & $\begin{array}{c}\begin{array}{c}\text { Number of } \\
\text { uninfected } \\
\text { butterflies released } \\
\text { each time }\end{array} \\
\end{array}$ & $\begin{array}{c}\text { Number of } \\
\text { Wolbachia-infected } \\
\text { butterflies released } \\
\text { each time }\end{array}$ \\
\hline $\begin{array}{l}\text { Model 1: } \\
\text { Uninfected no-CRR }\end{array}$ & 0 & 0 & 0 \\
\hline $\begin{array}{l}\text { Model 2: } \\
\text { Single release } \\
\text { uninfected } 300\end{array}$ & 1 & 300 at $t_{5}$ & 0 \\
\hline $\begin{array}{l}\text { Model 3: } \\
\text { Single release } \\
\text { uninfected } 1000\end{array}$ & 1 & 1000 at $\mathrm{t}_{5}$ & 0 \\
\hline $\begin{array}{l}\text { Model 4: } \\
\text { Single release } \\
\text { Wolbachia-infected } 50\end{array}$ & 1 & 0 & 50 at $t_{5}$ \\
\hline $\begin{array}{l}\text { Model 5: } \\
\text { Single release } \\
\text { Wolbachia-infected } 300\end{array}$ & 1 & 300 at $t_{5}$ & 0 \\
\hline $\begin{array}{l}\text { Model 6: } \\
\text { Single release } \\
\text { Wolbachia-infected } 1000\end{array}$ & 8 & 0 & 1000 at $t_{5}$ \\
\hline $\begin{array}{l}\text { Model 7: } \\
\text { Multiple release } \\
\text { uninfected } 300\end{array}$ & 8 & 300 at $t_{5}$ to $t_{19}$ & 0 \\
\hline $\begin{array}{l}\text { Model 8: } \\
\text { Multiple release Wolbachia- } \\
\text { infected } 300\end{array}$ & & 0 & 300 at $t_{5}$ to $t_{19}$ \\
\hline $\begin{array}{l}\text { Model 9: } \\
\text { Combined multiple release } \\
\text { uninfected 300, Wolbachia- } \\
\text { infected } 50\end{array}$ & 8 & 300 at $t_{5}$ to $t_{19}$ & 50 at $t_{5}$ to $t_{19}$ \\
\hline $\begin{array}{l}\text { Model 10: } \\
\text { Combined multiple release } \\
\text { uninfected 50, Wolbachia- } \\
\text { infected } 30\end{array}$ & 8 & 50 at $t_{5}$ to $t_{19}$ & 300 at $t_{5}$ to $t_{19}$ \\
\hline
\end{tabular}


Table 1.4: Definition of parameters and symbols used in the model.

\begin{tabular}{cl}
\hline Symbols & Definitions \\
\hline$u_{t}$ & Number of uninfected butterflies at time $t$ \\
$w_{t}$ & Number of Wolbachia-infected butterflies at time $t$ \\
$N_{t}$ & Total number of butterflies at time $t$ \\
$s$ & Number of butterflies released to supplement population \\
$r$ & The product of the number of eggs laid, and larvae survival \\
$p$ & Adult butterfly survival \\
$K$ & Carrying Capacity \\
\hline
\end{tabular}

I then extended equation (1) to include supplementation. I simulated the release of virgin adult butterflies into the control population either once at time point $t_{5}$ or eight times on every odd time point from $\mathrm{t}_{5}$ to $\mathrm{t}_{19}$. In all models, I assumed that virgin adult butterflies were released corresponding to the time that resident adult butterflies reached reproductive age; therefore, supplementation aimed to increase the absolute population size. I assumed that supplemented and resident adult butterflies had the same survival rate and included supplementation with the release of uninfected virgin adult butterflies by

$$
u_{t+1}=\left[u_{t} r\left(1-\frac{u_{t}}{K}\right)+s_{u}\right] p
$$

where $s_{u}$ denotes the number of adult uninfected butterflies released.

Next, the population dynamics when Wolbachia was introduced into the uninfected control population were described. Under the same assumptions as equation (2), I simulated a single release of virgin adult Wolbachia-infected butterflies by

(3) $\quad w_{t+1}=\left[w_{t} r\left(1-\frac{w_{t}}{K}\right)+s_{w}\right] p$, 
where $s_{w}$ denotes the number of virgin adult Wolbachia-infected butterflies released into the population. Matings between uninfected females and Wolbachia-infected males were assumed to be completely reproductively inviable (i.e. they exhibited complete CI). Thus, I define $\mathrm{CI}$ as the probability that an uninfected female mated with an uninfected male butterfly. I accounted for this probability in the model by including the proportion of uninfected males in the population by $\frac{u}{N}$. Therefore, when Wolbachia was introduced into the population, equation (1) became

$$
\text { (4) } \quad u_{t+1}=\frac{u_{t}^{2} r}{N_{t}}\left(1-\frac{u_{t}}{K}\right) p
$$

Lastly, I described the population dynamics of supplementation into the control population by eight combined releases of uninfected and Wolbachia-infected butterflies from $t_{5}$ to $t_{19}$. Equation (4) became

$$
u_{t+1}=\left[\frac{u_{t}^{2} r}{N_{t}}\left(1-\frac{u_{t}}{K}\right)+s_{u}\right] p
$$

to include the release of uninfected butterflies in the presence of Wolbachia-infected butterflies. I described the changes in the total number of butterflies in the population from one generation to the next as the sum of equations (3) and (5).

Maternal transmission of Wolbachia and embryonic mortality rates from CI are unknown for $S$. $z$. hippolyta, but are known to vary depending on host species, host genetic background, and the Wolbachia strain type (Zabalou et al. 2004; Duplouy et al. 2015). Based on several studies for other butterfly species (Narita et al. 2007; Hornett et al. 2008; Narita et al. 2009), my model assumed perfect maternal transmission and 100\% embryonic mortality due to CI; thus, the highest impact from CI-inducing Wolbachia on the butterfly population dynamics was demonstrated in the models. 
I simulated population dynamics from each supplementation scenario for 100 years. For each model, I ran 100 iterations then calculated the average value across the iteration for each time point. The time point from each model that had the smallest average value was defined as the year with the lowest population size. To determine whether different supplementation scenarios had different effects on population size, I compared the models with analysis of variance (ANOVA) in two ways. First, I used the population size at the lowest point in each model iteration ( $\mathrm{n}=100$ iterations/model). Similarly, I also compared the population size at the 50-year time point in each of four models, using the 100 iterations per model in the ANOVA. I performed a Tukey's posthoc test for each ANOVA to determine which of each of the single release and multiple release population models differed from one another.

\section{RESULTS}

I found that 62.7\% (146/233) of female S. z. hippolyta samples from Mount Hebo, Rock Creek, and Cascade Head were infected by Wolbachia (Appendix A Figure A1). Additionally, the proportion of Wolbachia-infected butterflies increased over time (Figure 1.1), from an average of 30\% during the first three years of the data (1999-2002), to $78 \%$ between $2008-2010$, and finally reaching $100 \%$ in 2011 . This increase suggests Wolbachia spread through the populations over a 13-year period.

Uninfected female S. z. hippolyta laid fewer eggs than Wolbachia-infected butterflies from 1999-2011 (Figure 1.2; Mann-Whitney test: $\mathrm{U}=3785, \mathrm{P}_{\text {exact }}=0.019$ ). The body sizes of uninfected and Wolbachia-infected butterflies were not significantly different ( $\mathrm{t}$-test: $\mathrm{t}=-1.041, \mathrm{~N}=120, \mathrm{P}=0.301)$ and $\mathrm{I}$ concluded that butterfly body size 
did not affect the number of eggs a female butterfly laid (Regression uninfected equation $\mathrm{Y}=-13.79 * \mathrm{X}+372.2$, Wolbachia $\left.-\mathrm{F}_{1,119}=0.018, \mathrm{P}=0.893\right)$ or the Hatch Success (Regression uninfected equation $\mathrm{Y}=0.01959 * \mathrm{X}+12.78$, Wolbachia-infected equation $\mathrm{Y}$ $\left.=-0.2163 * X+13.12, F_{1,119}=0.392, r^{2}=0.004, P=0.533\right)$.

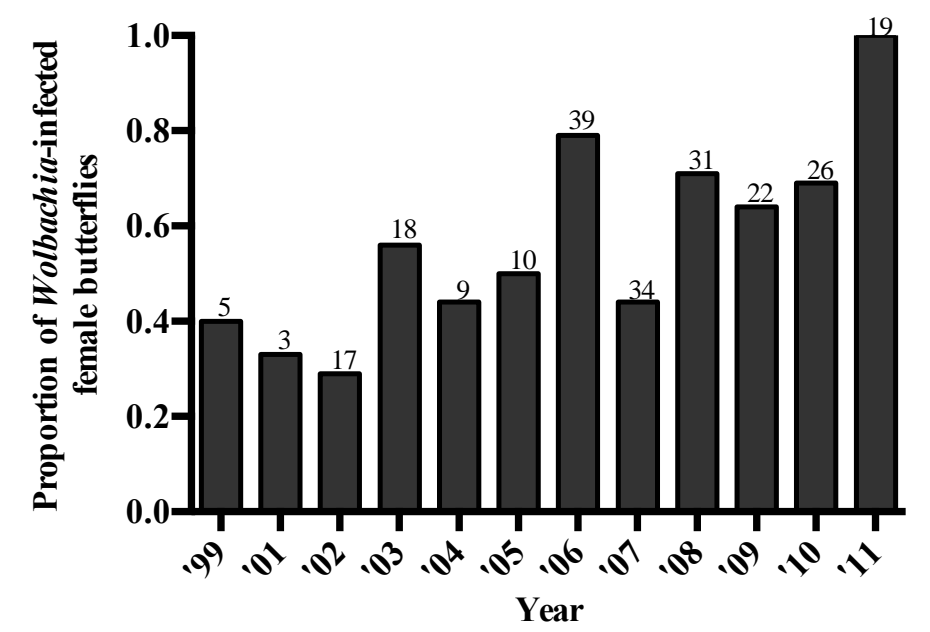

Figure 1.1: Proportion of Wolbachia-infected female S. zerene hippolyta for each year. Numbers above bars represent the number of combined sampled females from three populations, Cascade Head, Rock Creek, and Mt. Hebo for years 1999 and 2001-2011.

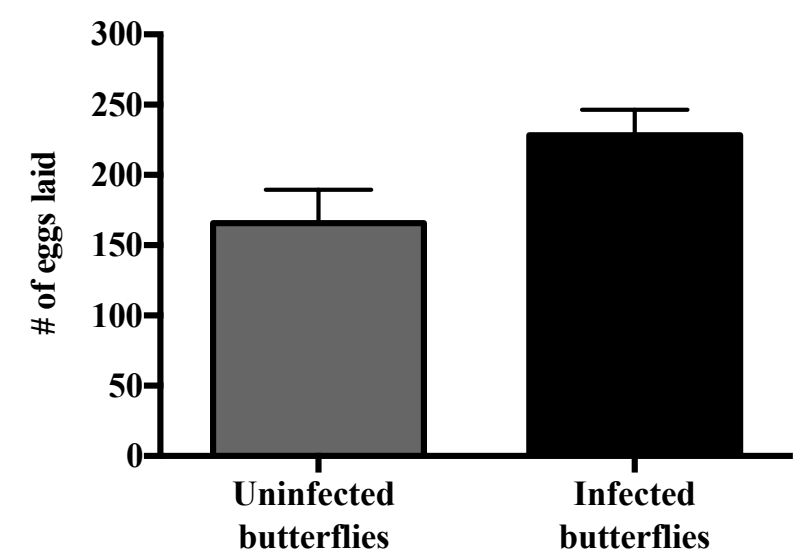

Figure 1.2: Comparison of the number of eggs laid by uninfected $(\mathrm{N}=70)$ versus Wolbachia-infected (N=135) female $S$. $z$. hippolyta butterflies. Uninfected butterflies laid fewer eggs than infected butterflies. Bars represent SE. 
Scatterplots of Hatch Success against frequency of Wolbachia-infected butterflies suggested that as the proportion of Wolbachia-infected butterflies increased, the number of eggs that hatched from uninfected butterflies decreased (Figure 1.3a). Moreover, Figure 1.3b shows a negligible change in the number of eggs that hatched from Wolbachia-infected butterflies as the frequency of Wolbachia-infected butterflies increased. Figure 1.3c demonstrates that the ratio of Hatch Success from uninfected to Wolbachia-infected butterflies decreased as the frequency of Wolbachia-infected butterflies increased. These trends suggest a positive-frequency dependent relationship between Wolbachia-infection frequency and fertility reduction of uninfected butterflies.

Finally, statistical analysis of $S . z$. hippolyta reproductive data detected a significant relationship between Wolbachia-infection status and egg Hatch Success. Results from the GLMM showed that uninfected female butterflies $(\mathrm{N}=70)$ had significantly lower Hatch Success, measured as the number of eggs that hatched (68.34 \pm 11.73 mean \pm SE) given the number that failed to hatch, compared to Hatch Success of Wolbachia-infected butterflies $(81.20 \pm 7.4, \mathrm{~N}=135$; Table 1.5; GLMM z $=-8.067, \mathrm{P}<$ $0.0001)$. 

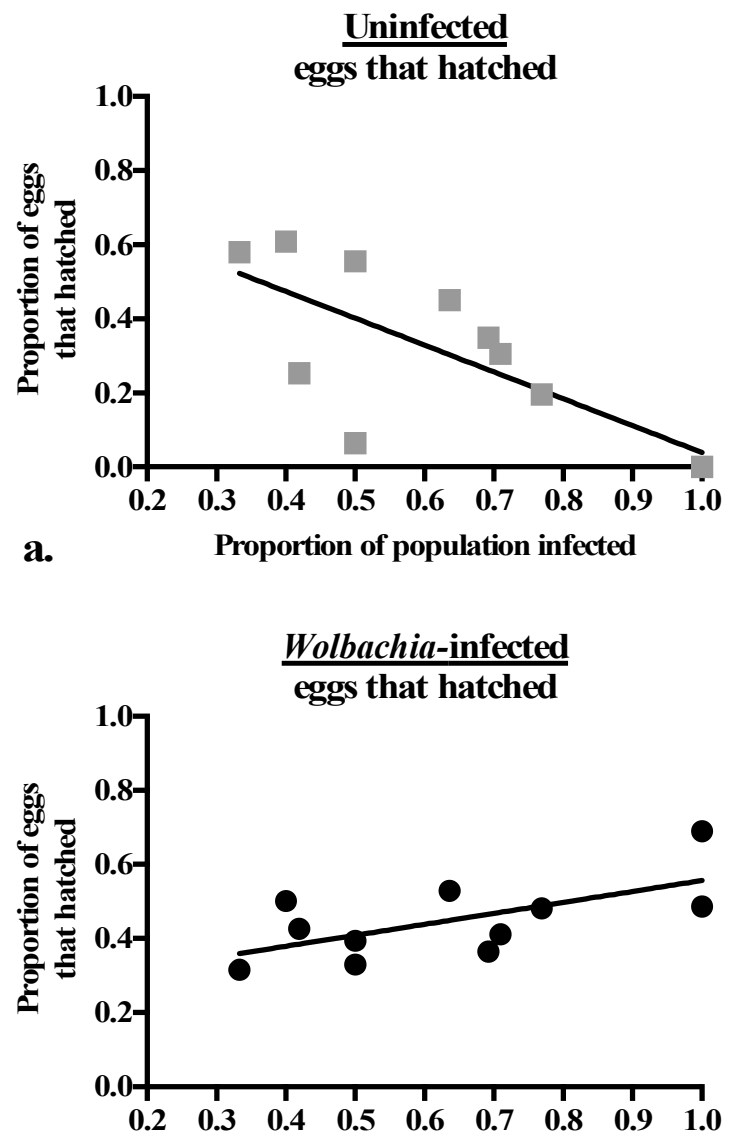

b. Proportion of population infected

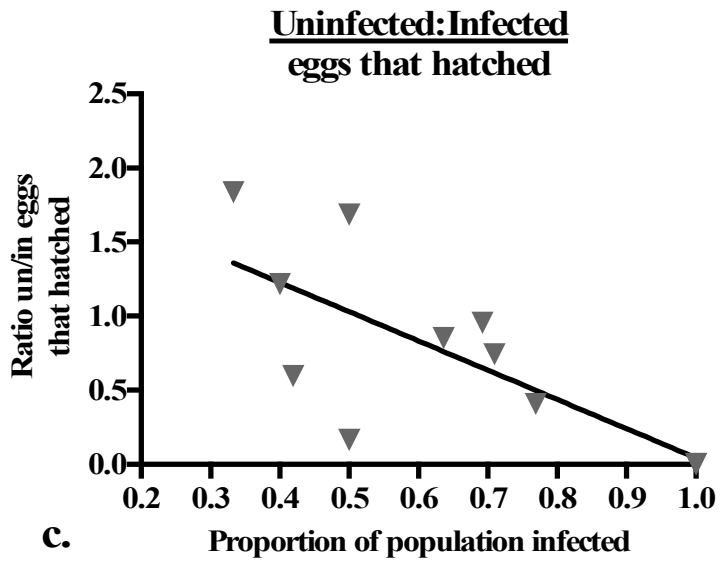

Figure 1.3: Average proportion of eggs that developed into larvae a) from uninfected female butterflies, b) from infected female butterflies, and c) as a ratio of uninfected to infected butterflies, each as a function of the proportion of Wolbachia-infected. 
Model simulations of population supplementation with single release scenarios using empirical values revealed that supplementation with CI-inducing Wolbachiainfected butterflies significantly depressed the host-population size compared to no supplementation, whether examining the smallest population size or population size after 50 years. This effect was even more pronounced when compared to supplementation with Wolbachia-free butterflies (Figures 1.4, 1.5, Appendix A Tables A1-A4; ANOVA: F5,593 $=3349 \mathrm{P}<0.0001, \mathrm{r}^{2}=0.97$ and $\mathrm{F}_{5,593}=1526, \mathrm{P}<0.0001, \mathrm{r}^{2}=0.93$ respectively). All models differed significantly from one another regardless of whether I compared smallest population sizes or population sizes at 50 years (Figure 1.5; Tukey test: $P<0.0001$ for all combinations; Appendix A Tables A1.2 \& A1.4). Model 2 and 3, which simulated population supplementation by the addition of 300 and 1000 uninfected butterflies respectively during year five, produced a significantly larger population size compared to the other single release models, models 4, 5, and 6 ( $\mathrm{P}<0.0001)$. Model 4, which simulated the effects of a single release of 50 Wolbachia-infected butterflies into the population, had a significantly smaller population size compared to all other models $(P<$ 0.0001). The models showed that cytoplasmic incompatibility reduced the absolute population size of uninfected butterflies in these initially moderate-sized simulated initial populations.

Model simulations of population supplementation with multiple release scenarios also showed that supplementation with CI-inducing Wolbachia-infected butterflies significantly depressed the host-population size compared to no supplementation, whether examining the smallest population size or population size after 50 years. This effect was even more pronounced when compared to supplementation with Wolbachia- 
free butterflies (Figures 1.4, 1.5, Appendix A Tables A.5-A.8; ANOVA: $F_{4,524}=1891, \mathrm{P}<$ $0.0001, \mathrm{r}^{2}=0.94$ and $\mathrm{F}_{4,524}=1559, \mathrm{P}<0.0001, \mathrm{r}^{2}=0.92$ respectively). Except for models 8 and 10 $(\mathrm{P}=0.992)$, all models differed significantly from one another regardless of whether I compared smallest population sizes or population sizes at 50 years (Figure 1.5; Tukey test: $P<0.0001$ for all combinations; Appendix A Tables A1.6 \& A1.8). Model 7, which simulated population supplementation by the addition of 300 uninfected butterflies during each of eight different years, produced a significantly larger population size compared to the other models ( $\mathrm{P}<0.0001)$. Model 9, in which I used 300 uninfected and 50 Wolbachia-infected butterflies to supplement the population produced a significantly smaller population compared to models 7,8 , and $10(\mathrm{P}<0.0001)$. The models showed that cytoplasmic incompatibility reduced the absolute population size of uninfected butterflies in these initially moderate-sized simulated initial populations. 

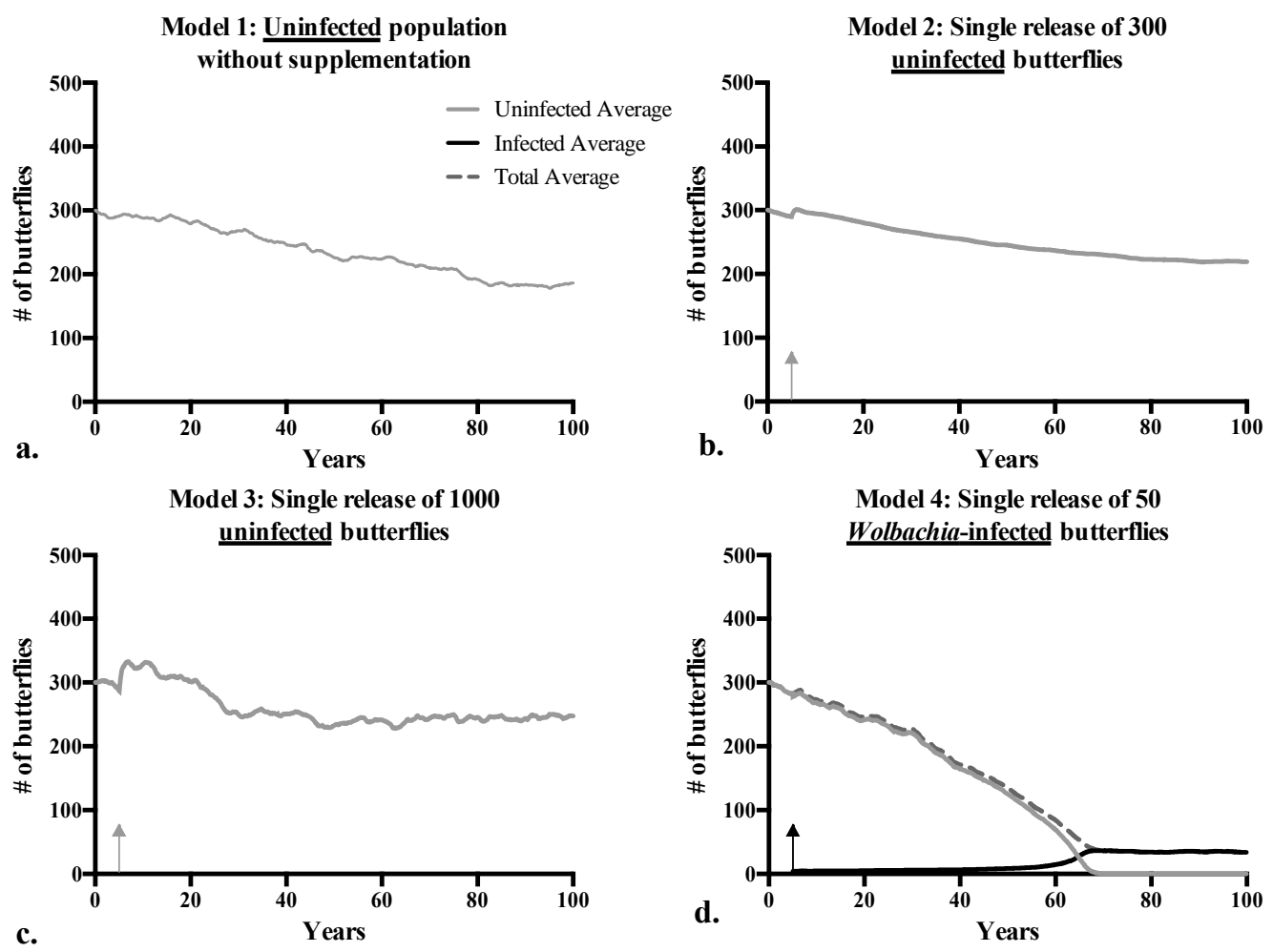

Model 4: Single release of 50

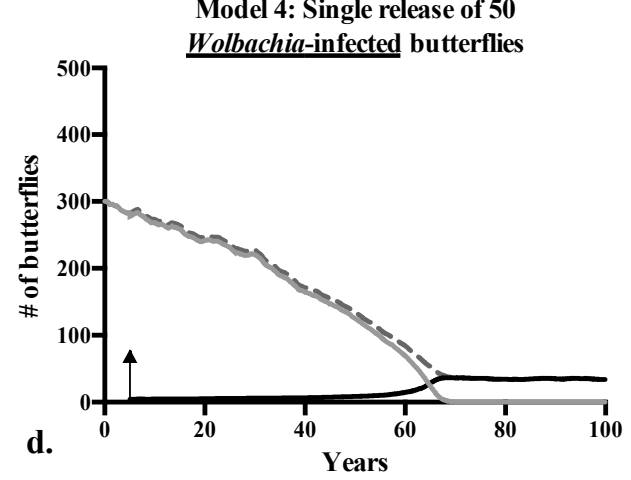

Model 5: Single release of 300

Model 6: Single release of 1000

Wolbachia-infected butterflies
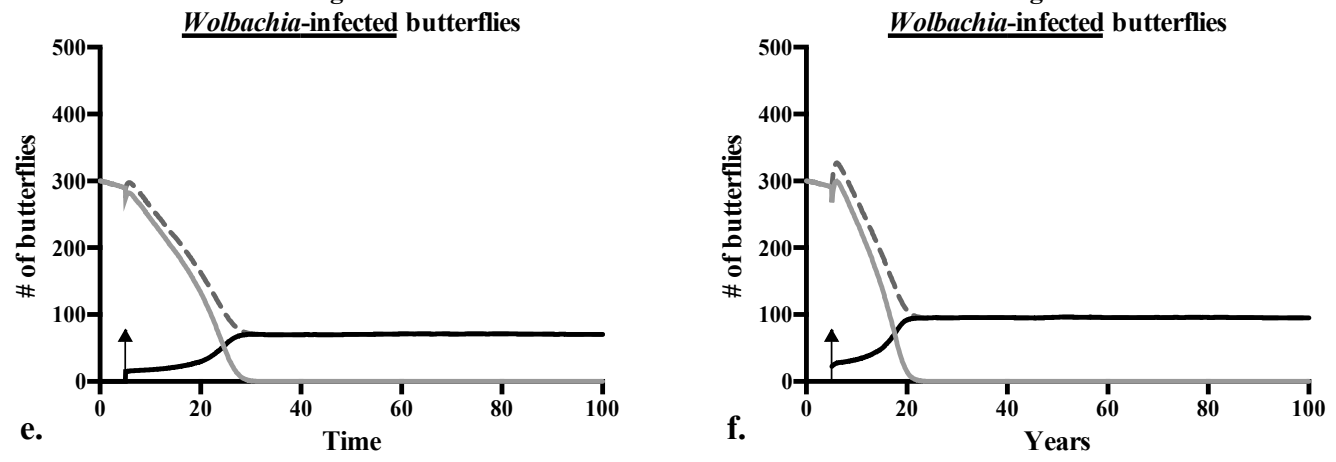

Figure 1.4: Simulation results from 100 iteration averages of single populations with non-overlapping generations under different single release at time point five supplementation scenarios. Graphs illustrate the dynamics of a butterfly population (a) without supplementation, (b) supplementation with 300 uninfected butterflies, (c) supplementation with 1000 uninfected butterflies, (4) supplementation with 50 Wolbachiainfected butterflies, (5) supplementation with 300 Wolbachia-infected butterflies, (6) supplementation with 1000 Wolbachia-infected butterflies. 

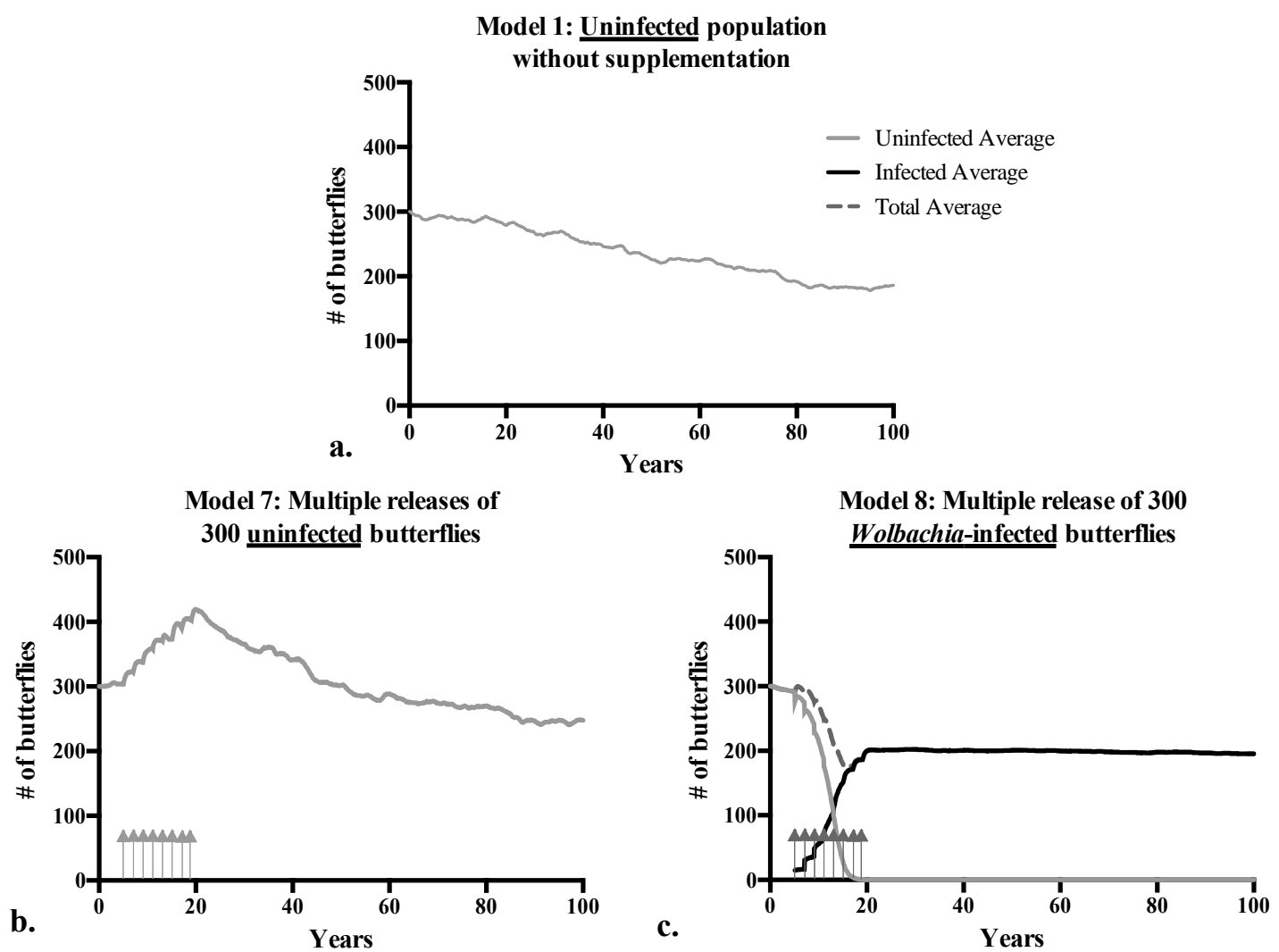

Model 9: Combined multiple releases of 300 uninfected and 50 Wolbachia-infected butterflies
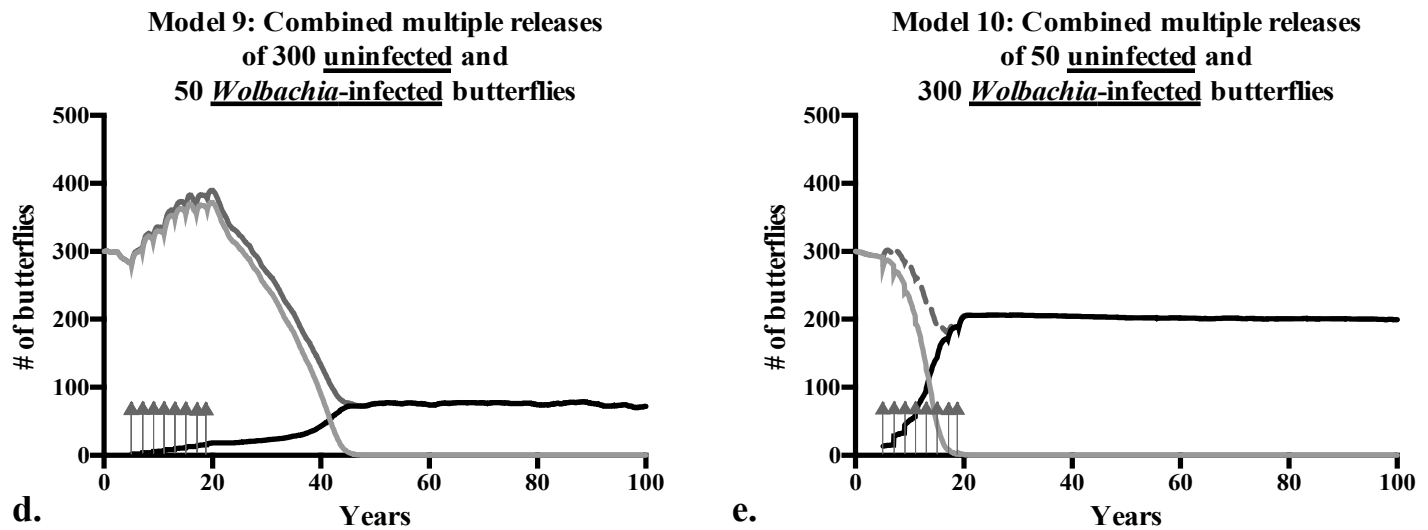

Figure 1.5: Simulation results from 100 iteration averages of single populations with non-overlapping generations under different multiple release at eight different time point (odd time points from $t_{5}$ to 19) supplementation scenarios. Graphs illustrate the dynamics of a butterfly population (a) without supplementation, (b) supplementation with 300 uninfected butterflies, (c) supplementation with 300 Wolbachia-infected butterflies, (4) supplementation with 300 uninfected 300 and 50 Wolbachia-infected butterflies, (d) supplementation with 50 uninfected butterflies, Wolbachia-infected 300, and (e) supplementation with 50 uninfected and 300 Wolbachia-infected butterflies. 

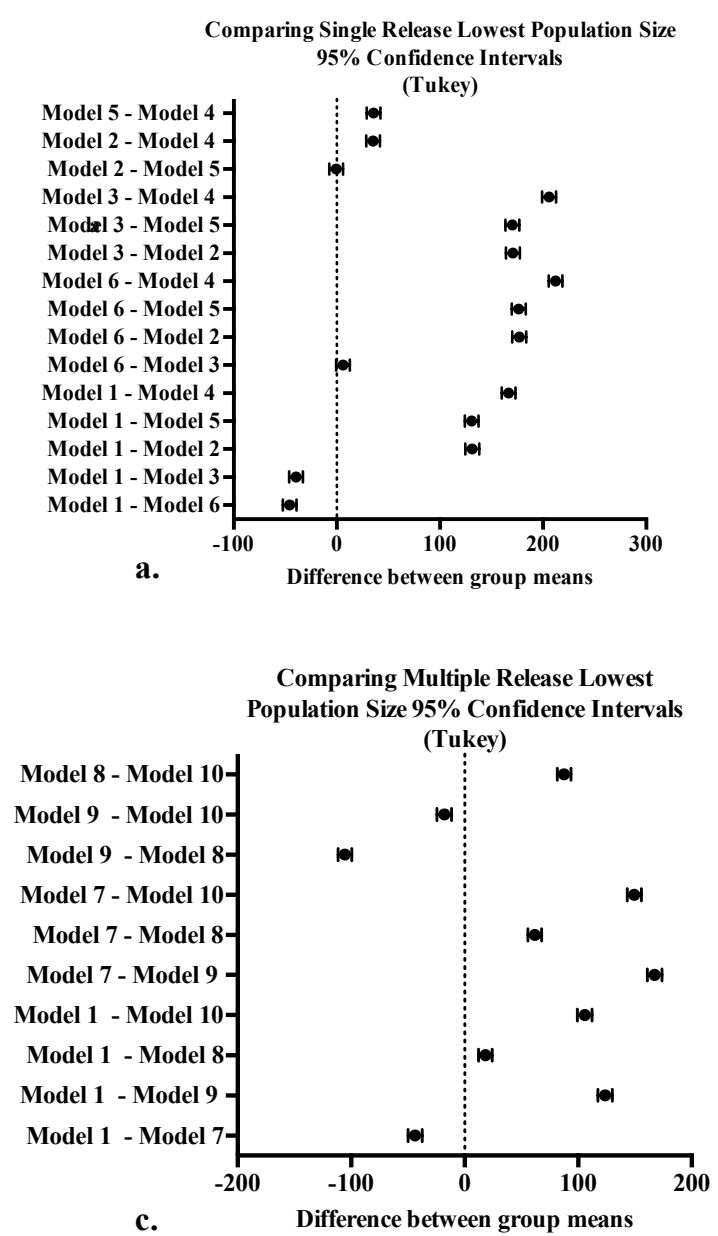
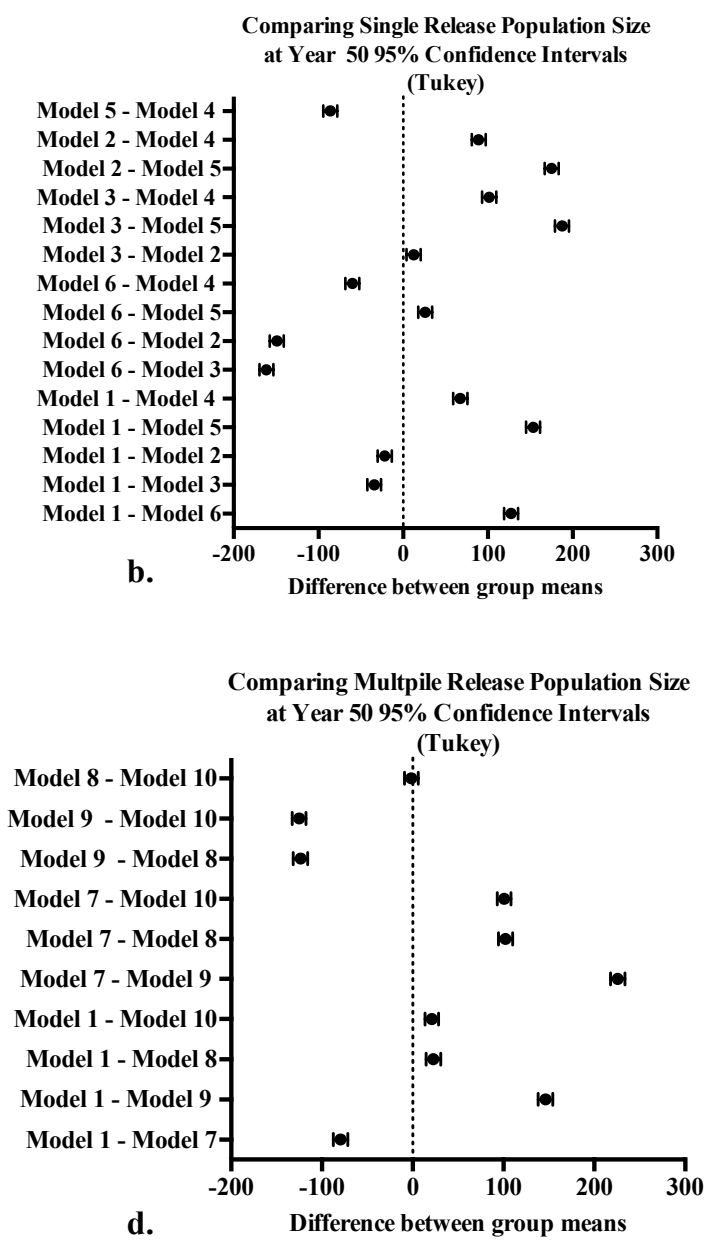

Figure 1.6: Confidence intervals for model comparisons of (a) single release lowest population sizes, (b) single release population sizes at year 50, (c) multiple release population lowest population sizes, and (d) multiple release populations sizes at year 50 .

\section{DISCUSSION}

The decline of $S$. z. hippolyta has been attributed to habitat destruction and fragmentation, as well as to the introduction of invasive plant species that compete with the butterfly's host plant (Schultz \& Chang 1998). Despite recent population supplementation efforts with captive rearing and release, four of the five extant 
populations of S. z. hippolyta remain at risk of extirpation. I screened for and detected the presence of Wolbachia in S. z. hippolyta female butterflies in all sampled populations. I discovered that the frequency of infection has increased and that the reproductive output of uninfected females has decreased in the three populations tested since the beginning of the population supplementation program (from 1999-2011). I conclude that Wolbachia may have been and could continue to be an additional stressor to $S$. $z$. hippolyta populations. In addition to the reproductive effects, in some species, Wolbachia can reduce host dispersal distances (Goodacre et al. 2009). Such dispersal reduction to $S . z$. hippolyta could increase species mortality from vehicle collisions as they rely on their dispersal ability in at least one of their populations, Rock Creek, where habitats for larval food plant (Viola adunca) and nectaring plants were divided by a busy coastal highway (Zielin et al. 2016).

Wolbachia's phenotypes encompass several reproductive manipulations: CI, parthenogenesis, feminization, and male killing. Cytoplasmic incompatibility is the most commonly described Wolbachia-induced phenotype in insects, causing reduced fertility of uninfected females mated with infected males (Yen \& Barr 1973; Werren 1997; Zabalou et al. 2004; Werren et al. 2008). As the S. z. hippolyta populations maintain a relatively equal sex ratio, the induction of parthenogenesis, feminization, and male killing by Wolbachia in this butterfly species seems unlikely. In contrast, my results are consistent with the hypothesis that the Wolbachia induces CI in S. z. hippolyta butterflies. Uninfected female $S$. z. hippolyta had reduced fertility as they laid significantly fewer eggs and showed significantly reduced hatch success compared to Wolbachia-infected female butterflies. Hatch Success was also highest in years and populations with lowest 
infection prevalence. Additionally, I showed that the fertility of uninfected female butterflies decreases as Wolbachia prevalence increases through $S$. z. hippolyta populations. Together, these results suggest that uninfected females have compromised fitness and that Wolbachia benefits infected female $S$. z. hippolyta butterflies, as has been previously shown in other CI-inducing Wolbachia infected host species (Dobson et al. 2004; Weeks et al. 2007; Brownlie et al. 2009). Unfortunately, I was unable to empirically measure CI in $S$. z. hippolyta as the butterflies do not mate in captivity; however, my results suggest that uninfected females sampled for this study suffered from $\mathrm{CI}$ and that CI may have resulted in population-level costs.

Small isolated populations face many threats that can lead to extirpation and extinction. Through model simulations, I showed that even a single exposure event to a small number of Wolbachia-infected butterflies can have a long-term negative effect on overall population size (Figure 1.4c). When a population is already small and afflicted by the risks associated with small populations (inbreeding depression, genetic drift, reduced population growth, decreased disease resistance), the introduction of Wolbachia can potentially push a vulnerable population to extinction. Although, it is unlikely that a population will recover to pre-infection size (Figure 1.4a-d), my model demonstrates that, under certain conditions, host populations can recover after Wolbachia introduction (Figure 1.4d); however, this is not without the incurred population-level cost by the extinction of uninfected haplotype(s) and subsequent loss of some genetic diversity. If one or more incompatible CI-inducing Wolbachia strains are introduced into a population, it could put populations at risk of extinction as butterflies are moved among populations through supplementation. Cytoplasmic incompatibility causes post-mating 
reproductive isolation, which reduces gene flow, and can lead to evolutionary selection of pre-mating isolation (Jaenike et al. 2006). Reproductive isolation reduces breeding opportunities and overall fitness leading to reduced population size in subsequent generations.

Using butterfly specimens that were collected before 1999, McHugh et al. (2013) screened six S. zerene subspecies, including S. z. hippolyta, for Wolbachia. While Wolbachia was detected in two of the subspecies, it was not detected in any of the $12 \mathrm{~S} . z$. hippolyta individuals tested. There are several potential reasons for why McHugh et al. (2013) did not detect Wolbachia from their S. z. hippolyta specimens. First, Wolbachia may not have been present in the $S$. z. hippolyta populations at the time the samples were collected. Alternatively, Wolbachia could have been present but they might not have detected Wolbachia because their sample size was small and may not have been representative of the populations. Third, they stated in their paper that they experienced limited success with PCR amplification of nuclear DNA from S. z. hippolyta samples, which suggests they potentially encountered similar issues with the amplification of Wolbachia DNA, therefore, yielding false negatives.

Wolbachia are not the only endosymbiotic bacteria that manipulate their host's reproduction. The stage for reproductive parasitism is shared with Spiroplasma, Rickettesia, and most notably, Cardinium, which all are known to induce CI and are commonly found in arthropods (Hunter 2007; Jaenike et al. 2007; Weinert et al. 2015). However, Wolbachia linked selective mitochondrial sweeps have been shown in many species and in small populations the mtDNA haplotype associated with uninfected individuals may become extinct (Turelli et al. 1992; Jiggins 2003; Rasgon \& Scott 2003; 
Hurst \& Jiggins 2005; Schuler et al. 2013). With my discovery of Wolbachia in the extant populations of this $S$. z. hippolyta, the mixing of infected and uninfected butterflies during supplementation could lead to the extinction of uninfected butterflies, further reducing genetic diversity.

Echoing the conclusions from Nice et al. (2009), I suggest that conservation programs currently using population supplementation strategies consider the risks of Wolbachia to endangered or threatened species. As with all threatened and endangered species recovery plans, success of these programs requires not only screening for visibly infected pathogens but also extensive knowledge of the biology of the species (Snyder et al. 1996), including intracellular symbiotic relationships such as those with Wolbachia, which may affect the reproductive success of the species. A more thorough analysis is needed to understand the effects that Wolbachia have on their specific hosts, their host's populations, and their ecosystems. Results from this study can be used to inform all invertebrate species conservation plans; particularly those currently supplemented by captive propagation or that are being considered as potential candidates for supplementation. 


\section{Chapter 2: Eurema butterflies are quite hospitable: characterization of their parasitoids revealed some sharing of identical Wolbachia strains INTRODUCTION}

Host-bacteria relationships, particularly those between endosymbionts and insects, are increasingly accepted as pivotal to biological and ecological processes (McFall-Ngai et al. 2013; Archibold 2014). Endosymbiotic bacteria are primarily vertically transmitted (from mother to offspring) and form relationships with their hosts that are either obligate of facultative. In obligate endosymbiosis, the host bacteria are crucial to host survival. Conversely, facultative endosymbiotic bacteria, such as Wolbachia, can also be transmitted horizontally between species, are not necessary for host survival, and can have a range of effects on host fitness (Oliver et al. 2006; Moran et al. 2008). Whether an endosymbiont is facultative or obligate, their vertical transfer is coupled with other maternally inherited genetic elements present in host cytoplasm, most notably, mitochondria (Cosmides \& Tooby 1981).

Wolbachia are a group of facultative endosymbiotic bacteria that are estimated to be present in approximately 53\% of terrestrial arthropod species and 52\% of aquatic insects (Zug \& Hammerstein 2012; Weinert et al. 2015; Sazama et al. 2017). They have varying effects on their hosts; however, they have garnered interest because of the reproductive phenotypes they induce in their hosts: feminization, male killing, parthenogenesis, or cytoplasmic incompatibility (CI) (Werren et al. 2008; Werren 2011). Reproductive manipulating Wolbachia strains resemble selfish genetic elements by altering their host's reproductive phenotypes to selectively favor infected females and enhance their own transmission (Werren 1997; Hatcher 2000; Werren et al. 2008; Werren 
2011). Wolbachia induced feminization, male killing, and parthenogenesis are phenotypes that favor infected females by reducing males in the population (Hurst \& Werren 2001; Werren et al. 2008). Cytoplasmic incompatibility is the most prevalent phenotype, characterized by increased embryo mortality when an egg from an uninfected female is fertilized by a sperm from an infected male; thereby, Wolbachia-infected females are selectively favored over uninfected females (Hurst \& Werren 2001; Werren et al. 2008).

It is well established that Wolbachia are able to perpetuate in a host population because of their nearly complete to complete intergenerational vertical transmission (Bandi et al. 2001). Despite being widespread and present in both terrestrial and aquatic insects, the routes by Wolbachia for interspecies transmission are less understood. Moreover, explanations for Wolbachia in phylogenetically distantly diverged taxa cannot be explained by vertical transmission. Molecular phylogenetic analyses of endosymbiont and host mitochondria have revealed incongruence between Wolbachia and host species, providing strong evidence that supports frequent horizontal movement of Wolbachia between host species (O’Neill et al. 1992; Vavre et al. 1999; Haine et al. 2005; Baldo et al. 2006; Miller \& Riegler 2006). Though, the mechanisms of horizontal transmission in nature are not fully understand, close ecological interactions appear fundamental to Wolbachia's ability to cross species boundaries (Raychoudhury et al. 2009; Stahlhut et al. 2010; Schuler et al. 2013; Ahmed et al. 2015b; Li et al. 2016).

Previous studies have shown that horizontal transmission events can be mediated during larval development by sharing a food source (Sintupachee et al. 2006), through cannibalistic consumption (Le Clec'h et al. 2013), or through blood to blood to contact 
that can result from an altercation (Rigaud \& Juchault 1995). Interspecific horizontal transmission can also be mediated by vector species such as parasitoids (Werren et al. 1995b) as was accomplished in a laboratory experiment that demonstrated a parasitoid successfully transferring Wolbachia from Drosophila simulans to Leptopilina boulardi (Heath et al. 1999). Since emerging as potential routes of interspecies transmission, hostparasitoid interactions have dominated Wolbachia horizontal transmission research. These interspecies interactions are both ecologically important and provide an opportunity for a parasitoid to acquire Wolbachia through a trophic interaction: parasitoid development requires consuming their tissues of their larval host thought to transmit Wolbachia (Schilthuizen \& Stouthamer 1997; West et al. 1998; Heath et al. 1999; Huigens et al. 2004; Morrow et al. 2014; Ahmed et al. 2015b).

Eurema (Lepidoptera, Pieridae) comprises a diverse group of butterfly species commonly known as grass yellows, with extensive distribution throughout Africa, Asia and Australia (Kemp 2002; Kemp 2008). Two different strains of Wolbachia with very different effects on host reproduction, the CI-inducing strain $w \mathrm{CI}$ and the feminization strain $w$ Fem, were discovered in Eurema populations from Japan (Hiroki et al. 2004; Narita et al. 2007a; Narita et al. 2007b). The wFem Wolbachia strain has been further detected in Eurema species from China, Indonesia, Vietnam (Narita et al. 2006), and India (Salunke et al. 2012).

In Australia, the six Eurema butterfly species - E. smilax, E. hecabe, E. alitha, E. laeta, E. herla, and E. brigitta - inhabit various geographic and climatic regions. Each species uses a specific life history strategy (diapause vs. migration) to cope with extended periods of drought and seasonal precipitation changes in tropical and subtropical 
Australia (Jones \& Rienks 1987; Jones 1992). Except for E. smilax, all Australian Eurema species are infected with Wolbachia (Kern et al. unpublished). Four of these species share a Wolbachia strain that is identical to $w \mathrm{CI}$ and designated to sequence type (ST) ST-41 (Figure 2.1) (Kern et al. unpublished), which is a frequently identified strain type in various butterfly species around the world (Ilinsky \& Kosterin 2017). Eurema herla and E. brigitta are infected with another strain designated to ST-125 (Figure 2.1). Recent phylogenetic analysis of mtDNA from Eurema butterfly species revealed that mitochondrial lineages of each species lack geographical structure and that Wolbachiainfected species have far less mtDNA diversity compared to the uninfected species, $E$. smilax (Kern et al. unpublished). Additionally, results from the phylogenetic analysis showed that each Australian Eurema species had a unique mtDNA sequence and that mtDNA was not shared between the species (Kern et al. unpublished). This result indicates that none of the species are interspecies hybrids, the species have diverged, and there is no evidence of the mitochondrial hitchhiking that is generally associated with CIinducing Wolbachia strains, which if present, would have suggested that the strain originated with E. smilax (Kern et al. unpublished). Given these findings that the same Wolbachia strain exists in multiple fully diverged Eurema species with overlapping geographic distributions, a compelling case can be made that horizontal transmission has been paramount to Wolbachia invasion into this group of butterflies.

I postulated that horizontal transmission of Wolbachia in Eurema species was most likely mediated by parasitoid vectors. Although parasitoids have been characterized for a vast number of butterfly species (Smith et al. 2007; Smith et al. 2008; Janzen et al. 2009), parasitoids afflicting this group of butterflies have not yet been extensively 
investigated. In this study, my aims were to 1) characterize parasitoids from Eurema butterfly species, 2) screen parasitoids for Wolbachia, and 3) determine whether parasitoids are infected with the same Wolbachia strain as their hosts. I addressed these aims by surveying Eurema larvae collected at four different locations in Queensland, Australia for parasitoids and by conducting a Wolbachia screen using a genetic approach based on Multi Locus Sequencing Technique (MLST) of Wolbachia house-keeping genes (Baldo et al. 2006) and the Wolbachia surface protein gene, wsp (Zhou et al. 1998).

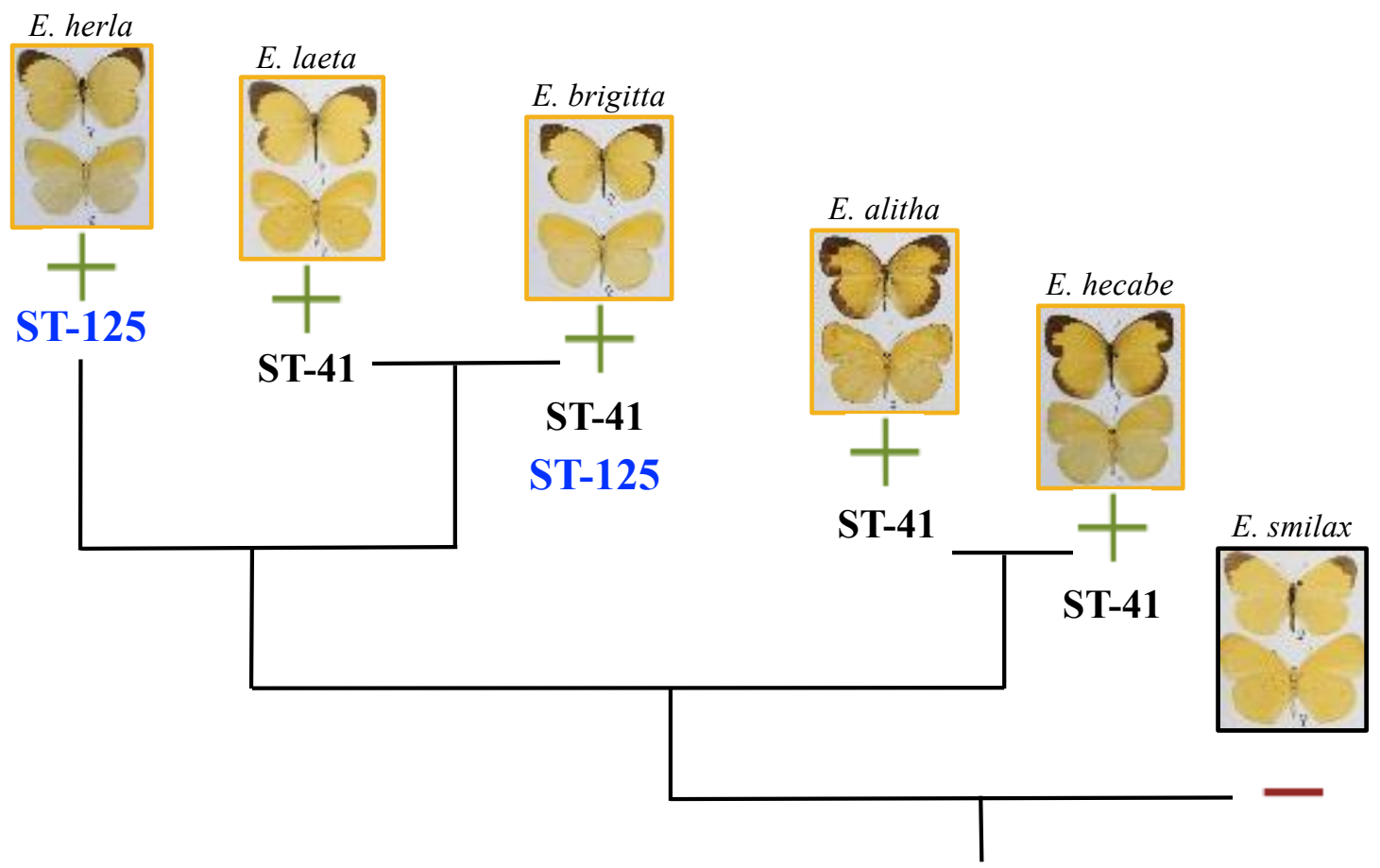

Figure 2.1: Schematic of a phylogeny tree that depicts the relationship between Australian Eurema butterfly species and their associated Wolbachia strain types (STs) as listed below each species. Green plus signs below a species indicates the species is infected with Wolbachia and the red minus sign indicates the species does not carry Wolbachia.

Building on molecular phylogenetic analysis suggesting horizontal transmission between divergent Eurema species (Kern et al. unpublished), I predicted that parasitoids 
and butterfly hosts would share Wolbachia strains, which would bolster support for the hypothesis that host-parasitoid interactions are probable routes for interspecies Wolbachia transmission. Results from this research provide the first characterization of the parasitoids associated with Eurema butterflies, estimates of parasitization rates in $E$. hecabe, and the presence of shared Wolbachia strains between host and parasitoids. Additionally, I provide the first empirical field evidence demonstrating inter-ordinal sharing of identical Wolbachia strains in species that engage in close ecological interactions.

\section{MATERIALS AND METHODS}

\section{Eurema and parasitoid collection and identification}

Eurema butterfly larvae were collected from host plants in four locations in northern Queensland, Australia, between March and April 2015 (Table 2.1). Larvae and host plant were transported to the laboratory where they were reared separately in individual translucent 60ml plastic containers (Polar Ice PIJS040200). I examined all collected larvae for signs of parasitization, indicated by the presence of melanization, resulting from the encapsulation of the parasitoid egg by the host's immune response. As parasitoid larvae exited hosts, they were isolated in fresh $60 \mathrm{ml}$ containers where they were allowed to pupate. Dead hosts, either larvae or pupae, and newly emerged parasitoids were stored in absolute ethanol. Ethanol preserved samples were transferred to the laboratory and stored at $-20^{\circ} \mathrm{C}$. Larvae that were not affected by parasitoids and developed in adult butterflies were preserved in specimen envelopes. Parasitoids were then assigned to morphotypes. 
Table 2.1: Australia field collection site locations, coordinates, and altitudes.

\begin{tabular}{llllc}
\hline Site & Location & Latitude & Longitude & Altitude (m) \\
\hline Cairns & $\begin{array}{l}\text { Machan Beach Rd., } \\
\text { Machans Beach QLD 4878 }\end{array}$ & -16.86282 & 145.732963 & 2 \\
Mt. Sophia & $\begin{array}{l}\text { 69727 Bruce HWY, } \\
\text { Aloomba QLD 4861 }\end{array}$ & -17.161521 & 145.874346 & 14 \\
Babinda & $\begin{array}{l}\text { Clyde Rd., } \\
\text { Babinda QLD 4861 }\end{array}$ & -17.335391 & 145.93606 & 8 \\
Mareeba Wetlands & $\begin{array}{l}\text { Pickford Rd., Biboohra } \\
\text { QLD 4880 }\end{array}$ & -16.91913 & 145.404252 & 387 \\
\hline
\end{tabular}

\section{DNA extraction}

To eliminate foreign DNA and microbes from external surfaces of parasitoids and larvae or pupae hosts, prior to DNA extraction, individual specimens were rinsed five times with molecular grade water and five times with absolute ethanol before being transferred to sterile microcentrifuge tubes that contained absolute ethanol. DNA was extracted using a small tissue sample $\left(2-5 \mathrm{~mm}^{3}\right)$ from individual Eurema larvae and their adult parasitoids. Three Eurema larvae from which parasitoids emerged survived and developed into adult butterflies. I extracted DNA from the three parasitoid surviving adults and from a subsample of parasitoid-free adult butterflies. To avoid false negatives in the Wolbachia screen that can sometimes occur when using DNA extracted from legs (Duron et al. 2010), I used abdomen tissue samples from adult specimens. Tissues were homogenized in $1.5 \mathrm{ml}$ microcentrifuge tubes using microtube pestles (Scientific Specialties Inc., Lodi, CA). All DNA extractions were performed using Qiagen DNeasy Blood and Tissue kit (Qiagen, Valencia, CA, USA), following the manufacturer's protocol. I tested DNA quality by PCR amplification of arthropod 28S rDNA (Werren et 
al. 1995a; Table 2.2). For samples that yielded weak or no amplification of the 28S rDNA fragment $(\mathrm{N}=8$ Eurema larvae and $\mathrm{N}=2$ parasitoids $)$, DNA was extracted for a second time. The second round of DNA extractions were all successful and no subsequent extraction were needed. 
Table 2.2: List of primers used for PCR amplification of loci, targeted genome, and references.

\begin{tabular}{|c|c|c|c|c|}
\hline Loci & Primers & $\begin{array}{l}\text { Target } \\
\text { genomes }\end{array}$ & Sequences (5'-3') & References \\
\hline \multirow[t]{2}{*}{$\begin{array}{l}16 S \\
\text { rDNA }\end{array}$} & $16 \mathrm{SW}$ spec F & Mitochondria & CATACCTATTCGAAGGGATAG & $\begin{array}{l}\text { Werren \& } \\
\text { Windsor }\end{array}$ \\
\hline & 16SW spec R & & AGCTTCGAGTGAAACCAATTC & 2000 \\
\hline \multirow[t]{2}{*}{$\begin{array}{l}28 S \\
\text { rDNA }\end{array}$} & $28 \mathrm{SF}$ & Nuclear & CCCTGTTGAGCTTGACTCTAGTCTGGC & $\begin{array}{l}\text { Werren et } \\
\text { al. } 1995 \mathrm{a}\end{array}$ \\
\hline & 28SR & & AAGAGCCGACATCGAAGGATC & \\
\hline \multirow[t]{2}{*}{$\mathrm{COI}$} & LCO1490 & Mitochondria & GGTCAACAAATCATAAAGATATTGG & $\begin{array}{l}\text { Folmer et } \\
\text { al. } 1994\end{array}$ \\
\hline & $\mathrm{HCO} 2198$ & & TAAACTTTCAGGGTGACAAAAAATCA & \\
\hline \multirow[t]{2}{*}{$w s p$} & $81 \mathrm{~F}$ & Wolbachia & TGGTCCAATAAGTGATGAAGAAAC & $\begin{array}{l}\text { Zhou et al. } \\
1998\end{array}$ \\
\hline & $691 \mathrm{R}$ & & AAAAATTAAACGCTACTCCA & \\
\hline \multirow[t]{2}{*}{ gatB } & gatB F1 & Wolbachia & GAKTTAAAYCGYGCAGGBGTT & $\begin{array}{l}\text { Baldo et al. } \\
2006\end{array}$ \\
\hline & gatB R1 & & TGGYAAYTCRGGYAAAGATGA & \\
\hline \multirow[t]{2}{*}{$\operatorname{cox} A$} & coxA F1 & Wolbachia & TTGGRGCRATYAACTTTATAG & $\begin{array}{l}\text { Baldo et al. } \\
2006\end{array}$ \\
\hline & coxA R1 & & CTAAAGACTTTKACRCCAGT & \\
\hline \multirow[t]{2}{*}{ hcpA } & hcpA F1 & Wolbachia & GAAATARCAGTTGCTGCAAA & $\begin{array}{l}\text { Baldo et al. } \\
2006\end{array}$ \\
\hline & hcpA R1 & & GAAAGTYRAGCAAGYTCTG & \\
\hline \multirow[t]{2}{*}{$f t s Z$} & ftsZ F1 & Wolbachia & ATYATGGARCATATAAARGATAG & $\begin{array}{l}\text { Baldo et al. } \\
2006\end{array}$ \\
\hline & ftsZ R1 & & TCRAGYAATGGATTRGATAT & \\
\hline \multirow[t]{2}{*}{$f b p A$} & fbpA F1 & Wolbachia & GCTGCTCCRCTTGGYWTGAT & $\begin{array}{l}\text { Baldo et al. } \\
2006\end{array}$ \\
\hline & fbpA R1 & & CCRCCAGARAAAAYYACTATTC & \\
\hline
\end{tabular}

\section{Detection and identification Wolbachia}

Wolbachia experience high rates of recombination; thus, to avoid the misidentification of Wolbachia strains I used a multi-gene protocol rather than a single gene approach (Baldo et al. 2006). An initial diagnostic Wolbachia screen of individual samples was conducted by PCR amplification using Wolbachia specific 16S rDNA 
(Werren \& Windsor 2000) and wsp primers (Zhou et al. 1998). For characterization of Wolbachia strains, I performed PCR amplification of five Wolbachia MLST loci - gatB, $\operatorname{coxA}, f t s Z, h c p A$, and $f b p A$. All polymerase chain reactions were performed using a BioRad T100'TM thermocycler (Hercules, CA. USA). Primers are listed in Table 2.2.

To determine whether Wolbachia was present on the external surfaces of parasitoids, I tested for the presence of Wolbachia DNA in the ethanol in which the specimens were stored using direct PCR amplification of arthropod 28S rDNA and Wolbachia specific 16S rDNA primer sets (Table 2.2).

I used PCR to amplify the mitochondrial cytochrome oxidase I subunit (COI) loci from all individuals with the primer set LCO1490 and HCO2198 (Folmer et al. 1994) to estimate haplotype diversity of both parasitoids and Eurema butterflies. Eurema species identity was then established with the help of existing DNA barcodes for Australian Eurema species.

Polymerase chain reactions were each a total of $25 \mu 1$ comprised of $1.25 \mu 1$ of each $10 \mu \mathrm{M}$ forward and reverse primer, $12.5 \mu 1$ of $2 \mathrm{X}$ Phusion High-Fidelity PCR Master Mix (New England BioLabs Inc.), 2-4 $\mu 1$ template DNA, and nuclease-free water to $25 \mu 1$. To confirm that PCR products were the same size as target genes and to determine whether multiple bands were present, I visualized $5 \mu 1$ of each on a $1 \%$ agarose gel. The remaining $20 \mu 1$ of crude PCR products were sent to Functional Biosciences (Madison, WI) for sequencing. Specific annealing temperatures and thermocycler conditions for the amplification of each gene are listed in Tables 2.3 and 2.4. 
Table 2.3: Annealing temperatures specific to primers sets.

\begin{tabular}{lc}
\hline Loci and primers & $\begin{array}{c}\text { Primer specific } \\
\text { annealing } \\
\text { temperatures (T) }\end{array}$ \\
\hline 16S rDNA - 16SWspecF/16SWspecR & $\mathrm{T}=60^{\circ} \mathrm{C}$ \\
$28 S$ rDNA - 28SF/28SR & $\mathrm{T}=56^{\circ} \mathrm{C}$ \\
COI - LCO1490/HCO2198 & $\mathrm{T} 1=45^{\circ} \mathrm{C}$ \\
Tsp - 81F/691R & $\mathrm{T} 2=51^{\circ} \mathrm{C}$ \\
$g a t B-$ gatB F1/gatB R1 & $59^{\circ} \mathrm{C}$ \\
$c o x A-$ coxA F1/coxA R1 & $56^{\circ} \mathrm{C}$ \\
$h c p A-$ hcpA F1/hcpA R1 & $55^{\circ} \mathrm{C}$ \\
$f t s Z$ - ftsZ F1/ ftsZ R1 & $53^{\circ} \mathrm{C}$ \\
$f b p A-$ fbpA F1/fbpA R1 & $54^{\circ} \mathrm{C}$ \\
\hline
\end{tabular}

Table 2.4: Thermocycler conditions for PCR of each loci.

\begin{tabular}{|c|c|c|c|}
\hline & $\begin{array}{l}\text { Wolbachia MLST loci } \\
w s p \text {, gat } B, \operatorname{cox} A, \text { hcpA, } \\
\text { ftsZ, and } f b p A\end{array}$ & $\begin{array}{l}\text { Mitochondrial loci } \\
16 S \text { rDNA and } C O I\end{array}$ & $\begin{array}{l}\text { Nuclear loci } \\
28 S \text { rDNA }\end{array}$ \\
\hline Denaturation & $98^{\circ} \mathrm{C}$ for $2 \mathrm{~min}$ & $98^{\circ} \mathrm{C}$ for $4 \mathrm{~min}$ & $98^{\circ} \mathrm{C}$ for $2 \mathrm{~min}$ \\
\hline \multirow[t]{3}{*}{ Cycling } & $\begin{array}{l}35 \text { cycles: } \\
98^{\circ} \mathrm{C} \text { for } 30 \mathrm{sec}, \\
\text { loci } \mathbf{T} \text { for } 30 \mathrm{sec}, \\
\text { and } 72^{\circ} \mathrm{C} \text { for } 2 \mathrm{~min}\end{array}$ & $\begin{array}{l}5 \text { cycles: } \\
98^{\circ} \mathrm{C} \text { for } 2 \mathrm{~min}, 16 \mathrm{~S} \mathrm{~T} \\
\text { or } \mathrm{COI} \mathrm{T} 1 \text { for } 1 \mathrm{~min} \text {, } \\
\text { and } 72^{\circ} \mathrm{C} \text { for } 1 \mathrm{~min}\end{array}$ & $\begin{array}{l}1 \text { cycle: } \\
98^{\circ} \mathrm{C} \text { for } 1 \mathrm{~min}, \\
28 \mathrm{~S} \text { for } 1 \mathrm{~min}, \\
\text { and } 72^{\circ} \mathrm{C} \text { for } 2 \mathrm{~min}\end{array}$ \\
\hline & & $\begin{array}{l}35 \text { cycles: } \\
95^{\circ} \mathrm{C} \text { for } 30 \mathrm{sec}, \mathbf{1 6 S} \mathrm{T} \\
\text { or } \boldsymbol{C O I} \mathbf{T} 2 \text { for } 45 \mathrm{sec} \text {, } \\
\text { and } 72^{\circ} \mathrm{C} \text { for } 1 \mathrm{~min}\end{array}$ & $\begin{array}{l}35 \text { cycles: } \\
98^{\circ} \mathrm{C} \text { for } 15 \mathrm{sec}, \\
28 \mathrm{~T} \text { for } 1 \mathrm{~min}, \\
\text { and } 72^{\circ} \mathrm{C} \text { for } 2 \mathrm{~min}\end{array}$ \\
\hline & & & $\begin{array}{l}\frac{1 \text { cycle: }}{94^{\circ} \mathrm{C} \text { for } 15 \mathrm{sec},} \\
28 \mathrm{~T} \text { for } 1 \mathrm{~min}\end{array}$ \\
\hline Final elongation & $72^{\circ} \mathrm{C}$ for $2 \mathrm{~min}$ & $72^{\circ} \mathrm{C}$ for $10 \mathrm{~min}$ & $72^{\circ} \mathrm{C}$ for $7 \mathrm{~min}$ \\
\hline
\end{tabular}




\section{Phylogenetic analysis}

I carefully screened sequence chromatograms of the $\operatorname{cox} A, f b p A, f t s Z$, gatB, and $h c p A$ genes for ambiguities to exclude the presence of multiple infections. Sequences were then edited manually and trimmed using Geneious 38.1 .8 software (Kearse et al. 2012). I determined DNA sequences by BLAST analysis and compared Wolbachia sequences to the Wolbachia MLST database (http://pubmlst.org/wolbachia). Reference species MLST profiles were retrieved from the database and aligned with sequences obtained in this study using the MUSCLE algorithm within the Geneious 38.1 .8 software (Kearse et al. 2012). I determined pairwise genetic distances between different Wolbachia strains using the Tamura 3-parameter model in Mega 7.0.21 (Kumar et al. 2016).

Sequence chromatograms of the $C O I$ gene were edited manually and trimmed using Geneious 3 8.1.8 software (Kumar et al. 2016). I then used BLAST query analysis to compare obtained sequences against the NCBI database. Reference sequences were retrieved from GenBank and aligned with my sequences using the MUSCLE algorithm within Geneious 3 8.1.8 software (Kearse et al. 2012). The pairwise genetic distances between different $C O I$ sequences were calculated using Kimura 2 parameter model in Mega 7.0.21 (Kumar et al. 2016).

The substitution models with the lowest BIC values were selected from Find Best DNA Model using Mega 7.0.21 (Kumar et al. 2016) for phylogenetic analysis of MLST and COI. Maximum Likelihood phylogenetic analyses were performed and tree topology robustness was determined by non-parametric bootstrapping with 1000 iterations. The MLST profile ST-35 from Bruglia malayi was used as an outgroup to root the Wolbachia 
MLST tree. The parasitoid COI gene tree was rooted with Nasonia vistripennis and Eurema COI gene tree was rooted with Colias erate.

\section{RESULTS}

In total, I collected 404 larvae from Eurema host plants across four sites. Collectively, these larvae yielded a combined 24 fly and wasp parasitoids, which I characterized and screened for Wolbachia along with the Eurema hosts from which they emerged (Table 2.5). Results from COI gene analysis revealed all larvae with parasitoids and a subsample of adult butterflies that did not yield parasitoids were E. hecabe (Figure 2.2). Eurema hecabe had a $5.9 \%$ rate of parasitization. Apart from three larvae that survived, all larvae from which parasitoids emerged died. Of the larvae that survived, wasps emerged from two and a fly emerged from one. In 16 other E. hecabe larvae, I detected evidence of the host's immune response as indicated by melanization. Since no parasitoids emerged from these 16 larvae and they all developed into adult butterflies, I assumed they survived parasitization by killing the parasitoid. An additional surprising result was the discovery of a parasitoid moth species that developed inside a butterfly pupa. The parasitoid moth was not included in the analyses.

Table 2.5: Lists the number of larvae and parasitoids collected at each site.

\begin{tabular}{llll}
\hline Site & $\begin{array}{l}\text { Number of Eurema } \\
\text { larvae collected }\end{array}$ & $\begin{array}{l}\text { Number of } \\
\text { parasitoids }\end{array}$ & $\begin{array}{l}\text { \% larvae with } \\
\text { parasitoids }\end{array}$ \\
\hline Cairns & 90 & 7 & 7.8 \\
Mt. Sophia & 78 & 4 & 5.1 \\
Babinda & 109 & 2 & 1.8 \\
Mareeba Wetlands & 127 & 11 & 8.7 \\
\hline
\end{tabular}




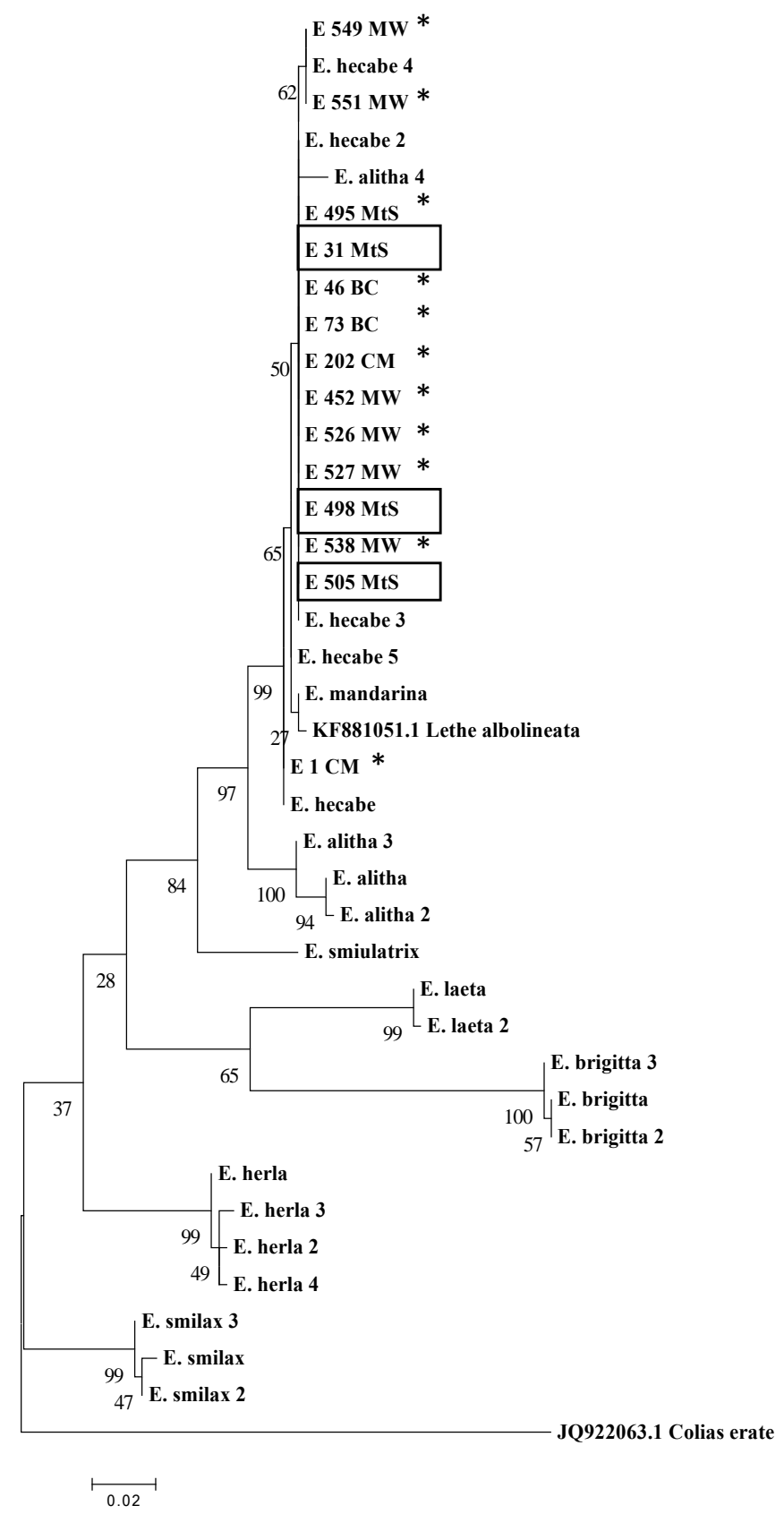

Figure 2.2: Inferred phylogenetic tree based on COI sequence fragments (544bp) of Eurema constructed by maximum likelihood method (Model T92+G). Eurema hecabe samples from this study are shaded in grey boxes, with dark grey boxes highlight E. hecabe samples collected at Mt. Sophia. Outgroups from other Eurema species were retrieved from the NCBI database (accession numbers not listed here are listed in Appendix C). Numbers at nodes represent bootstrap values (1000 replicates) $>50 \%$ and scale bar represents number of nucleotide substitutions per site. 
Parasitoids were morphologically grouped into fly or wasp morphotypes. Matches based on $C O I$ sequence BLAST searches indicated that the parasitoid wasp species were Miroplitis demolitor $(\mathrm{N}=1)$ and Cotesia congregate $(\mathrm{N}=1)$, and two species of flies, Exorista cantans $(\mathrm{N}=18)$ and Senometopia cinerea $(\mathrm{N}=1)$. According to phylogenetic analysis, the remaining three flies belonged to the Exorista genus (Figure 2.3). The two wasps, $M$. demolitor, C. congregata, and unique fly species, $S$. cinerea, were collected from the same location, Mt. Sophia (Figure 2.3).

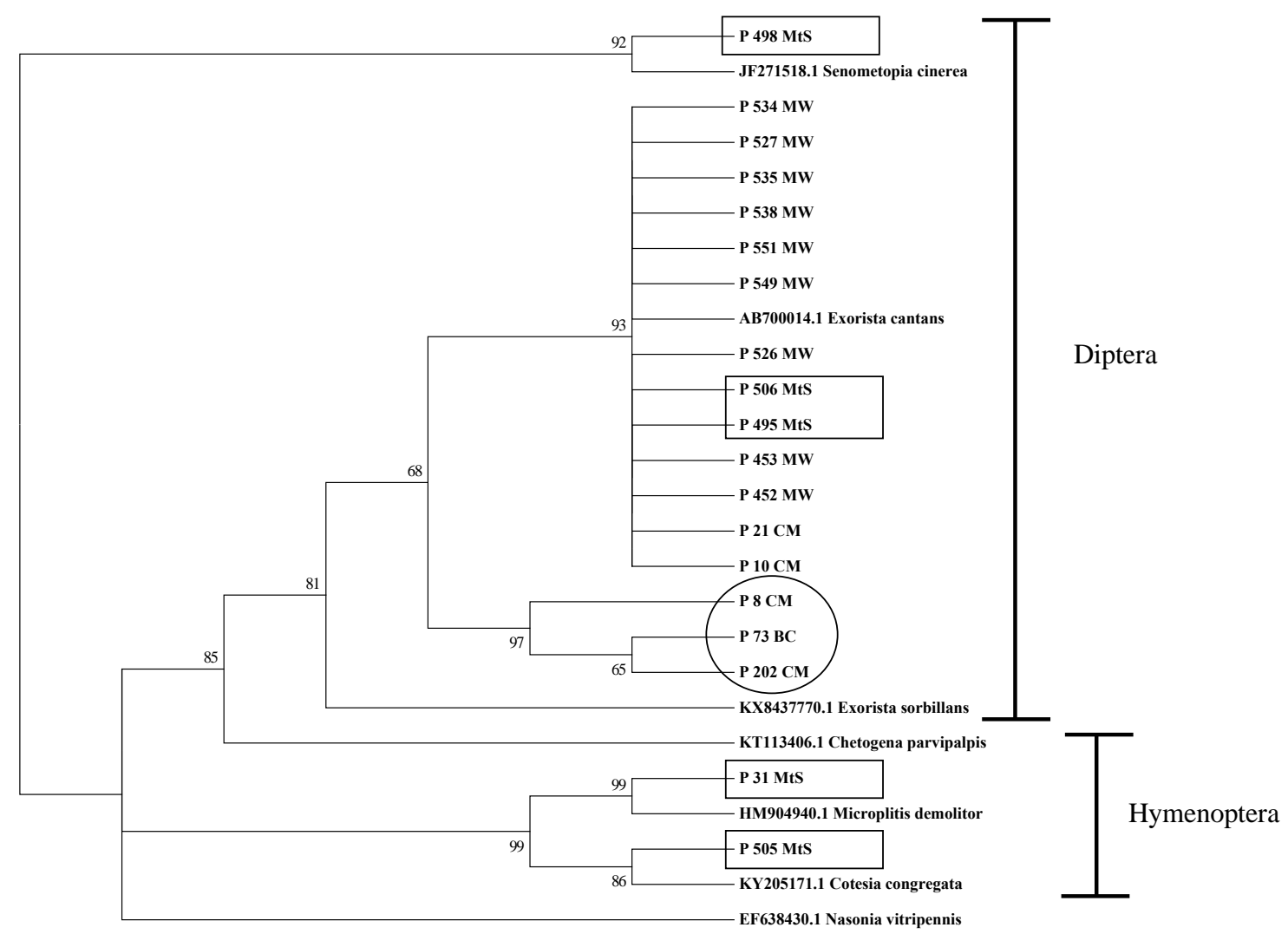

Figure 2.3: Phylogenetic tree based on COI sequence fragments (523bp) constructed by maximum likelihood method (Model T93+G+I). Parasitoid samples from this study are shaded in grey boxes, with dark grey boxes highlighting parasitoids collected from Mt. Sophia. Species identified from COI sequence BLAST queries were retrieved from the NCBI database and are listed by name and accession number Numbers at nodes represent bootstrap values (1000 replicates) $>50 \%$. 


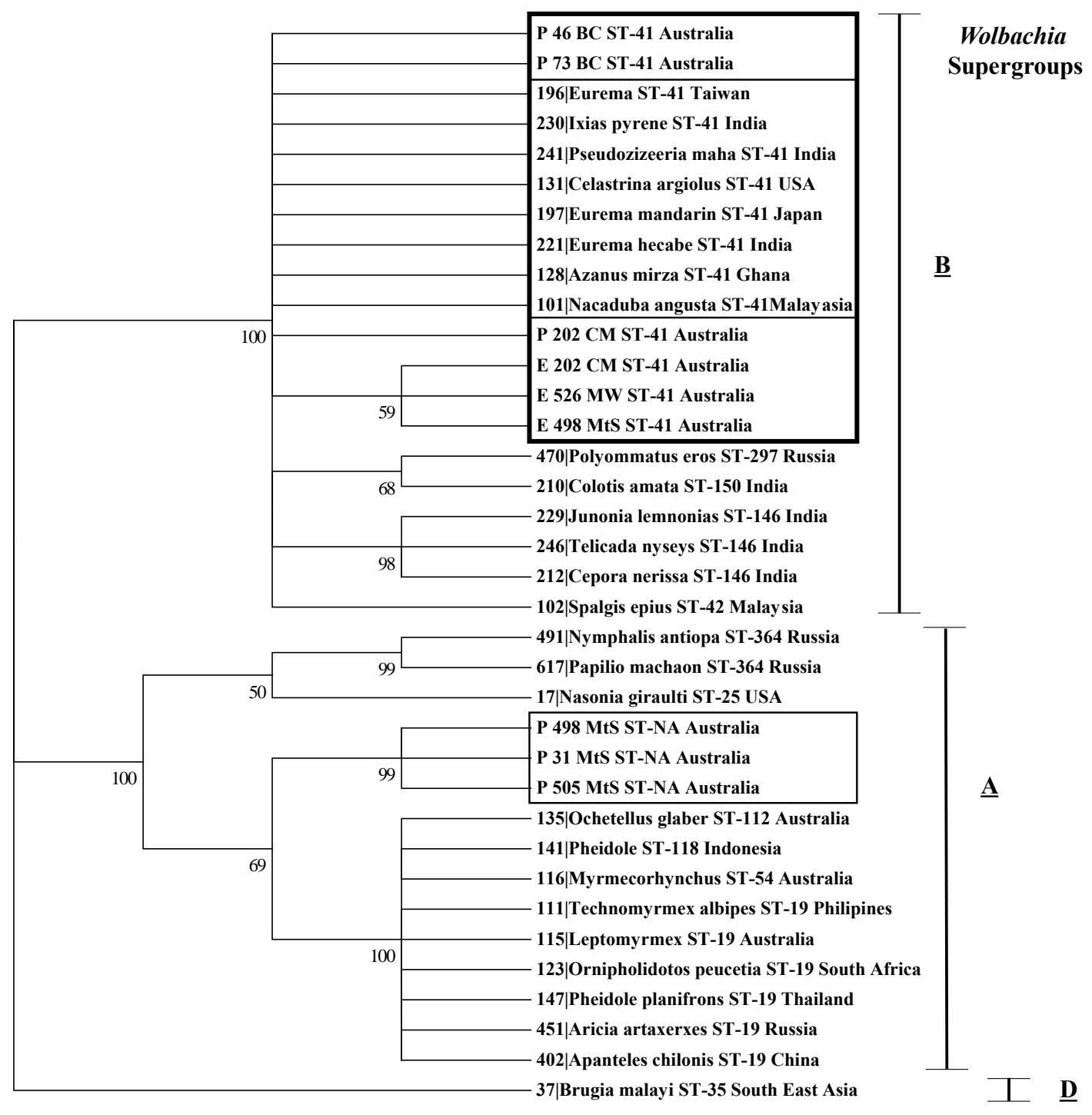

Figure 2.4: Phylogenetic tree based on concatenated MLST genes (2079bp) constructed by maximum likelihood method (Model T93+G). Outgroups from other known Wolbachia ST and supergroups, listed by ID, host name, and sequence type, were retrieved from the Wolbachia MLST database. Host names of sequences isolate from this study are delineated by grey boxes. Numbers at nodes represent bootstrap values (1000 replicates) $>50 \%$ and letters indicate Wolbachia supergroups. 
All 24 parasitoids and 24 hosts were positive for Wolbachia infection. Direct sequencing of marker genes from the Wolbachia MLST complex produced clear chromatograms and complete profiles for each Eurema specimen and for all but one parasitoid specimen, which was missing sequence data for the $f b p A$ locus. Overall, two MLST profiles were found, one complete and one that was incomplete. The MLST profiles revealed that all $24 \mathrm{E}$. hecabe host larvae and 20 of the 24 emerged parasitoids were infected with a Wolbachia strain designated to the sequence type (ST) ST-41. This Wolbachia strain, $w \mathrm{CI}$, has been previously identified in both Australian and Japanese Eurema species (Table 2.6 and 2.7) (Narita et al. 2006; Kern et al. unpublished). Interestingly, alleles from the incomplete MLST profile match to STs from both supergroup A and B, which could indicate presence of a double infection (Table 2.8, Figure 2.4). 
Table 2.6: Results showing alleles from PCR and sequencing analysis of the five Wolbachia MLST loci from each parasitoid collected. Parasitoids morphotypes are listed as: D stands for Diptera and $\mathrm{H}$ for Hymenoptera, D1 = Tachinid fly $(\mathrm{N}=17), \mathrm{D} 2=$ Tachinid unique from the others $(\mathrm{N}=3), \mathrm{H} 1=$ small Braconids, larvae yielded six small wasps, but they were pooled for DNA extraction $(\mathrm{N}=1)$, and $\mathrm{H} 2=$ large Braconid $(\mathrm{N}=1)$. Parasitoids from Mt. Sophia are highlighted in grey. Samples that had unique strains are listed in bold text.

\begin{tabular}{|c|c|c|c|c|c|c|c|c|c|}
\hline Parasitoid & Morphotype & Site & gatB & $\operatorname{coxA}$ & hcpA & $f t s Z$ & $f b p A$ & ST & Supergroup \\
\hline 1 & D1 & $\mathrm{CM}$ & 39 & 14 & 40 & 36 & 4 & 41 & B \\
\hline C9 & D1 & $\mathrm{BC}$ & 39 & 14 & 40 & 36 & 4 & 41 & B \\
\hline 8 & D1 & $\mathrm{CN}$ & 39 & 14 & 40 & 36 & 4 & 41 & B \\
\hline 10 & D1 & $\mathrm{CM}$ & 39 & 14 & 40 & 36 & 4 & 41 & B \\
\hline 21 & D1 & $\mathrm{CM}$ & 39 & 14 & 40 & 36 & 4 & 41 & B \\
\hline 31 & H1 & MtS & 89 & 1 & 1 & 3 & 1 & New & $\mathbf{A}$ \\
\hline 46 & D1 & $\mathrm{BC}$ & 39 & 14 & 40 & 36 & 4 & 41 & B \\
\hline 73 & D1 & $\mathrm{BC}$ & 39 & 14 & 40 & 36 & 4 & 41 & B \\
\hline 202 & D1 & $\mathrm{CM}$ & 39 & 14 & 40 & 36 & 4 & 41 & B \\
\hline 452 & D1 & MW & 39 & 14 & 40 & 36 & 4 & 41 & B \\
\hline 453 & D1 & MW & 39 & 14 & 40 & 36 & 4 & 41 & B \\
\hline 458 & D1 & MW & 39 & 14 & 40 & 36 & 4 & 41 & B \\
\hline 495 & D1 & $\mathrm{MtS}$ & 87 & 9 & 6 & 70 & $\mathrm{n} / \mathrm{a}$ & $\mathrm{n} / \mathrm{a}$ & $\mathrm{n} / \mathrm{a}$ \\
\hline 498 & D2 & MtS & 89 & 1 & 1 & 3 & 1 & New & A \\
\hline 505 & H2 & MtS & 89 & 1 & 1 & 3 & 1 & New & A \\
\hline 506 & D1 & $\mathrm{MtS}$ & 39 & 14 & 40 & 36 & 4 & 41 & B \\
\hline 526 & D1 & MW & 39 & 14 & 40 & 36 & 4 & 41 & B \\
\hline 527 & D1 & MW & 39 & 14 & 40 & 36 & 4 & 41 & B \\
\hline 538 & D1 & MW & 39 & 14 & 40 & 36 & 4 & 41 & B \\
\hline 549 & D1 & MW & 39 & 14 & 40 & 36 & 4 & 41 & B \\
\hline 551 & D1 & MW & 39 & 14 & 40 & 36 & 4 & 41 & B \\
\hline 552 & D1 & MW & 39 & 14 & 40 & 36 & 4 & 41 & B \\
\hline
\end{tabular}


Table 2.7: Allelic profiles at the five Wolbachia MLST loci from each Eurema butterfly tested. Butterflies collected at Mt. Sophia are highlighted in grey. The life stage listed for each Eurema is the stage from which we sampled tissues for DNA extractions. Eurema that survived adult the stage are listed in bold text.

\begin{tabular}{|c|c|c|c|c|c|c|c|c|c|}
\hline Eurema & $\begin{array}{c}\text { Life stage } \\
\text { died }\end{array}$ & Site & gatB & $\operatorname{cox} A$ & hcpA & $f t s Z$ & $f b p A$ & ST & Supergroup \\
\hline 1 & Pupal & $\mathrm{CM}$ & 39 & 14 & 40 & 36 & 4 & 41 & B \\
\hline C9 & Adult & BC & 39 & 14 & 40 & 36 & 4 & 41 & B \\
\hline 8 & Pupal & $\mathrm{CM}$ & 39 & 14 & 40 & 36 & 4 & 41 & B \\
\hline 10 & Pupal & $\mathrm{CM}$ & 39 & 14 & 40 & 36 & 4 & 41 & B \\
\hline 21 & Pupal & $\mathrm{CM}$ & 39 & 14 & 40 & 36 & 4 & 41 & B \\
\hline 31 & Adult & MtS & 39 & 14 & 40 & 36 & 4 & 41 & B \\
\hline 46 & Pupal & $\mathrm{BC}$ & 39 & 14 & 40 & 36 & 4 & 41 & B \\
\hline 73 & Pupal & $\mathrm{BC}$ & 39 & 14 & 40 & 36 & 4 & 41 & B \\
\hline 202 & Pupal & $\mathrm{CM}$ & 39 & 14 & 40 & 36 & 4 & 41 & B \\
\hline 452 & Pupal & MW & 39 & 14 & 40 & 36 & 4 & 41 & B \\
\hline 453 & Pupal & MW & 39 & 14 & 40 & 36 & 4 & 41 & B \\
\hline 458 & Pupal & MW & 39 & 14 & 40 & 36 & 4 & 41 & B \\
\hline 495 & Pupal & MtS & 39 & 14 & 40 & 36 & 4 & 41 & B \\
\hline 498 & Pupal & $\mathrm{MtS}$ & 39 & 14 & 40 & 36 & 4 & 41 & B \\
\hline 505 & Adult & MtS & 39 & 14 & 40 & 36 & 4 & 41 & B \\
\hline 506 & Pupal & $\mathrm{MtS}$ & 39 & 14 & 40 & 36 & 4 & 41 & B \\
\hline 526 & Pupal & MW & 39 & 14 & 40 & 36 & 4 & 41 & B \\
\hline 527 & Pupal & MW & 39 & 14 & 40 & 36 & 4 & 41 & B \\
\hline 538 & Pupal & MW & 39 & 14 & 40 & 36 & 4 & 41 & B \\
\hline 549 & Pupal & MW & 39 & 14 & 40 & 36 & 4 & 41 & B \\
\hline 551 & Pupal & MW & 39 & 14 & 40 & 36 & 4 & 41 & B \\
\hline 552 & Pupal & MW & 39 & 14 & 40 & 36 & 4 & 41 & B \\
\hline
\end{tabular}


Table 2.8: Results from BLAST search using COI sequences of parasitoids. Species listed were the closest match in the NCBI database where $\mathrm{N}$ indicates the number of samples.

\begin{tabular}{ccccccc}
\hline $\begin{array}{c}\text { COI BLAST search } \\
\text { closest species match }\end{array}$ & Site & Strain & N & $\begin{array}{c}\text { Query } \\
\text { coverage \% }\end{array}$ & e-value & Indentity \% \\
\hline Microplitis demolitor & Mt. Sophia & New & 1 & 100 & 0.0 & 99 \\
Senometopia cinerea & Mt. Sophia & New & 1 & 99 & 0.0 & 96 \\
$\begin{array}{c}\text { Cotesia congregata } \\
\text { Exorista cantans }\end{array}$ & Mt. Sophia & New & 1 & 99 & 0.0 & 98 \\
& Mareeba Wetlands & ST-41 & 17 & 100 & 0.0 & 98 \\
Cairns & & & & & \\
Babinda & & & & & \\
& Mareeba Wetlands & ST-41 & 3 & 100 & 0.0 & \\
& Cairns & & & & & \\
\hline
\end{tabular}

\section{DISCUSSION}

Horizontal transmission of Wolbachia has been largely inferred from phylogenetic analyses that provide indirect evidence consistent with such transmission (Haine et al. 2005; Sintupachee et al. 2006; Ahmed et al. 2016). Recent ecological studies have revealed identical Wolbachia strains in multiple species among two different genera belonging to the same order (Morrow et al. 2014; Schuler et al. 2016). Results presented here are the first, to my knowledge, to identify a shared identical Wolbachia strain $(w \mathrm{CI})$ among a Lepidoptera host, E. hecabe, and Diptera parasitoids from the genus Exorista. This finding indicates that the Wolbachia strain is shared across species within the genus. Frequent occurrence of shared Wolbachia strains among host and parasitoid strongly suggests that horizontal transmission was paramount to the successful invasion of Wolbachia in this group of butterflies. 
The sequence type I identified in both parasitoids and E. hecabe, ST-41, is especially common in Lepidoptera with 34 of the 38 ST-41 isolates in the MLST database assigned to Lepidoptera species from all continents apart from Europe. A previous study suggests evidence for inter-ordinal transfer of ST-41, ST-19, and ST-37 Wolbachia (Ahmed et al. 2016). However, the evidence is based on identification of STs among species belonging to different orders from different parts of the world. Although an important finding, they did not find species of multiple orders at the same location sharing STs.

Because I tested parasitoids that emerged from infected E. hecabe for Wolbachia, in theory there are perhaps three reasons why they all tested positive: 1) they all carry heritable infections, meaning that Wolbachia reside in the parasitoids' germline cells, 2) they could all carry infections that are not heritable and Wolbachia is localized in somatic tissues, and 3) they are not infected at all and I detected Wolbachia DNA carryover or contamination. To determine which of these infection scenarios is true for parasitoids of E. hecabe requires laboratory experiments and testing several generations of offspring from parasitoids for Wolbachia infection. It is feasible that Wolbachia infections in these parasitoids are non-heritable and reside in somatic tissues. A laboratory embryo microinjection study detected positive adult parasitoids emerging from the embryos, but their offspring were uninfected (Zabalou et al. 2004). I postulate that if the parasitoids have somatic infections, such infections could be a starting point for Wolbachia-spillover and, consequently, potentially establish inheritable infection in new lineages.

Although non-specific DNA was not detected in DNA extractions from either host or parasitoid, I am not able to eliminate the possibility that parasitoids were exposed 
to Wolbachia during development. I took several precautions to avoid contamination between parasitoids and Eurema during every stage of this investigation. Evidence that my results are not an artifact from contamination include 1) COI gene amplifications were specific and there was no detection of non-target DNA and 2) I detected unique strains from four parasitoid DNA extractions that were not detected in host E. hecabe DNA extractions.

Larvae and pupae have developed immune responses to defend themselves against different parasites and parasitoids (Altizer \& de Roode 2010). Clusters of immune cells called hemocytes adhere to parasitoid eggs, encapsulating them with the deposition of melanin pigment, in an attempt to kill them by asphyxiation (Altizer et al. 2010). Melanization of parasitoids in Eurema butterflies is easily visible and indicates the invasion and presence of one or more endoparasitoids. Thus, to estimate Eurema survival from parasitoids, I screened Eurema larvae for melanization and recorded whether they survived to the adult stage. In total, I found that 19 E. hecabe in this study survived parasitization. I postulate that when a larva launches an immune response that kills the parasitoid and emerges as an adult butterfly, there may be an opportunity for horizontal transmission of Wolbachia from an infected parasitoid to an uninfected larva host. Acquisition of Wolbachia by a larva could occur by Wolbachia escaping the dead parasitoid cells and migrating to the larva's germ line cells, which are responsible for Wolbachia's vertical transmission (Van Meer \& Stouthamer 1999; Huigens et al. 2004; Frydman et al. 2006). Conversely, a parasitoid could potentially acquire Wolbachia during development inside a larva. This is a probable route of passage for Wolbachia from a larva to a parasitoid because parasitoid development depends exclusively on 
consumption of host tissue. Once inside of the parasitoid digestive tract, Wolbachia has the potential to migrate into parasitoid germ lines and be passed to the next generation (Frydman et al. 2006).

Approximately 10,000 described parasitoid species worldwide comprise the Tachinidae family, the most speciose family of Diptera. Though morphologically diverse, many tachinids are parasitoids of caterpillars (Irwin et al. 2003). While seemingly immense, the Tachnidae are all but eclipsed by the Bracondidae family (Hymenoptera) consisting of up to 45,000 species of parasitoid wasps (Jones et al. 2009). The substantial biodiversity of parasitoids poses many challenges to species classification and identification, as only approximately $1 \%$ of the species can be identified using $C O I$ barcoding methods (Godfray 1994). Consequently, the extent to which parasitoids vector Wolbachia between closely or distantly related taxa is difficult to assess or even predict.

Furthermore, I discovered that three of the five E. hecabe collected from Mt. Sophia had unique parasitoids that shared an identical Wolbachia strain, which is unique from the $w \mathrm{CI}$ strain I found in E. hecabe and parasitoid Exorista species. Parasitoids, especially tachinid flies, have been widely accepted as generalists, parasitizing multiple host species (Stireman et al. 2005; Stireman et al. 2006). However, host-specificity among parasitoids is widely debated, may vary between geographic regions, and may depend on the presence or absence of available host species at a given time (Stireman et al. 2005; Smith et al. 2006; Stireman et al. 2006). Mount Sophia may be void of other hosts of the three parasitoids species and E. hecabe larvae were available. The variables affecting host-specificity might interfere with predictive accuracy on host-parasitoid Wolbachia horizontal transmission events as generalist parasitoids have more 
opportunities to both expose novel hosts to and be exposed to the endosymbiont.

Climate change may lead to increased parasitization as temperate regions warm, subsequently spreading Wolbachia to novel hosts (Ahmed et al. 2016). Some strains of Wolbachia induce CI and can lead to decreased host genetic diversity (Hurst \& Jiggins 2005). Hence, understanding the mechanisms of horizontal transmission will give researchers better predictive power and ability to inform management decisions for vulnerable insect species.

Finally, while the original aim of this study was to collect multiple Eurema species to investigate whether parasitoids among multiple species share identical Wolbachia strains, I was successful only in collecting E. hecabe. It is possible that I was unsuccessful in collecting multiple Eurema species because E. hecabe is extremely prevalent in the region where I collected larvae and have less restricted geographic distribution compared to some of the other Eurema species. In addition, morphological identification of different Eurema species is impossible at the larval stage and I was not able to discern species at time of collection. This study of a host-parasitoid system presents a platform for further investigations into the mechanisms of Wolbachia horizontal transmission. Future studies should include a more exhaustive and long-term survey of Eurema larvae and their parasitoid communities, followed with multigenerational laboratory experiments to show interspecies transmission. 


\section{Chapter 3: Chill out: Wolbachia associated cooling off of Drosophila melanogaster in thermal gradient temperature preference choice assays}

\section{INTRODUCTION}

Endosymbiotic bacteria interact with insects in multifarious ways, including altering the reproductive phenotype of their hosts to enhance their own transmission (Werren et al. 2008). One such group endosymbionts are extremely widespread, infecting approximately 53\% of arthropod species and belong to the genus Wolbachia (Zug \& Hammerstein 2012; Weinert et al. 2015; Sazama et al. 2017).

Wolbachia have garnered extensive interest due to the reproductive manipulations they inflict on their hosts: parthenogenesis, male killing, feminization, and cytoplasmic incompatibility (reviewed by Werren et al. 2008). The relationships they form with their hosts are diverse and not all Wolbachia are master manipulators. For example, some strains are obligate mutualists while others form facultative relationships (Miller 2013; Zug \& Hammerstein 2014). There are Wolbachia strains that increase fecundity to female hosts (Miller et al. 2010) and strains that provide their hosts with protection against viruses (Hedges et al. 2008; Teixeira et al. 2008; Martinez et al. 2014). Additionally, Wolbachia-induced cytoplasmic incompatibility (CI) can promote mate discrimination (Miller et al. 2010; Buellesbach et al. 2014), which can lead to reproductive isolation one of the key driving forces of speciation (Coyne \& Orr 2004).

All terrestrial insects infected with Wolbachia are ectotherms that seek external sources of heat, cold, or shelter to maintain their body temperature within a thermoregulatory range (Angilletta 2009). In addition, Wolbachia's replication behavior is positively temperature-dependent (Hoffmann et al. 1990; Reynolds et al. 2003; Mouton 
et al. 2006; Mouton et al. 2007; Bordenstein \& Bordenstein 2011; Correa \& Ballard 2012; Chrostek et al. 2013; Strunov et al. 2013a; Strunov et al. 2013b; Murdock et al. 2014; Versace et al. 2014). Host-symbiont conflict could arise due to the disparities between the physiological requirements of Wolbachia and those of their hosts. For example, some insects induce behavioral fever (Louis et al. 1986) or behavioral chill (Fedorka et al. 2016) as an immune strategy to fight pathogen infection. Conversely, some bacterial symbionts are known to alter their host's thermal tolerance range (Russell \& Moran 2006; Dunbar et al. 2007; reviewed by Wernegreen 2012).

Whether host or symbiont, an organism's ability to remain within its upper and lower thermal tolerance limits is paramount to its survival (Huey \& Berrigan 2001; Angilletta et al. 2004; Hoffmann 2010; Huey et al. 2012). Temperature preference can vary between species within a genus, or among populations of a species that have been exposed to different biological factors, including pathogens (Matute et al. 2009).

Research has shown that geography, elevation, and genetic background can influence $D$. melanogaster environmental temperature preferences (Martin \& Huey 2008; Hoffmann \& Sgrò 2011; Huey et al. 2012; Rajpurohit \& Schmidt 2016). In addition, research examining temperature effects on Wolbachia have found that replication of some strains increases at warmer temperatures (Mouton et al. 2006; Chrostek et al. 2013; Strunov et al. 2013). However, despite widespread and diverse Wolbachia infections in Drosophila species on every continent, no studies have explicitly addressed Wolbachia-dependent temperature preference in Drosophila. Thus, I conducted a laboratory experiment to determine whether Wolbachia affects the environmental temperature preference of $D$. melanogaster. 
Drosophila melanogaster is infected with several closely related genetic variants of the Wolbachia strain $w$ Mel: $w$ Mel, $w$ MelCS, and $w$ MelPop (Riegler et al. 2005). All three variants cause weak CI and provide virus protection to varying degrees (Osborne et al. 2009; Chrostek et al. 2013). The $w$ Mel-strain variants $w \mathrm{Mel}$ and $w$ MelCS infect natural populations of $D$. melanogaster, whereas the $w$ MelPop was isolated from a laboratory Drosophila stock during a survey for genetic mutations and is not found in natural populations (Min \& Benzer 1997; Riegler et al. 2005; Richardson et al. 2012). The $w$ MelPop variant is considered a unique example of a pathogenic symbiont (Min \& Benzer 1997). The life-span of D. melanogaster infected with wMelPop is reduced twofold as a result of the bacteria over-replicating in host tissues, such as the brain, retina, and muscles (Min \& Benzer 1997; Strunov et al. 2013b). Additionally, at $25^{\circ} \mathrm{C}$, wMelPop reaches densities in its hosts that are 20 times higher than $w \mathrm{Mel}$ and at least twice as high as wMelCS (Chrostek et al. 2013).

I performed this study to determine the effects of Wolbachia on D. melanogaster temperature preferences using a laboratory reared population. My goal was to determine whether Wolbachia-infected flies have different preferred temperatures compared to uninfected flies. In D. melanogaster, different genetic variants of Wolbachia are known to provide varying extents of anti-viral protection (Chrostek et al. 2013). In addition, temperature preference divergence could negatively affect insects of conservation concern if Wolbachia-infected and uninfected conspecifics adapt to different sets of environmental conditions. The resulting diverged adaptation could lead to reproductive isolation, ultimately reducing the overall fecundity of the population. Therefore, I wanted to know whether flies of the same genetic background infected with different genetic 
variants of Wolbachia-strains had different temperature preferences. I hypothesized that Wolbachia-infected flies would prefer lower temperatures compared to uninfected flies as a response aimed at regulating or inhibiting Wolbachia replication. Additionally, I hypothesized that $w$ MelPop infected flies would prefer a lower temperature compared to the other three D. melanogaster-Wolbachia combinations because wMelPop actively proliferates and is pathogenic at $25^{\circ} \mathrm{C}$ and warmer (Strunov et al. 2013b).

Here, I compare temperature preferences of the isogenic strain D. melanogaster infected by different $w \mathrm{Mel}$ strain variants $-w \mathrm{Mel}, w \mathrm{MelCS}$, and $w$ MelPop - to temperature preferences of uninfected (w-) flies. I define temperature preference as the temperature along the gradient where the highest number of flies aggregate (Appendix B Figure B.1). I demonstrate that the temperature preference of D. melanogaster correlates with the presence or absence of Wolbachia. In addition, I show that a significant relationship exists between temperature preference of D. melanogaster and the wMelstrain variant with which the flies are infected. This research elucidates fundamental ecological conflicts between host and symbiont that may arise in natural insect populations.

\section{MATERIALS AND METHODS}

To determine whether D. melanogaster's environmental temperature preference varied with Wolbachia infection status and strain-type variant, I conducted a behavioral laboratory experiment using a thermal gradient apparatus (Appendix B Figure B.1). I used flies from each of four different infection scenarios: uninfected (w-) and flies infected with $w \mathrm{Mel}, w \mathrm{MelCS}$, or $w$ MelPop. In each assay, I introduced 75-100 flies to the 
thermal gradient chamber, allowed them to settle, and then recorded their preferred temperature distribution within the chamber. I performed seven replicates in a randomly selected order for each of these infection scenarios. I thoroughly cleaned the equipment before and after each run. In this section and in the appendices, I describe the fly lines used, a detailed description of the thermal gradient apparatus, and the method used for confirming Wolbachia infection and wMel- strain variant.

\section{Fly Lines}

Wolbachia infected and uninfected Drosophila melanogaster ${ }^{\text {w1118 }}$ (mutant whiteeyed) fly lines were kindly provided by Luis Teixeira and previously described by Chrostek et al. (2013). For all assays, I used D. melanogaster without Wolbachia (w-) as well as three genetic variants of the Wolbachia wMel-strain, wMel, wMelCS, and $w$ MelPop all set in the $w^{1118}$ isogenic background.

Flies were incubated at $25^{\circ} \mathrm{C}$, in a $12: 12$ light - dark cycle with constant $45 \%$ humidity, and raised on Drosophila Formula 4-24® Instant Medium (Carolina ${ }^{\circledR}$, NC) that was supplemented with fresh yeast. Vials contained approximately 30 flies each. Approximately equal numbers of male and female flies were used in each assay except for assays that explicitly addressed whether behavior was different between male and female flies.

\section{Confirmation of fly Wolbachia strains}

Genome sections that contain hypervariable regions or hypervariable regions and tandem repeats are used as genetic markers to differentiate Wolbachia strains and strain 
variants (O’Neill et al. 1992; Werren et al. 1995; Zhou et al. 1998; Riegler et al. 2012). To confirm Wolbachia-infection status, I performed diagnostic PCR amplification using primers for a gene that encodes the Wolbachia surface protein, wsp (Jeyaprakash \& Hoy 2000), and for an intergenic region with $141 \mathrm{bp}$ tandem repeats, VNTR-141 loci (Riegler et al. 2005). The PCR reactions for wsp amplification were each a total of $10 \mu 1$ containing $2 \mu 1$ Promega 5x Green GoTaq buffer, $4 \mathrm{mM}$ Promega $\mathrm{MgCl}_{2}, 0.8 \mu \mathrm{M}$ of forward and reverse primers, $35 \mu \mathrm{M}$ of each dNTP, $0.04 \mathrm{U}$ Promega GoTaq DNA Polymerase, and $1 \mu 1$ of genomic DNA template. Diagnostic VNTR-141 PCR reactions were each a total of $10 \mu 1$ comprised of the following: $2 \mu 1$ Promega 5x Green GoTaq buffer, $1.5 \mathrm{mM}$ Promega $\mathrm{MgCl}_{2}, 0.3 \mu \mathrm{M}$ of forward and reverse primers, $35 \mu \mathrm{M}$ of each dNTP, 0.04 U Promega GoTaq DNA Polymerase, and $1 \mu 1$ of genomic DNA template. Sequences and thermocycler conditions are listed in Tables 3.1 and 3.2. PCR products were visualized on a $1 \%$ agarose gel (Figure 3.1).

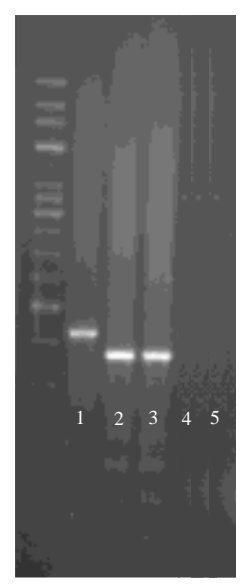

Figure 3.1: $1 \%$ agarose gel with $1 \mathrm{~kb}$ DNA ladder on the far left and PCR amplification products of VNTR141 loci from: $w \mathrm{Mel}$ in lane 1, wMelCS in lane 2, wMelPop in lane 3, w- in lane 4, and blank quality control in lane 5 . 
Table 3.1: List of primers used for PCR amplification of loci, targeted genome, and references.

\begin{tabular}{llll}
\hline Loci & Primers & Sequences (5'-3') & References \\
\hline \multirow{2}{*}{$w s p$} & wsp-F & TGGTCCAATAAGTGATGAAGAAACTAGCTA & $\begin{array}{l}\text { Jeyaprakash \& } \\
\text { Hoy 2000 }\end{array}$ \\
& wsp-R & AAAAATTAAACGCTACTCCAGCTTCTGCAC & \\
VNTR-141 & VNTR-F & GGAGTATTATTGATATGCG & Riegler et al. 2005 \\
& VNTR-R & GACTAAAGGTTAGTTGCAT & \\
\hline
\end{tabular}

Table 3.2: Thermocycler conditions for PCR of each loci.

\begin{tabular}{|c|c|c|}
\hline & $w s p$ & VNTR-141 \\
\hline Denaturation & $94^{\circ} \mathrm{C}$ for $2 \mathrm{~min}$ & $94^{\circ} \mathrm{C}$ for $2 \mathrm{~min}$ \\
\hline \multirow[t]{10}{*}{ Cycling } & 10 cycles: & 35 cycles: \\
\hline & $94^{\circ} \mathrm{C}$ for $10 \mathrm{sec}$ & $94^{\circ} \mathrm{C}$ for $30 \mathrm{sec}$ \\
\hline & $\begin{array}{l}65^{\circ} \mathrm{C} \text { for } 30 \mathrm{sec}, \\
\text { and } 68^{\circ} \mathrm{C} \text { for } 1 \mathrm{~min}\end{array}$ & $\begin{array}{l}55^{\circ} \mathrm{C} \text { for } 1 \mathrm{~min}, \\
\text { and } 72^{\circ} \mathrm{C} \text { for } 1 \mathrm{~min}\end{array}$ \\
\hline & 25 cycles: & \\
\hline & $94^{\circ} \mathrm{C}$ for $10 \mathrm{sec}$ & \\
\hline & $65^{\circ} \mathrm{C}$ for $30 \mathrm{sec}$ & \\
\hline & and $68^{\circ} \mathrm{C}$ for $1 \mathrm{~min}$, & \\
\hline & plus an additional & \\
\hline & $20 \mathrm{sec}$ added for every & \\
\hline & consecutive cycle & \\
\hline Final elongation & $68^{\circ} \mathrm{C}$ for $10 \mathrm{~min}$ & $72^{\circ} \mathrm{C}$ for $10 \mathrm{~min}$ \\
\hline
\end{tabular}




\section{Thermal gradient apparatus}

Temperature preference assays were performed using a three-dimensional thermal gradient apparatus (adapted from Rajpurohit \& Schmidt 2016; Appendix B Figure B.4). A temperature gradient was created along an aluminum rod (length $74.93 \mathrm{~cm}$, diameter 3.02cm; Part \#R31-316 Metals Depot, Winchester, KY) that was encased within a $58.76 \mathrm{~cm}$ long and $6.35 \mathrm{~cm}$ inside diameter polycarbonate tube, creating an enclosed chamber allowing for three-dimensional movement. Constant voltage was applied to Peltier devices on each end of the aluminum rod to create a temperature gradient inside the thermal preference chamber. Temperatures along the gradient were measured at seven evenly spaced $(8.39 \mathrm{~cm})$ points using K-type thermocouples and two four-channel thermocouple recorders. I recorded temperatures on the aluminum rod and inside polycarbonate tube surfaces (bottom, top, and mid-point between the top and bottom surfaces; Appendix B Figure B.5). The average temperatures from each thermocouple point on all surfaces from 18 different assays are depicted in Figure 3.2. Mean temperatures increased linearly and ranged from $12^{\circ} \mathrm{C}$ at the coldest point to $40^{\circ} \mathrm{C}$ at the hottest point of the aluminum rod, $58.76 \mathrm{~cm}$ distance (Figure 3.2). Along the aluminum rod, for every $4.2 \mathrm{~cm}$ from cold to hot, the temperature increased $2^{\circ}$. Temperatures along each of the measured polycarbonate tube surfaces (bottom, mid-point, and top) increased $1^{\circ} \mathrm{C}$ every $4.2 \mathrm{~cm}$ from cold to hot. The gradient reached thermal stability after approximately 20 minutes and remained stable for at least 3 hours. Assays were only conducted when the device had attained thermal stability. 


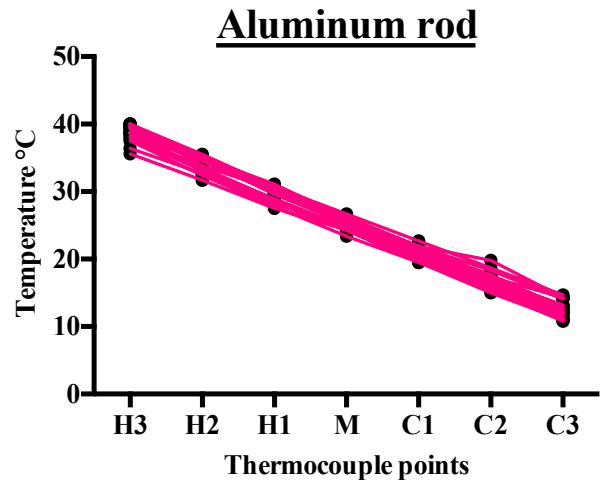

a.

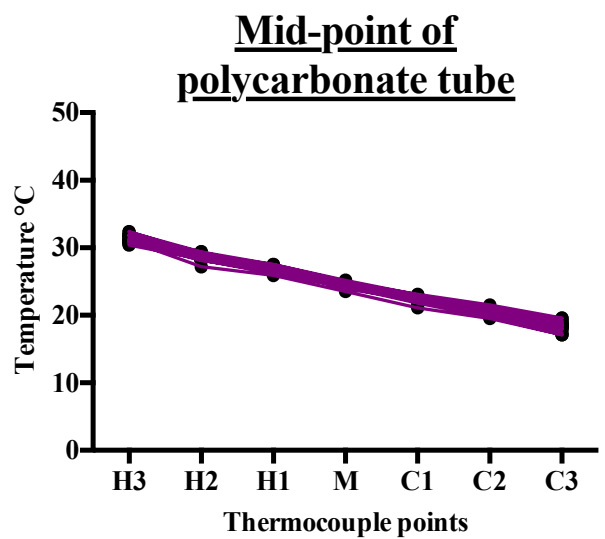

Bottom surface of polycarbonate tube

b.

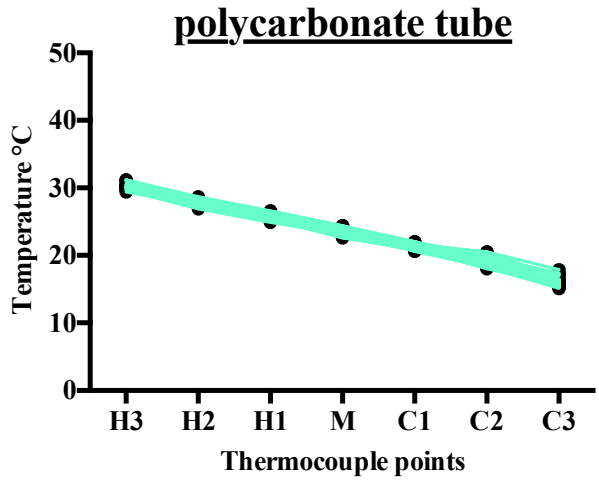

$\mathrm{N}=18$

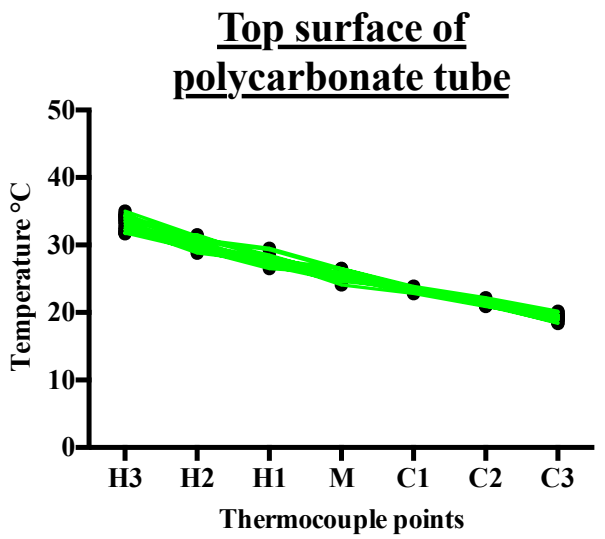

c.

d.

Figure 3.2: Plots showing linearity of temperature change for the different surfaces (a. aluminum rod, b. top, c. bottom, and mid-point of the polycarbonate tube) as measured with K-type thermocouples at regular intervals along the length of apparatus from the hottest end (H3) to the coldest (C3).

\section{Thermal preference assays}

All experiments were conducted in a room with a constant temperature of $24^{\circ} \mathrm{C}$ and constant $40 \%$ humidity. I determined the number of flies that represented a meaningful distribution along the thermal gradient without over-crowding in preferred temperature ranges to be 75-100 flies for each assay. Therefore, I used 75-100 flies that were aged 3-7 days old for each assay. Flies were introduced by aspiration into the temperature gradient chamber through a small hole located halfway along the top of the 
polycarbonate tube, where the temperature averaged $25^{\circ} \mathrm{C}$. Flies used for thermal preference assays were never anesthetized because of the strong effects that $\mathrm{CO}_{2}$ has on Drosophila behavior. The assays ran for thirty minutes. Between assays, the temperature gradient chamber was taken apart and thoroughly cleaned to avoid contamination from any pheromone particles. All aluminum parts were cleaned using 95\% ethanol. Because ethanol and polycarbonate are chemically incompatible, the polycarbonate tube and end caps were cleaned using hot water and soap, followed by a four-minute rinse with hot water to ensure that surfaces were free of soap residue.

\section{Data collection and analyses}

Using three GoPro HERO3+ cameras, I collected data for each assay in the format of digital images. To capture images of the entire thermal gradient and the flies within it, I mounted the cameras above, lateral to, and below the apparatus, capturing images every 30 seconds for the duration of each treatment (30 minutes). Images were analyzed using Adobe Photoshop CS6. All 60 images from each assay were reviewed, from which I determined that A) the flies were highly active, retaining the ability to relocate as necessary, for the entire assay, and B) after being introduced to the thermal gradient, actively flew around for up to 15 mins before they settled on either the aluminum rod or polycarbonate tube surfaces. Therefore, I selected images for analysis of fly distribution at the 20-minute time point as representative of the 30-minute experiment. For each assay, I manually counted flies and marked the location of flies on a custom grid that delineated gradient surfaces and surface temperatures.

I confirmed that the data approximated a normal distribution using the 
Kolmogrov-Smirnov test and homoscedastic variance using the Brown-Forsythe test. I performed a two-way ANOVA to examine the effects of Wolbachia infection status (w-, $w \mathrm{Mel}, w \mathrm{MelCS}$, and, $w \mathrm{MelPop})$, temperature, and Wolbachia infection $\mathrm{X}$ temperature interaction on the preferred temperature of $D$. melanogaster. To identify significant pairwise comparisons, I performed Tukey’s multiple comparison post-hoc tests.

\section{RESULTS}

\section{The effect of Wolbachia on temperature preference}

Results from a two-way analysis of variance (ANOVA) elucidated that uninfected and Wolbachia-infected D. melanogaster had significantly different environmental temperature preferences (Wolbachia-infection status * temperature interaction effect $F_{21}$, $128=49.54, \mathrm{P}<0.0001 ;$ Table 3.3). Using Tukey's post-hoc pairwise comparison, I determined that for each Wolbachia-infection status the temperature at which the most flies landed had significantly more flies compared to the number of flies that landed at each of the other temperatures on the gradient. I concluded that the temperature at which the highest number flies settled, hereon called 'temperature preferences', for each Wolbachia-infection status was $26^{\circ} \mathrm{C}$ for $\mathrm{w}-, 24^{\circ} \mathrm{C}$ for $w$ Mel-infected flies, and $18^{\circ} \mathrm{C}$ for both $w$ MelCS- or $w$ MelPop-infected D. melanogaster (P always $<0.0001$; Table 3.4, Appendix B Table B6, and Figure 3.3). 
Table 3.3: Results from two-way ANOVA examining the effects of Wolbachia-infection, strain-variant, and temperature on D. melanogaster temperature preference.

\begin{tabular}{llllll}
\hline Two-way ANOVA table & SS & DF & MS & F(DFn, DFd) & P value \\
\hline $\begin{array}{l}\text { Wolbachia-strain variation } \\
\text { Temperature }\end{array}$ & $2.12 \mathrm{E}-05$ & 3 & $7.05 \mathrm{E}-06$ & $\mathrm{~F}(3,128)=0.0051$ & $\mathrm{P}=0.9995$ \\
$\begin{array}{l}\text { Interaction } \\
\text { Residual }\end{array}$ & 1.57 & 7 & 0.2243 & $\mathrm{~F}(7,128=163.3$ & $\mathrm{P}<0.0001$ \\
\hline
\end{tabular}

Table 3.4: Results from Tukey's post hoc multiple comparison test comparing the temperature preference values (the temperature at which the $w$ Mel- variant had the highest proportion of flies) to the proportion of flies at all the other available temperatures.

\begin{tabular}{|c|c|c|c|c|}
\hline Temperature $^{\circ} \mathbf{C}$ & $w-26^{\circ} \mathrm{C}$ & $w \operatorname{Mel} 24^{\circ} \mathrm{C}$ & $w$ MelCS $<18^{\circ} \mathrm{C}$ & $w$ MelPop $<18^{\circ} \mathrm{C}$ \\
\hline 18 & $\mathrm{P}<0.0001$ & $\mathrm{P}<0.0001$ & $\mathrm{x}$ & $\mathrm{x}$ \\
\hline 20 & $\mathrm{P}<0.0001$ & $\mathrm{P}<0.0001$ & $\mathrm{P}<0.0001$ & $\mathrm{P}<0.0001$ \\
\hline 22 & $\mathrm{P}<0.0001$ & $\mathrm{P}<0.0001$ & $\mathrm{P}<0.0001$ & $\mathrm{P}<0.0001$ \\
\hline 24 & $\mathrm{P}<0.0001$ & $\mathrm{x}$ & $\mathrm{P}<0.0001$ & $\mathrm{P}<0.0001$ \\
\hline 26 & $\mathrm{x}$ & $\mathrm{P}<0.0001$ & $\mathrm{P}<0.0001$ & $\mathrm{P}<0.0001$ \\
\hline 28 & $\mathrm{P}<0.0001$ & $P<0.0001$ & $\mathrm{P}<0.0001$ & $\mathrm{P}<0.0001$ \\
\hline 30 & $\mathrm{P}<0.0001$ & $\mathrm{P}<0.0001$ & $\mathrm{P}<0.0001$ & $\mathrm{P}<0.0001$ \\
\hline 32 & $\mathrm{P}<0.0001$ & $\mathrm{P}<0.0001$ & $\mathrm{P}<0.0001$ & $\mathrm{P}<0.0001$ \\
\hline
\end{tabular}

In addition, preferred temperatures for $\mathrm{w}$ - flies and $w$ Mel-infected flies significantly differed from one another and from both $w$ MelCS and $w$ MelPop-infected 
flies (Tukey's post hoc pairwise comparison $\mathrm{P}$ always <0.0001; Table 3.5). Finally, temperature preferences from $w \mathrm{MelCS}$ and $w$ MelPop-infected flies were not significantly different ( $\mathrm{P}>0.9999$; Table 3.4. Figure 3.3).

Age (Appendix B Figure B.2) or sex of flies (Appendix B Figure B.3), time of day, and orientation of the apparatus had no apparent influence on the flies' behavior or choice of temperature preference.

Table 3.5: Results from Tukey's post hoc multiple comparison test comparing the temperature preference values of each Wolbachia infection treatment (w-(uninfected) D. melanogaster and wMel, wMelCS, and wMelPop-infected D. melanogaster). The temperature where most of the flies landed varied based on their infection: the temperature preference of $\mathrm{w}$ - flies significantly differed from that of $w \mathrm{Mel}$ infected flies and both were significantly different from those of $w$ MelCS and $w$ MelPop

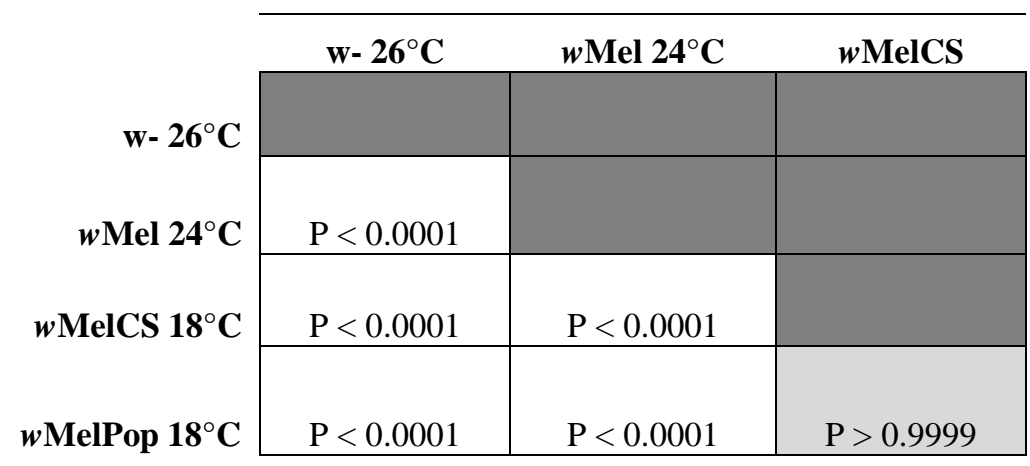


$\underline{\mathbf{W}}-$

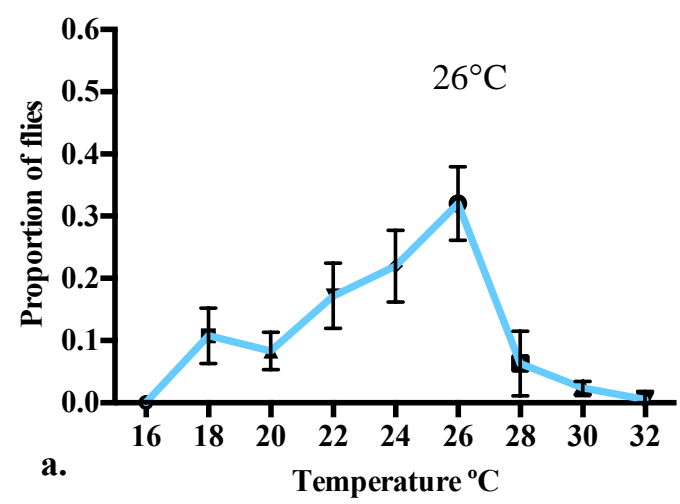

$\underline{w M e l C S}$

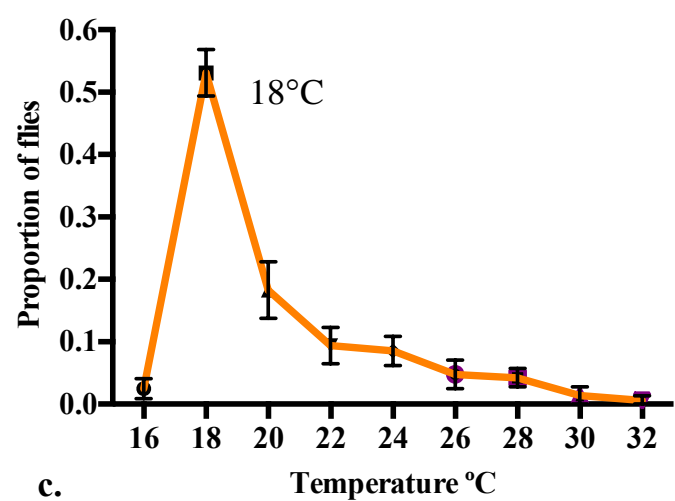

wMel

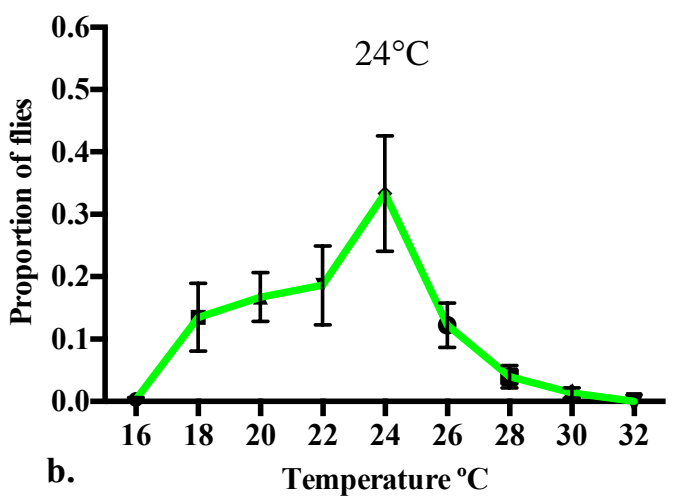

$\underline{w \text { MelPop. }}$

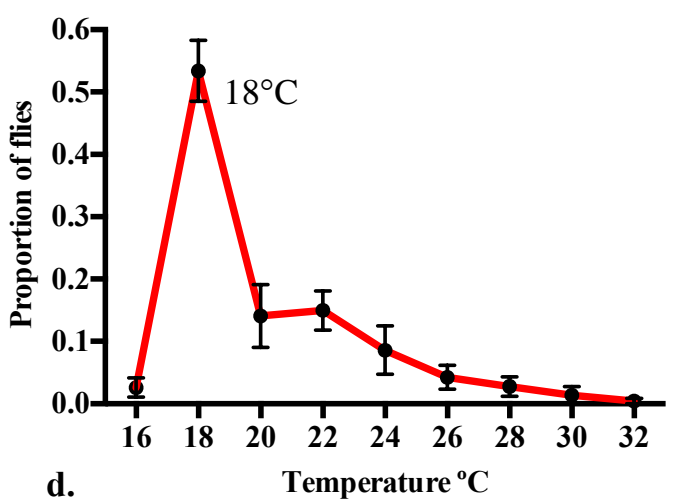

Figure 3.3: Results from temperature preference assays with standard error bars; Y-Axis in each graph is the proportion of flies and the X-Axis represents range of the temperature where flies congregated. Twoway ANOVA results revealed a significant relationship between Wolbachia-infection and the temperature preference of D. melanogaster (Wolbachia- infection X temperature interaction $\mathrm{F}_{21,128}=49.54, \mathrm{P}<0.0001$. Tukey's multiple comparison post-hoc tests showed that: a) w- flies had a significantly higher proportion at $\left.26^{\circ} \mathrm{C}(\mathrm{P}<0.0001) ; \mathrm{b}\right) w$ Mel-variant infected flies had a significantly higher proportion at $24^{\circ} \mathrm{C}(\mathrm{P}<$ $0.0001)$; c) $w$ MelCS-variant infected flies had a significantly higher proportion at $18^{\circ} \mathrm{C}(\mathrm{P}<0.0001)$; and d) $w$ MelPop-variant infected flies had a significantly higher proportion at $18^{\circ} \mathrm{C}(\mathrm{P}<0.0001)$. 


\section{DISCUSSION}

This study elucidates, for the first time, a significant relationship between temperature preference of D. melanogaster and the presence of Wolbachia infection. Using behavior choice thermal gradient assays, I showed that Wolbachia infected $D$. melanogaster prefer $2^{\circ} \mathrm{C}$ to $8^{\circ} \mathrm{C}$ cooler temperatures, depending on with which $w$ Melstrain variant they are infected, compared to uninfected conspecifics. Uninfected $D$. melanogaster flies preferred $26^{\circ} \mathrm{C}$, w Mel-variant infected flies preferred $24^{\circ} \mathrm{C}$, and both $w \mathrm{MelCS}$ and $w$ MelPop-variant infected flies preferred $18^{\circ} \mathrm{C}$. I postulate that, in my study, D. melanogaster responded to Wolbachia by inducing a self-medicating behavior or behavioral chill (Fedorka et al. 2016), which may be a mechanism they use to attenuate the fitness costs associated with Wolbachia infection.

Temperature preference can vary significantly between populations of the same species (Matute et al. 2009; Rajpurohit \& Schmidt 2016) and can have profound effects on immune function, fitness, and fecundity (Huey \& Berrigan 2001; Martin \& Huey 2008; Hoffmann 2010). The first stages of speciation result from geographical and/or ecological isolation (Keller \& Seehausen 2012). If ecologically diverging populations do not come into contact, reproductive isolation follows, causing individuals to lose the ability to produce viable offspring (Keller \& Seehausen 2012). Interestingly, Matute et al. (2009) discovered that differences in thermal tolerance and temperature preference produced reproductive isolation between two tropical Drosophila sister species with sympatric populations, $D$. santomea and $D$. yakuba. This is a unique example in Drosophila demonstrating different temperature preferences corresponding to ecological and reproductive isolation (Matute et al. 2009). Nuclear genes and organelles have 
largely dominated the speciation paradigm as the sole mechanisms paramount to driving speciation (reviewed by Brucker \& Bordenstein 2012). Yet, recent studies have discovered microbes as additional genetic elements that catalyze speciation and they have been incorporated into the speciation paradigm (reviewed by Brucker \& Bordenstein 2012; Bordenstein \& Theis 2015). Wolbachia-associated temperature preference variation within a species could lead to conspecifics occupying different microclimates and habitats. Conspecifics experience genetic adaptation to different sets of specific environmental conditions, which can eventually result in reproductive isolation. For endangered and threatened insects, such reproductive isolation of conspecifics can further reduce the number of individuals in a population. Species recovery programs that employ population supplementation should be careful to not release Wolbachia-infected individuals into an uninfected population until the effect of the endosymbiont on their host physiology has been determined.

Small fluctuations in temperature can cause considerable modifications to hostsymbiont interactions (Blanford \& Thomas 1999). Pathogenicity of $w$ MelPop is attributed to its active proliferation in host tissues at temperatures $\geq 19^{\circ} \mathrm{C}$. The increase of $w$ MelPop density confers strong anti-viral protection but leads to a two-fold reduction in host lifespan. However, at temperatures $<19^{\circ} \mathrm{C}$, anti-viral protection is weakened and pathogenicity of $w$ MelPop is eliminated (Reynolds et al. 2003). Wolbachia's ability to provide anti-viral protection to their hosts has emerged as the most promising approach to combatting insect-vector borne pathogens that pose serious health risks to humans, such as Dengue Fever and Zika (Hedges et al. 2008; Teixeira et al. 2008; Iturbe-Ormaetxe et al. 2011). However, this anti-viral protection is a temperature sensitive trait that is absent 
under certain thermal conditions. My findings suggest that thermal preference of Wolbachia's hosts could have implications for the field application of arbovirus vectorrelease control programs. Most applied biology research regarding Wolbachia use fixed temperatures, ignoring the innate thermoregulatory behavior of insects, which might impact the efficacy and success of the applications. Thus, prior to field applications using Wolbachia as a biocontrol measure, it is important to understand specific host-insect temperature preferences in the presence and absence of Wolbachia.

Finally, recent analyses of $w \mathrm{Mel}$-variants and mitochondria from D. melanogaster have provided evidence that in the past few thousand years, $w$ MelCS variants have been largely replaced in the field by $w$ Mel variants (Riegler et al. 2005; Richardson et al. 2012; Chrostek et al. 2013; reviewed by Miller 2013). Although the reason for the sweep remains elusive, it has been proposed that $w \mathrm{Mel}$ has adapted better to the genetic background of D. melanogaster and less cost is incurred to the host compared to cost associate with wMelCS, which ensures Wolbachia's persistence in the population (Chrostek et al. 2013; reviewed by Miller 2013). I postulate that results from the current study provide evidence that the $w$ Mel-variant was selected for after invading $w$ MelCSinfected D. melanogaster populations because flies infected with $w$ Mel have temperature preferences within a natural ecological range (Petavy et al. 2001).

In conclusion, this study is the first to correlate the presence of Wolbachia to the environmental temperature preference of their insect host. I present an example of an ecological conflict between host and symbiont that has profound effects on host physiology. Further understanding of the ecological intersection between Wolbachia and their hosts is needed. 


\section{GENERAL CONCLUSIONS}

The goal of my research was to investigate the impact of spillovers into populations and communities and the implications to the conservation and management of endangered and threatened insects. I accomplished this goal by examining the biological and ecological impacts of Wolbachia infections in three different host systems: a federally threatened butterfly species, Speyeria zerene hippolyta; a commonly used laboratory biological model organism, Drosophila melanogaster; and Eurema hecabe and its parasitoids. I analyzed reproductive data from uninfected and Wolbachia-infected S. z. hippolyta to determine whether Wolbachia had an impact on host fertility. I expanded on this analysis by developing a single-population demographic model to examine population dynamics from different supplementation scenarios. Next, to investigate horizontal of Wolbachia, I collected and surveyed E. hecabe larvae from four locations in Queensland, Australia for parasitoids. I screened both parasitoids and larvae for Wolbachia, and characterized their Wolbachia strains. Finally, I designed a threedimensional thermal gradient choice assay and conducted a laboratory experiment to show temperature preferences of D. melanogaster with four different Wolbachiainfection statuses.

Uninfected $S$. z. hippolyta butterflies suffered a reduction to their fertility when Wolbachia-infected butterflies were present in a population. The reduction to the number of offspring produced by uninfected butterflies, consequently decreased the population's net fecundity. Wolbachia's impact on S. z. hippolyta fecundity was reflected in results from model simulations that showed even a single exposure event to a small number of Wolbachia-infected butterflies can have a long-term negative effect on overall population 
size. In some supplementation scenarios, populations can recover after Wolbachia introduction; however, the population is unlikely to return to pre-infection size and not without the incurred population-level cost by the loss of genetic diversity. While a previous study presented hypothetical research regarding Wolbachia and translocation of endangered butterfly species, this study is the first to use empirical reproductive data from a federally listed species with populations supplemented from a captive rearing and release program. Furthermore, these results suggest that Wolbachia is an emerging threat to insect biodiversity and, if infected individuals evade detection, Wolbachia could hinder species recovery efforts. The phenotypes Wolbachia express in a host differ depending on a host's genetic background, with some strains causing reduced fitness and some strains producing no reproductive phenotype. Therefore, prior to implementing population supplementation or translocation programs and beyond screening a species for reproductive manipulating endosymbionts, I recommend that experiments be conducted to determine the phenotype induced in a specific host by Wolbachia. If screening for Wolbachia or conducting experiments prior to supplementation is not possible, I recommend that managers release offspring into the same population from which their parents were taken.

I provide the first empirical ecological evidence demonstrating inter-ordinal Wolbachia transmission. I identified an identical Wolbachia strain in a Lepidopteran butterfly species, E. hecabe, and their Dipteran parasitoid species, Exorista cantans. Twenty of 24 parasitoids and all 24 host larvae were infected with an identical Wolbachia strain type. A recent review on Wolbachia in Lepidoptera identified identical Wolbachia strains in species belonging to different arthropod orders (Ahmed et al. 2016); however, 
the strains were identified in separate studies and from species on different continents. Therefore, this study is the first to identify identical strains in Lepidoptera and Diptera species in a single study. I was not able to accomplish my initial goal of characterizing parasitoids and their Wolbachia strains from all six Australia Eurema species. To do so would require more extensive sampling and would need to be conducted over multiple seasons. Additionally, I suggest that a laboratory experiment be performed to test for direct interspecies and inter-generational transfer of Wolbachia between E. hecabe and E. cantans. My results contribute significantly to advancing the understanding of horizontal transmission by Wolbachia and reaffirm that conservation managers be careful to not move or release Wolbachia infected individuals among or between populations until the effect of the bacteria on the host species is known.

Finally, my research elucidates, for the first time, that a significant relationship exists between temperature preference of D. melanogaster and the presence of Wolbachia infection. I showed that Wolbachia infected D. melanogaster prefer $2^{\circ} \mathrm{C}$ to $8^{\circ} \mathrm{C}$ cooler temperatures, depending on with which $w$ Mel-strain variant they are infected, compared to uninfected conspecifics. I postulate that Wolbachia-infected D. melanogaster prefer cooler temperatures as a behavioral mechanism to attenuate the fitness costs associated with over-replication of Wolbachia at warmer temperatures (Chrostek et al. 2013). I recommend that this research be expanded to test temperature preferences of Wolbachia hosts additionally infected with viruses. My discovery of Wolbachia-influenced temperature preferences has implications for research associated with Wolbachia use as biocontrol agents against insect vector-borne human diseases. I further recommend these results be integrated into climate change predictions for insects and used to inform 
species conservation decisions, particularly when programs include population augmentation. Within species temperature preference disparities could lead to reproductive and ecological isolation of conspecifics, which reduces mating opportunities and fecundity of an insect population.

The threat diseases pose to insect biodiversity is widely accepted (Daszak 2000; Dobson \& Foufopoulos 2001; Harvell et al. 2002; Altizer \& de Roode 2010; Graystock et al. 2013). However, there has yet to be a foundational framework developed for natural resource managers and conservation biologists to use for identifying and preventing anthropogenic disease spread through population augmentation programs. Managing for endosymbiont infections presents new challenges that will require integrating new technology into current protocols. 


\section{REFERENCES}

Ahmed, M. Z., Araujo-Jnr, E. V, Welch, J. J., \& Kawahara, A. Y. (2015a). Wolbachia in butterflies and moths: geographic structure in infection frequency. Frontiers in Zoology, 12(1), 16. http://doi.org/10.1186/s12983-015-0107-z

Ahmed, M. Z., Breinholt, J. W., \& Kawahara, A. Y. (2016). Evidence for common horizontal transmission of Wolbachia among butterflies and moths. BMC Evolutionary Biology, 16(1), 118. http://doi.org/10.1186/s12862-016-0660-x

Ahmed, M. Z., Li, S.-J., Xue, X., Yin, X.-J., Ren, S.-X., Jiggins, F. M., ... Qiu, B.-L. (2015b). The Intracellular Bacterium Wolbachia Uses Parasitoid Wasps as Phoretic Vectors for Efficient Horizontal Transmission. PLOS Pathogens, 11(2), e1004672. http://doi.org/10.1371/journal.ppat.1004672

Altizer, S. M., \& de Roode, J. (2010). When butterflies get bugs: The ABCs of Lepidopteran disease. American Butterflies, Summer, 16-27. Retrieved from http://www.biology.emory.edu/research/deRoode/publications.html\%5Cnpapers3://p ublication/uuid/391EA2A6-44D0-43F2-AB76-CC0C417379EE

Angilletta, M. J., Steury, T. D., \& Sears, M. W. (2004). Temperature, Growth Rate, and Body Size in Ectotherms : Fitting Pieces of a. Integrative and Comparative Biology, 44, 498-509. http://doi.org/10.1093/icb/44.6.498

Archibald, J. (2014). One plus one equals one: symbiosis and the evolution of complex life. Oxford University Press, USA.

Baldo, L., Dunning Hotopp, J. C., Jolley, K. A, Bordenstein, S. R., Biber, S. A, Choudhury, R. R., ... Werren, J. H. (2006). Multilocus sequence typing system for the endosymbiont Wolbachia pipientis. Applied and Environmental Microbiology, 
72(11), 7098-110. http://doi.org/10.1128/AEM.00731-06

Bale, J. S., Masters, G. J., Hodkinson, I. D., Awmack, C., Bezemer, T. M., Brown, V. K., ... Whittaker, J. B. (2002). Herbivory in global climate change research: direct effects of rising temperature on insect herbivores. Global Change Biology, 8(1), 116. http://doi.org/10.1046/j.1365-2486.2002.00451.x

Bandi, C., Dunn, A. M., Hurst, G. D. D., \& Rigaud, T. (2001). Inherited microorganisms, sex-specific virulence and reproductive parasitism. Trends in Parasitology, 17(2), 88-94. http://doi.org/10.1016/S1471-4922(00)01812-2

Bates, D., Mächler, M., Bolker, B., \& Walker, S. (2014). Fitting Linear Mixed-Effects Models using lme4. Eprint arXiv:1406.5823, 51. http://doi.org/10.18637/jss.v067.i01

Blanford, S., \& Thomas, M. B. (1999). Host thermal biology: the key to understanding host-pathogen interactions and microbial pest control? Agricultural and Forest Entomology, 1(3), 195-202. http://doi.org/10.1046/j.1461-9563.1999.00027.x

Bordenstein, S. R. (2003). Symbiosis and the Origin of Species.

Bordenstein, S. R., \& Bordenstein, S. R. (2011). Temperature affects the tripartite interactions between bacteriophage WO, Wolbachia, and cytoplasmic incompatibility. PLoS ONE, 6(12). http://doi.org/10.1371/journal.pone.0029106

Bordenstein, S. R., \& Theis, K. R. (2015). Host biology in light of the microbiome: Ten principles of holobionts and hologenomes. PLoS Biology, 13(8), 1-23. http://doi.org/10.1371/journal.pbio.1002226

Bourtzis, K. (2008). Transgenesis and the Management of Vector-Borne Disease. Springer, New York. pp. 104-113. 
Breeuwer, J. A. J., Stouthamer, R., Barns, S. M., Pelletier, D. A., Weisburg, W. G., \& Werren, J. H. (1992). Phylogeny of the cytoplasmic incompatibility microorganism in the parasitoid wasp of the genus Nasonia (Hymenoptera: Pteromalidae) based on 16S ribosomal DNA sequences. Insect. Mol. Biol., 1(December 1991), 25-36.

Brower, L. P. (1995). On the dangers of interpopulational transfers of monarch butterflies. BioScience, 45(8), 540-544.

Brownlie, J. C., Cass, B. N., Riegler, M., Witsenburg, J. J., Iturbe-Ormaetxe, I., McGraw, E. A., \& O’Neill, S. L. (2009). Evidence for metabolic provisioning by a common invertebrate endosymbiont, Wolbachia pipientis, during periods of nutritional stress. PLoS Pathogens, 5(4). http://doi.org/10.1371/journal.ppat.1000368

Brucker, R. M., \& Bordenstein, S. R. (2012). Speciation by symbiosis. Trends in Ecology \& Evolution, 27(8), 443-51. Retrieved from http://www.ncbi.nlm.nih.gov/pubmed/22541872

Buellesbach, J., Greim, C., Raychoudhury, R., \& Schmitt, T. (2014). Asymmetric assortative mating behaviour reflects incomplete pre-zygotic isolation in the Nasonia species complex. Ethology, 120(8), 834-843.

http://doi.org/10.1111/eth.12250

Caspari, E. \& Watson, G. (1959). On the evolutionary importance of cytoplasmic sterility in mosquitoes. Evolution. 13, 568-570.

Christian, N., Whitaker, B. K., \& Clay, K. (2015). Microbiomes: Unifying animal and plant systems through the lens of community ecology theory. Frontiers in Microbiology, 6(SEP), 1-15. http://doi.org/10.3389/fmicb.2015.00869

Chrostek, E., Marialva, M. S. P., Esteves, S. S., Weinert, L. a., Martinez, J., Jiggins, F. 
M., \& Teixeira, L. (2013). Wolbachia Variants Induce Differential Protection to Viruses in Drosophila melanogaster: A Phenotypic and Phylogenomic Analysis. PLoS Genetics, 9(12), e1003896. http://doi.org/10.1371/journal.pgen.1003896

Comandatore, F., Cordaux, R., Bandi, C., Blaxter, M., Darby, A., Makepeace, B. L., ... Sassera, D. (2015). Supergroup C Wolbachia, mutualist symbionts of filarial nematodes, have a distinct genome structure. Open Biology, 5(12), 150099-. http://doi.org/10.1098/rsob.150099

Correa, C. C., \& Ballard, J. W. O. (2012). Wolbachia gonadal density in female and male Drosophila vary with laboratory adaptation and respond differently to physiological and environmental challenges. Journal of Invertebrate Pathology, 111(3), 197-204. http://doi.org/10.1016/j.jip.2012.08.003

Cosmides, L. D., \& Tooby, J. (1981). Cytoplasmic inheritance. Journal of Theoretical Biology, 89, 83-129. http://doi.org/10.1038/178214b0

Coyne, J. A., \& Orr, H. A. (2004). Speciation. Sinauer Associates, Sunderland, Massachusetts.

Crandall, K. A., Bininda-Emonds, O. R. R., Mace, G. M., \& Wayne, R. K. (2000). Considering evolutionary processes in conservation biology. Trends in Ecology and Evolution, 15(7), 290-295. http://doi.org/10.1016/S0169-5347(00)01876-0

Crone, E., Pickering, D., \& Schultz, C. (2007a). Can captive rearing promote recovery of endangered butterflies? An assessment in the face of uncertainty. Biological Conservation, 139(1-2), 103-112. http://doi.org/10.1016/j.biocon.2007.06.007

Daszak, P., Cunningham, A. A., \& Hyatt, A. D. (2001). Anthropogenic environmental change and the emergence of infectious diseases in wildlife. Acta Tropica, 78(2), 
103-116. http://doi.org/10.1016/S0001-706X(00)00179-0

Daszak, P., Cunningham, A. a, \& Hyatt, A. D. (2000). Emerging infectious diseases of wildlife - threats to biodiversity and human health. Science, 287(January), 443-449. http://doi.org/10.1126/science.287.5452.443

De Bary, A. (1879). Die Erscheinung der Symbiose. Verlag von Karl J. Trubner, Strasbourg, France.

DeSalle, R., \& Amato, G. (2004). The expansion of conservation genetics. Nature Reviews. Genetics, 5(9), 702-12. http://doi.org/10.1038/nrg1425

DeVries, P. J. (1984). Butterflies and Tachinidae: does the parasite always kill its host? Journal of Natural History, 18(2), 323-326. http://doi.org/10.1080/00222938400770251

Dobson, A\& Foufopoulos, J. (2001). Emerging infectious pathogens of wildlife. Philosophical Transactions of the Royal Society B: Biological Sciences, 356(1411), 1001-12. http://doi.org/10.1098/rstb.2001.0900

Dobson, S. L., Fox, C. W., \& Jiggins, F. M. (2002). The effect of Wolbachia-induced cytoplasmic incompatibility on host population size in natural and manipulated systems. Proceedings. Biological Sciences / The Royal Society, 269(1490), 437-45. http://doi.org/10.1098/rspb.2001.1876

Dobson, S. L., Rattanadechakul, W., \& Marsland, E. J. (2004). Fitness advantage and cytoplasmic incompatibility in Wolbachia single- and superinfected Aedes albopictus. Heredity, 93(2), 135-142. http://doi.org/10.1038/sj.hdy.6800458

Dunbar, H. E., Wilson, A. C. C., Ferguson, N. R., \& Moran, N. A. (2007). Aphid thermal tolerance is governed by a point mutation in bacterial symbionts. PLoS Biology, 
5(5), 1006-1015. http://doi.org/10.1371/journal.pbio.0050096

Duplouy, A., Couchoux, C., Hanski, I., \& Nouhuys, S. Van. (2015). Wolbachia Infection in a Natural Parasitoid Wasp Population. PLoS ONE, 10(8), 1-16. http://doi.org/10.5061/dryad.34sv3.Funding

Duplouy, A., Hurst, G. D. D., O’Neill, S. L., \& Charlat, S. (2010). Rapid spread of malekilling Wolbachia in the butterfly Hypolimnas bolina. Journal of Evolutionary Biology, 23(1), 231-5. http://doi.org/10.1111/j.1420-9101.2009.01891.x

Duron, O., Wilkes, T. E., \& Hurst, G. D. D. (2010). Interspecific transmission of a malekilling bacterium on an ecological timescale. Ecology Letters, 13, 1139-1148. http://doi.org/10.1111/j.1461-0248.2010.01502.x

Fedorka, K. M., Kutch, I. C., Collins, L., \& Musto, E. (2016). Cold temperature preference in bacterially infected Drosophila melanogaster improves survival but is remarkably suboptimal. Journal of Insect Physiology, 93-94, 36-41. http://doi.org/10.1016/j.jinsphys.2016.08.005

Fine, P. E. M. (1978). On the dynamics of symbiote-dependent cytoplasmic incompatibility in culicine mosquitoes. Journal of Invertebrate Pathology, 31(1), 10-18. http://doi.org/10.1016/0022-2011(78)90102-7

Flor, M., Hammerstein, P., \& Telschow, A. (2007). Wolbachia-induced unidirectional cytoplasmic incompatibility and the stability of infection polymorphism in parapatric host populations. Journal of Evolutionary Biology, 20(2), 696-706. http://doi.org/10.1111/j.1420-9101.2006.01252.x

Folmer, O., BLACK, M., HOEH, W., Lutz, R., \& Vrijenhoek, R. (1994). DNA primers for amplification of mitochondrial cytochrome c oxidase subunit I from diverse 
metazoan invertebrates. Molecular Marine Biology and Biotechnology, 3(5), 294 299. http://doi.org/10.1371/journal.pone.0013102

Frydman, H. M., Li, J. M., Robson, D. N., \& Wieschaus, E. (2006). Somatic stem cell niche tropism in Wolbachia. Nature, 441(7092), 509-12. http://doi.org/10.1038/nature04756

Gebiola, M., White, J. A., Cass, B. N., Kozuch, A., Harris, L. R., Kelly, S. E., ... Hunter, M. S. (2016). Cryptic diversity, reproductive isolation and cytoplasmic incompatibility in a classic biological control success story. Biological Journal of the Linnean Society, 117(2), 217-230. http://doi.org/10.1111/bij.12648

Gerth, M. \& Bleidorn C. (2016). Comparative genomics provides a timeframe for Wolbachia evolution and exposes a recent biotin synthesis operon transfer. Nature Microbiology, 2: 16241.

Godfray, H. (1994). Parasitoids-behavioural and evolutionary behaviour. Monographs in Behavioural Ecology. Princeton University Press.

Goodacre, S. L., Martin, O. Y., Bonte, D., Hutchings, L., Woolley, C., Ibrahim, K., ... Hewitt, G. M. (2009). Microbial modification of host long-distance dispersal capacity. BMC Biology, 7(1), 32. http://doi.org/10.1186/1741-7007-7-32

Graystock, P., Yates, K., Darvill, B., Goulson, D., \& Hughes, W. O. H. (2013). Emerging dangers: deadly effects of an emergent parasite in a new pollinator host. Journal of Invertebrate Pathology, 114(2), 114-9. http://doi.org/10.1016/j.jip.2013.06.005

Haine, E. R., Pickup, N. J., \& Cook, J. M. (2005). Horizontal transmission of Wolbachia in a Drosophila community. Ecological Entomology, 30(4), 464-472. 
http://doi.org/10.1111/j.0307-6946.2005.00715.x

Hamm, C. a, Handley, C. a, Pike, A., Forister, M. L., \& Fordyce, J. a. (2014). Wolbachia infection and Lepidoptera of conservation concern. Journal of Insect Science, 14(6), 1-8. http://doi.org/10.1093/jis/14.1.6

Hancock, P. a, Sinkins, S. P., \& Godfray, H. C. J. (2011). Population dynamic models of the spread of Wolbachia. The American Naturalist, 177(3), 323-33. http://doi.org/10.1086/658121

Harvell, C. D., Mitchell, C. E., Ward, J. R., Altizer, S., Dobson, A. P., Ostfeld, R. S., \& Samuel, M. D. (2002). Climate warming and disease risks for terrestrial and marine biota. Science (New York, N.Y.), 296(5576), 2158-62. http://doi.org/10.1126/science.1063699

Hatcher, M. J. (2000). Persistence of selfish genetic elements: Population structure and conflict. Trends in Ecology and Evolution, 15(7), 271-277. http://doi.org/10.1016/S0169-5347(00)01875-9

Heath, B. D., Butcher, R. D., Whitfield, W. G., \& Hubbard, S. F. (1999). Horizontal transfer of Wolbachia between phylogenetically distant insect species by a naturally occurring mechanism. Current Biology : $C B, 9(6), 313-6$. Retrieved from http://www.ncbi.nlm.nih.gov/pubmed/10209097

Hedges, L. M., Brownlie, J. C., O’Neill, S. L., \& Johnson, K. N. (2008). Wolbachia and virus protection in insects. Science (New York, N.Y.), 322(5902), 702. http://doi.org/10.1126/science.1162418

Hiroki, M., Tagami, Y., Miura, K., \& Kato, Y. (2004). Multiple infection with Wolbachia inducing different reproductive manipulations in the butterfly Eurema hecabe. 
Proceedings. Biological Sciences / The Royal Society, 271(1549), 1751-5. http://doi.org/10.1098/rspb.2004.2769

Hoffmann, A. A. (2010). Physiological climatic limits in Drosophila: patterns and implications. Journal of Experimental Biology, 213(6), 870-80. http://doi.org/10.1242/jeb.037630

Hoffmann, A. A., Turellit, M., \& Harshman, L. G. (1990). Factors Affecting the Distribution of Cytoplasmic Incompatibility in. Genetics, 126, 933-948.

Hoffmann, A. a, \& Sgrò, C. M. (2011). Climate change and evolutionary adaptation. Nature, 470(7335), 479-85. http://doi.org/10.1038/nature09670

Hornett, E. A., Duplouy, A. M. R., Davies, N., Roderick, G. K., Wedell, N., Hurst, G. D. D., \& Charlat, S. (2008). You can’t keep a good parasite down: Evolution of a malekiller suppressor uncovers cytoplasmic incompatibility. Evolution, 62(5), 12581263. http://doi.org/10.1111/j.1558-5646.2008.00353.x

Huey, R. B., \& Berrigan, D. (2001). Temperature, demography, and ectotherm fitness. The American Naturalist, 158(2), 204-210. http://doi.org/10.1086/321314

Huey, R. B., Kearney, M. R., Krockenberger, A., Holtum, J. A. M., Jess, M., \& Williams, S. E. (2012). Predicting organismal vulnerability to climate warming: roles of behaviour, physiology and adaptation. Philosophical Transactions of the Royal Society of London. Series B, Biological Sciences, 367(1596), 1665-79. http://doi.org/10.1098/rstb.2012.0005

Huigens, M. E., de Almeida, R. P., Boons, P. A. H., Luck, R. F., \& Stouthamer, R. (2004). Natural interspecific and intraspecific horizontal transfer of parthenogenesisinducing Wolbachia in Trichogramma wasps. Proceedings. Biological Sciences / 
The Royal Society, 271(1538), 509-15. http://doi.org/10.1098/rspb.2003.2640

Huigens, M. E., Luck, R. F., Klaassen, R. H. G., Maas, M. F. P. M., Timmermans, M. J.

T. N., \& Stouthamer, R. (2000). Infectious parthenogenesis. Nature, 405(6783),

178-179. Retrieved from http://dx.doi.org/10.1038/35012066

Hunter, M. L. (2007). Climate change and moving species: furthering the debate on assisted colonization. Conservation Biology, 21(5), 1356-1358.

http://doi.org/10.1111/j.1523-1739.2007.00780.x

Hurst, G. D. D., \& Jiggins, F. M. (2000). Male-killing bacteria in insects: Mechanisms, incidence, and implications. Emerging Infectious Diseases, 6(4), 329-336. http://doi.org/10.3201/eid0604.000402

Hurst, G. D. D., \& Jiggins, F. M. (2005). Problems with mitochondrial DNA as a marker in population, phylogeographic and phylogenetic studies: the effects of inherited symbionts. Proceedings. Biological Sciences / The Royal Society, 272(1572), 15251534. http://doi.org/10.1098/rspb.2005.3056

Hurst, G. D. D. \& Werren, J. H. (2001). The role of selfish genetic elements in eukaryotic evolution. Nature Reviews. Genetics, 2(8), 597-606.

http://doi.org/10.1038/35084545

Hurst, L. D. (1991) The incidences and evolution of cytoplasmic male killers. Proceedings of the Royal Society of London. Series B, Biological Sciences, 244, 9199.

Ilinsky, Y. \& Kosterin, O. (2017). Molecular Diversity of Wolbachia in Lepidoptera: Prevalent Allelic Content and High Recombination of MLST Genes. Molecular Phylogenetics and Evolution, 109, pp.164-179. 
http://dx.doi.org/10.1016/j.ympev.2016.12.034.

Irwin, M. E., Schlinger, E. I., \& Thompson, F. C. (2003). Diptera, true flies. In the Natural History of Madagascar, ed. SM Goodman, JP Benstead, pp. 692-702. Chicago/London: Univ. Chicago Press.

Iturbe-Ormaetxe, I., Walker, T., \& O’ Neill, S. L. (2011). Wolbachia and the biological control of mosquito-borne disease. EMBO Reports, 12(6), 508-18. http://doi.org/10.1038/embor.2011.84

Jaenike, J., Dyer, K. A., Cornish, C., \& Minhas, M. S. (2006). Asymmetrical reinforcement and Wolbachia infection in Drosophila. PLoS Biology, 4(10), 18521862. http://doi.org/10.1371/journal.pbio.0040325

Jaenike, J., Polak, M., Fiskin, A., Helou, M., \& Minhas, M. (2007). Interspecific transmission of endosymbiotic Spiroplasma by mites. Biology Letters, 3(1), 23-25. http://doi.org/10.1098/rsbl.2006.0577

Jansen, V. A. A., Turelli, M., \& Godfray, H. C. J. (2008). Stochastic spread of Wolbachia. Proceedings. Biological Sciences / The Royal Society, 275(1652), 276976. http://doi.org/10.1098/rspb.2008.0914

Janzen, D. H., Hallwachs, W., Blandin, P., Burns, J. M., Cadiou, J. M., Chacon, I., ... Wilson, J. J. (2009). Integration of DNA barcoding into an ongoing inventory of complex tropical biodiversity. Molecular Ecology Resources, 9(SUPPL. 1), 1-26. http://doi.org/10.1111/j.1755-0998.2009.02628.x

Jeyaprakash, A., \& Hoy, M. A. (2000). Long PCR improves Wolbachia DNA amplification: wsp sequences found in $76 \%$ of sixty-three arthropod species. Insect Molecular Biology, 9(4), 393-405. http://doi.org/10.1046/j.1365-2583.2000.00203.x 
Jiggins, F. M. (2003). Male-killing Wolbachia and mitochondrial DNA: Selective sweeps, hybrid introgression and parasite population dynamics. Genetics, 164(1), 512.

Jones, O. R., Purvis, A., Baumgart, E., \& Quicke, D. L. J. (2009). Using taxonomic revision data to estimate the geographic and taxonomic distribution of undescribed species richness in the Braconidae (Hymenoptera: Ichneumonoidea). Insect Conservation and Diversity, 2(3), 204-212. http://doi.org/10.1111/j.17524598.2009.00057.x

Jones, R. L., Rienks, J. H., Wilson, L., Lokkers, C., \& Churchill, T. (1987). Temperature, development and survival in monophagous and polyphagous tropical Pierid butterflies. Australian journal of zoology, 35(3), 235-246. http://dx.doi.org/ 10.1071/ZO9870235.

Jones, R. E. (1992). Phenotypic variation in Australian Eurema species. Australian journal of zoology, 40(4), 371-383. http://dx.doi.org/10.1071/ZO9920371

Kearse, M., Moir, R., Wilson, A., Stones-Havas, S., Cheung, M., Sturrock, S., ... Drummond, A. (2012). Geneious Basic: An integrated and extendable desktop software platform for the organization and analysis of sequence data.

Bioinformatics, 28(12), 1647-1649. http://doi.org/10.1093/bioinformatics/bts199

Keller, I. and Seehausen, O. (2012). Thermal adaptation and ecological speciation. Molecular Ecology, 782-799. http://doi.org/10.1111/j.1365-294X.2011.05397.x

Kemp, D. J. (2002). Sexual selection constrained by life history in a butterfly. Proceedings. Biological Sciences / The Royal Society, 269(1498), 1341-5. http://doi.org/10.1098/rspb.2002.2000 
Kemp, D. J. (2008). Female mating biases for bright ultraviolet iridescence in the butterfly Eurema hecabe (Pieridae). Behavioral Ecology, 19(1), 1-8. http://doi.org/10.1093/beheco/arm094

Kern, P., Cook, J. M., Kageyama, D., \& Riegler, M. (2015). Double trouble : combined action of meiotic drive and Wolbachia feminization in Eurema butterflies. Biology Letters, 11(2015000095). Retrieved from http://dx.doi.org/10.1098/rsbl.2015.0095

Kern, P. (Unpublished). Wolbachia in Eurema butterflies: endosymbiont effects on host sex ratios and population genetics. Doctoral Dissertation, Western Sydney University.

Kondo, N., Ijichi, N., Shimada, M., \& Fukatsu, T. (2002). Prevailing triple infection with Wolbachia in Callosobruchus chinensis (Coleoptera: Bruchidae). Molecular Ecology, 11(2), 167-180. http://doi.org/10.1046/j.0962-1083.2001.01432.x

Kumar, S., Stecher, G., \& Tamura, K. (2016). MEGA7: Molecular Evolutionary Genetics Analysis version 7.0 for bigger datasets. Molecular Biology and Evolution, 33(7), msw054. http://doi.org/10.1093/molbev/msw054

Laven, H. (1967). Eradication of Culex pipiens fatigans through cytoplasmic incompatibility. Nature. 216, 383-384.

Le Clec'h, W., Chevalier, F. D., Genty, L., Bertaux, J., Bouchon, D., \& Sicard, M. (2013). Cannibalism and Predation as Paths for Horizontal Passage of Wolbachia between Terrestrial Isopods. PLoS ONE, 8(4). http://doi.org/10.1371/journal.pone.0060232

Levin, S. A. (1998). Ecosystems and the biosphere as complex adaptive systems. Ecosystems, 1(5), 431-436. http://doi.org/10.1007/s100219900037 
Li, S.-J., Ahmed, M. Z., Lv, N., Shi, P.-Q., Wang, X.-M., Huang, J.-L., \& Qiu, B.-L. (2016). Plant-mediated horizontal transmission of Wolbachia between whiteflies. The ISME Journal, 1-10. http://doi.org/10.1038/ismej.2016.164

Louis, C., Jourdan, M., \& Cabanac, M. (1986). Behavioral fever and therapy in a rickettsia-infected Orthoptera. The American Journal of Physiology, 250, R991R995.

Margulis, L. (2004). Serial endosymbiotic theory (SET) and composite individuality. Microbiology today, 31, 172-174.

Martin, T. L., \& Huey, R. B. (2008). Why "Suboptimal" Is Optimal: Jensen's Inequality and Ectotherm Thermal Preferences. Source: The American Naturalist, 171(3), 102118. http://doi.org/10.1086/527502

Martinez, J., Longdon, B., Bauer, S., Chan, Y. S., Miller, W. J., Bourtzis, K., ... Jiggins, F. M. (2014). Symbionts Commonly Provide Broad Spectrum Resistance to Viruses in Insects: A Comparative Analysis of Wolbachia Strains. PLoS Pathogens, 10(9). http://doi.org/10.1371/journal.ppat.1004369

Matute, D. R., Novak, C. J., \& Coyne, J. A. (2009). Temperature-Based Extrinsic Reproductive Isolation in Two Species of Drosophila. Evolution, 63(3), 595-612. http://doi.org/10.1111/J.1558-5646.2008.00588.X

Maure, F., Doyon, J., Thomas, F., \& Brodeur, J. (2014). Host behaviour manipulation as an evolutionary route towards attenuation of parasitoid virulence. Journal of Evolutionary Biology, 27(12), 2871-2875. http://doi.org/10.1111/jeb.12530 
McCorkel, D.V., Hammond, P., \& Penington, G. (1980). Ecological Investigation Report: Oregon Silverspot Butterfly (Speyeria zerene hippolyta). Forest Service, Pacific Northwest Region, Siuslaw National Forest.

McFall-Ngai, M., Hadfield, M. G., Bosch, T. C. G., Carey, H. V, Domazet-Lošo, T., Douglas, A. E., ... Wernegreen, J. J. (2013). Animals in a bacterial world, a new imperative for the life sciences. Proceedings of the National Academy of Sciences, 110(9), 3229-3236. http://doi.org/10.1073/pnas.1218525110

McHugh, A., Bierzychudek, P., Greever, C., Marzulla, T., Van Buskirk, R., \& Binford, G. (2013). A molecular phylogenetic analysis of Speyeria and its implications for the management of the threatened Speyeria zerene hippolyta. Journal of Insect Conservation, 17(6), 1237-1253. http://doi.org/10.1007/s10841-013-9605-5

Miller, W. J. (2013). Bugs in Transition: The Dynamic World of Wolbachia in Insects. PLoS Genetics, 9(12), e1004069. http://doi.org/10.1371/journal.pgen.1004069

Miller, W. J., Ehrman, L., \& Schneider, D. (2010). Infectious speciation revisited: Impact of symbiont-depletion on female fitness and mating behavior of Drosophila paulistorum. PLoS Pathogens, 6(12). http://doi.org/10.1371/journal.ppat.1001214

Miller, W. J., \& Riegler, M. (2006). Evolutionary Dynamics of wAu-Like Wolbachia Variants in Neotropical, 72(1), 826-835. http://doi.org/10.1128/AEM.72.1.826

Min, K. T., \& Benzer, S. (1997). Wolbachia, normally a symbiont of Drosophila, can be virulent, causing degeneration and early death. Proceedings of the National Academy of Sciences of the United States of America, 94(20), 10792-6. Retrieved from http://www.pubmedcentral.nih.gov/articlerender.fcgi $?$ artid=23488\&tool=pmcentrez 
\&rendertype $=$ abstract

Moran, N. A. (2006). Symbiosis. Current Biology, 16(20), 866-871.

Moran, N. A., McCutcheon, J. P., \& Nakabachi, A. (2008a). Genomics and evolution of heritable bacterial symbionts. Ann Rev Genet, 42(1), 165-190.

http://doi.org/10.1146/annurev.genet.41.110306.130119

Moritz, C. (1994). Defining “evolutionarily significant units” for conservation. Trends in Ecology and Evolution, 9(10), 373-375. http://doi.org/10.1016/01695347(94)90057-4

Morrow, J. L., Frommer, M., Shearman, D. C. A., \& Riegler, M. (2014). Tropical tephritid fruit fly community with high incidence of shared Wolbachia strains as platform for horizontal transmission of endosymbionts. Environmental Microbiology, 16(12), 3622-3637. http://doi.org/10.1111/1462-2920.12382

Mouton, L., Henri, H., Bouletreau, M., \& Vavre, F. (2006). Effect of temperature on Wolbachia density and impact on cytoplasmic incompatibility. Parasitology, 132(2006), 49-56. http://doi.org/10.1017/S0031182005008723

Mouton, L., Henri, H., Charif, D., Boulétreau, M., \& Vavre, F. (2007). Interaction between host genotype and environmental conditions affects bacterial density in Wolbachia symbiosis. Biology Letters, 3(2), 210-213. http://doi.org/10.1098/rsbl.2006.0590

Murdock, C. C., Blanford, S., Hughes, G. L., Rasgon, J. L., \& Thomas, M. B. (2014). Temperature alters Plasmodium blocking by Wolbachia. Sci Rep, 4, 3932. http://doi.org/10.1038/srep03932

Narita, S., Nomura, M., \& Kageyama, D. (2007). Naturally occurring single and double 
infection with Wolbachia strains in the butterfly Eurema hecabe: transmission efficiencies and population density dynamics of each Wolbachia strain. FEMS Microbiology Ecology, 61(2), 235-45. http://doi.org/10.1111/j.15746941.2007.00333.x

Narita, S., Nomura, M., Kato, Y., \& Fukatsu, T. (2006). Genetic structure of sibling butterfly species affected by Wolbachia infection sweep: evolutionary and biogeographical implications. Molecular Ecology, 15(4), 1095-108. http://doi.org/10.1111/j.1365-294X.2006.02857.x

Narita, S., Nomura, M., Kato, Y., Yata, O., \& Kageyama, D. (2007). Molecular phylogeography of two sibling species of Eurema butterflies. Genetica, 131(3), 241-53. http://doi.org/10.1007/s10709-006-9134-1

Narita, S., Shimajiri, Y., \& Nomura, M. (2009). Strong cytoplasmic incompatibility and high vertical transmission rate can explain the high frequencies of Wolbachia infection in Japanese populations of Colias erate poliographus (Lepidoptera: Pieridae). Bulletin of Entomological Research, 99(4), 385-91. http://doi.org/10.1017/S0007485308006469

Nice, C. C., Gompert, Z., Forister, M. L., \& Fordyce, J. A. (2009). An unseen foe in arthropod conservation efforts: The case of Wolbachia infections in the Karner blue butterfly. Biological Conservation, 142(12), 3137-3146. http://doi.org/10.1016/j.biocon.2009.08.020

O’Neill, S. L., Giordano, R., Colbert, A. M., Karr, T. L., \& Robertson, H. M. (1992). 16S rRNA phylogenetic analysis of the bacterial endosymbionts associated with cytoplasmic incompatibility in insects. Proceedings of the National Academy of 
Sciences of the United States of America, 89(7), 2699-702. Retrieved from http://www.pubmedcentral.nih.gov/articlerender.fcgi?artid=48729\&tool=pmcentrez \&rendertype $=$ abstract

Oliver, K. M., Degnan, P. H., Burke, G. R., \& Moran, N. A. (2010). Facultative symbionts in aphids and the horizontal transfer of ecologically important traits. Annual Review of Entomology, 55(August), 247-266. http://doi.org/10.1146/annurev-ento-112408-085305

Oliver, K. M., Moran, N. a, \& Hunter, M. S. (2006). Costs and benefits of a superinfection of facultative symbionts in aphids. Proceedings. Biological Sciences / The Royal Society, 273(1591), 1273-80. http://doi.org/10.1098/rspb.2005.3436

Orgel, L. E., \& Crick, F. H. (1980). Selfish DNA: the ultimate parasite. Nature, 284(5757), 604-607. http://doi.org/10.1038/284604a0

Osborne, S. E., Leong, Y. S., O’Neill, S. L., \& Johnson, K. N. (2009). Variation in antiviral protection mediated by different Wolbachia strains in Drosophila simulans. PLoS Pathogens, 5(11), e1000656. http://doi.org/10.1371/journal.ppat.1000656

Perlman, S. J., Kelly, S. E., \& Hunter, M. S. (2008). Population biology of cytoplasmic incompatibility: maintenance and spread of Cardinium symbionts in a parasitic wasp. Genetics, 178(2), 1003-11. http://doi.org/10.1534/genetics.107.083071

Petavy, G., David, J. R., Gibert, P., \& Moreteau, B. (2001). Viability and rate of development at different temperatures in Drosophila: A comparison of constant and alternating thermal regimes. Journal of Thermal Biology, 26(1), 29-39. http://doi.org/10.1016/S0306-4565(00)00022-X

Rajpurohit, S., \& Schmidt, P. S. (2016). Measuring thermal behavior in smaller insects: a 
case study in Drosophila melanogaster demonstrates effects of sex, geographic origin, and rearing temperature on adult behavior. Fly, (July), 00-00. http://doi.org/10.1080/19336934.2016.1194145

Rasgon, J. L., \& Scott, T. W. (2003). Wolbachia and Cytoplasmic Incompatibility in the California Culex pipiens Mosquito Species Complex : Parameter Estimates and Infection Dynamics in Natural Populations. Genetics, 165, 2029-2038.

Raychoudhury, R., Baldo, L., Oliveira, D. C. S. G., \& Werren, J. H. (2009). Modes of acquisition of Wolbachia: Horizontal transfer, hybrid introgression, and codivergence in the Nasonia species complex. Evolution, 63(1), 165-183. http://doi.org/10.1111/j.1558-5646.2008.00533.x

Reynolds, K. T., Thomson, L. J., \& Hoffmann, A. a. (2003). The effects of host age, host nuclear background, and temperature on phenotypic effects of the virulent Wolbachia strain popcorn in Drosophila melanogaster. Genetics, 164(3), 1027-34. Retrieved from http://www.pubmedcentral.nih.gov/articlerender.fcgi?artid=1462616\&tool=pmcentr ez\&rendertype $=a b s t r a c t$

Richardson, M. F., Weinert, L. A., Welch, J. J., Linheiro, R. S., Magwire, M. M., Jiggins, F. M., \& Bergman, C. M. (2012). Population Genomics of the Wolbachia Endosymbiont in Drosophila melanogaster. PLoS Genetics, 8(12). http://doi.org/10.1371/journal.pgen.1003129

Riegler, M., Iturbe-Ormaetxe, I., Woolfit, M., Miller, W. J., \& O’Neill, S. L. (2012). Tandem repeat markers as novel diagnostic tools for high resolution fingerprinting of Wolbachia. BMC Microbiol, 12 Suppl 1(Suppl 1), S12. 
http://doi.org/10.1186/1471-2180-12-S1-S12

Riegler, M., Sidhu, M., Miller, W. J., \& O’Neill, S. L. (2005). Evidence for a global Wolbachia replacement in Drosophila melanogaster. Current Biology : CB, 15(15), 1428-33. http://doi.org/10.1016/j.cub.2005.06.069

Rigaud, T., \& Juchault, P. (1995). Success and failure of horizontal transfers of feminizing Wolbachia endosymbionts in woodlice. Journal of Evolutionary Biology, 8(2), 249-255. http://doi.org/10.1046/j.1420-9101.1995.8020249.x

Rousset, F., \& Solignac, M. (1995). Evolution of single and double Wolbachia symbioses during speciation in the Drosophila simulans complex. Proceedings of the National Academy of Sciences of the United States of America, 92(14), 6389-6393. http://doi.org/10.1073/pnas.92.14.6389

Russell, J. A., \& Moran, N. A. (2006). Costs and benefits of symbiont infection in aphids: variation among symbionts and across temperatures. Proc. Biol. Sci., 273(1586), 603-610. http://doi.org/10.1098/rspb.2005.3348

Salunke, B. K., Salunkhe, R. C., Dhotre, D. P., Walujkar, S. a., Khandagale, A. B., Chaudhari, R., ... Shouche, Y. S. (2012). Determination of Wolbachia diversity in butterflies from Western Ghats, India, by a multigene approach. Applied and Environmental Microbiology, 78(12), 4458-4467. http://doi.org/10.1128/AEM.07298-11

Sazama, E. J., Bosch, M. J., Shouldis, C. S., Ouellette, S. P., \& Wesner, J. S. (2017). Incidence of Wolbachia in aquatic insects. Ecology and Evolution, (September 2016), 1-5. http://doi.org/10.1002/ece3.2742

Schilthuizen, M., \& Stouthamer, R. (1997). Horizontal transmission of parthenogenesis- 
inducing microbes in Trichogramma wasps. Proceedings of the Royal Society of London B-Biological Sciences, 264(1993), 361-366.

http://doi.org/10.1098/rspb.1997.0052

Schuler, H., Bertheau, C., Egan, S. P., Feder, J. L., Riegler, M., Schlick-Steiner, B. C., ... Stauffer, C. (2013). Evidence for a recent horizontal transmission and spatial spread of Wolbachia from endemic Rhagoletis cerasi (Diptera: Tephritidae) to invasive Rhagoletis cingulata in Europe. Molecular Ecology, 1-11.

http://doi.org/10.1111/mec.12362

Schuler, H., Kern, P., Arthofer, W., Vogt, H., Fischer, M., Stauffer, C., \& Riegler, M. (2016). Wolbachia in Parasitoids Attacking Native European and Introduced Eastern Cherry Fruit Flies in Europe. Environmental Entomology, 1-8. http://doi.org/10.1093/ee/nvw137

Schultz, C.B., \& Chang, G.C. (1998). Conservation Biology for the Coming Decade. Chapman Hall, New York, pp. 228-254.

Schultz, C.B., Russell, C., \& Wynn, L. (2008). Restoration, reintroduction, and captive propagation for at-risk butterflies: a review of British and American conservation efforts. Isr. J. Ecol. Evol., 54, 41-61.

Shaw M. R., \& Huddleston, T. (1991). Classification and biology of Braconid wasps (HYMENOPTERA: BRACONIDAE). Handbooks for the Identification of British Insects, 7(11), 1-126. Retrieved from http://onlinelibrary.wiley.com/doi/10.1111/j.1946-150X.1964.tb00309.x/abstract

Sintupachee, S., Milne, J. R., Poonchaisri, S., Baimai, V., \& Kittayapong, P. (2006). Closely related Wolbachia strains within the pumpkin arthropod community and the 
potential for horizontal transmission via the plant. Microbial Ecology, 51, 294-301. http://doi.org/10.1007/s00248-006-9036-x

Siozios, S., Sapountzis, P., Ioannidis, P., \& Bourtzis, K. (2008). Wolbachia symbiosis and insect immune response. Insect Science, 15, 89-100. http://doi.org/1111/j.17447917.2008.00189.x

Smith, M. A., Rodriguez, J. J., Whitfield, J. B., Deans, A. R., Janzen, D. H., Hallwachs, W., \& Hebert, P. D. N. (2008). Extreme diversity of tropical parasitoid wasps exposed by iterative integration of natural history, DNA barcoding, morphology, and collections. Proceedings of the National Academy of Sciences of the United States of America, 105(34), 12359-12364. http://doi.org/10.1073/pnas.0805319105

Smith, M. A., Wood, D. M., Janzen, D. H., Hallwachs, W., \& Hebert, P. D. N. (2007). DNA barcodes affirm that 16 species of apparently generalist tropical parasitoid flies (Diptera, Tachinidae) are not all generalists. Proceedings of the National Academy of Sciences of the United States of America, 104(12), 4967-4972. http://doi.org/10.1073/pnas.0700050104

Snyder, N. F. R., Derrickson, S. R., Beissinger, S. R., Wiley, J. W., Smith, T. B., Toone, W. D., ... Box, P. O. (1996). Limitations of Captive Breeding in Endangered Species Recovery. Conservation Biology, 10(2), 338-348.

Stahlhut, J. K., Desjardins, C. a, Clark, M. E., Baldo, L., Russell, J. a, Werren, J. H., \& Jaenike, J. (2010). The mushroom habitat as an ecological arena for global exchange of Wolbachia. Molecular Ecology, 19(9), 1940-52. http://doi.org/10.1111/j.1365294X.2010.04572.x

Stireman, J. O., Dyer, L. A., Janzen, D. H., Singer, M. S., Lill, J. T., Marquis, R. J., ,.. 
Diniz, I. R. (2005). Climatic unpredictability and parasitism of caterpillars: implications of global warming. Proceedings of the National Academy of Sciences of the United States of America, 102(48), 17384-7.

http://doi.org/10.1073/pnas.0508839102

Stireman, J. O., O'Hara, J. E., \& Wood, D. M. (2006). TACHINIDAE: Evolution, Behavior, and Ecology. Annual Review of Entomology, 51(1), 525-555. http://doi.org/10.1146/annurev.ento.51.110104.151133

Strunov, A. A., Ilinskii, Y. Y., Zakharov, I. K., \& Kiseleva, E. V. (2013a). Effect of high temperature on survival of Drosophila melanogaster infected with pathogenic strain of Wolbachia bacteria. Russian Journal of Genetics: Applied Research, 3(6), 435443. http://doi.org/10.1134/S2079059713060099

Strunov, A., Kiseleva, E., \& Gottlieb, Y. (2013b). Spatial and temporal distribution of pathogenic Wolbachia strain wMelPop in Drosophila melanogaster central nervous system under different temperature conditions. Journal of Invertebrate Pathology, 114(1), 22-30. http://doi.org/10.1016/j.jip.2013.05.001

Teixeira, L., Ferreira, Á., \& Ashburner, M. (2008). The bacterial symbiont Wolbachia induces resistance to RNA viral infections in Drosophila melanogaster. PLoS Biology, 6(12), 2753-2763. http://doi.org/10.1371/journal.pbio.1000002

Telschow, A., Flor, M., Kobayashi, Y., Hammerstein, P., \& Werren, J. H. (2007). Wolbachia-Induced Unidirectional Cytoplasmic Incompatibility and Speciation: Mainland-Island Model. PLoS ONE, 2(8), 10. http://doi.org/10.1371/journal.pone.0000701

Tolson, P. (2008). Conservation Matters: Contributions from the Conservation 
Committee Rearing Mitchell's satyr at the Toledo Zoo - a first step towards eventual re-introduction in secure habitats. Journal of The Lepidopterists' Society, $50(2), 2-3$.

Turelli, M. (1994). Evolution of Incompatibility-Inducing Microbes and Their Hosts. Evolution, 48(5), 1500-1513.

Turelli, M. (2010). Cytoplasmic incompatibility in populations with overlapping generations. Evolution. 64, 232-241.

Turelli, M., Hoffmannt, A. A., \& Mckechnie, S. W. (1992). Dynamics of Cytoplasmic Incompatibility and mtDNA Variation in Natural Drosophila simulans Populations. Genetics, 132, 713-723.

US Fish and Wildlife Service (2001). Oregon silverspot butterfly (Speyeria zerene hippolyta) revised recovery plan. US Fish and Wildlife Service, Portland, Oregon.

Van Borm, S., Wenseleers, T., Billen, J., \& Boomsma, J. J. (2001). Wolbachia in leafcutter ants: A widespread symbiont that may induce male killing or incompatible matings. Journal of Evolutionary Biology, 14(5), 805-814. http://doi.org/10.1046/j.1420-9101.2001.00321.x

Van Meer, M. M., \& Stouthamer, R. (1999). Cross-order transfer of Wolbachia from Muscidifurax uniraptor (Hymenoptera: Pteromalidae) to Drosophila simulans (Diptera: Drosophilidae). Heredity, 82 ( Pt 2)(March 1998), 163-169. http://doi.org/10.1038/sj.hdy.6884610 van Nouhuys, S., Kohonen, M., \& Duplouy, A. (2016). Wolbachia increases the susceptibility of a parasitoid wasp to hyperparasitism. The Journal of Experimental Biology, 219(19), 2984-2990. http://doi.org/10.1242/jeb.140699 
Vavre, F., Fleury, F., Lepetit, D., Fouillet, P., \& Boulétreau, M. (1999). Phylogenetic evidence for horizontal transmission of Wolbachia in host-parasitoid associations. Molecular Biology and Evolution, 16, 1711-1723.

Versace, E., Nolte, V., Pandey, R. V., Tobler, R., \& Schlötterer, C. (2014). Experimental evolution reveals habitat-specific fitness dynamics among Wolbachia clades in Drosophila melanogaster. Molecular Ecology, 23(4), 802-814. http://doi.org/10.1111/mec.12643

Weeks, A. R., Turelli, M., Harcombe, W. R., Reynolds, K. T., \& Hoffmann, A. A. (2007). From parasite to mutualist: rapid evolution of Wolbachia in natural populations of Drosophila. PLoS Biology, 5(5), e114. http://doi.org/10.1371/journal.pbio.0050114

Weinert, L. A., Araujo-jnr, E. V, Ahmed, M. Z., Welch, J. J., \& Welch, J. J. (2015). The incidence of bacterial endosymbionts in terrestrial arthropods. Proc. R. Soc. B, 282(20150249). http://dx.doi.org/10.1098/rspb.2015.0249

Wernegreen, J. J. (2012). Mutualism meltdown in insects: Bacteria constrain thermal adaptation. Current Opinion in Microbiology, 15(3), 255-262. http://doi.org/10.1016/j.mib.2012.02.001

Werren, J. H. (1997). Biology of Wolbachia. Annual Review of Entomology, 42(124), 587-609. http://doi.org/10.1146/annurev.ento.42.1.587

Werren, J. H. (2011). Selfish genetic elements, genetic conflict, and evolutionary innovation. Proceedings of the National Academy of Sciences USA, 108, 1086310870. http://doi.org/10.1073/pnas.1102343108

Werren, J. H., Baldo, L., \& Clark, M. E. (2008). Wolbachia: master manipulators of 
invertebrate biology. Nature Reviews. Microbiology, 6(10), 741-51.

http://doi.org/10.1038/nrmicro1969

Werren, J. H., Windsor, D., \& Guo, L. R. (1995). Distribution of Wolbachia among neotropical arthropods. Proceedings of the Royal Society of London B-Biological Sciences. http://doi.org/10.1098/rspb.1995.0196

Werren, J. H., \& Windsor, D. M. (2000). Wolbachia infection frequencies in insects: evidence of a global equilibrium? Proceedings. Biological Sciences / The Royal Society, 267(1450), 1277-85. http://doi.org/10.1098/rspb.2000.1139

Werren, J. H., Zhang, W., \& Guo, L. R. (1995). Evolution and phylogeny of Wolbachia: reproductive parasites of arthropods. Proceedings of the Royal Society of London BBiological Sciences. http://doi.org/10.1098/rspb.1995.0117

West, S. A., Cook, J. M., Werren, J. H., \& Godfray, H. C. (1998). Wolbachia in two insect host-parasitoid communities. Molecular Ecology, 7(11), 1457-65. http://www.ncbi.nlm.nih.gov/pubmed/9819901

Yen, J. H., \& Barr, A.R. (1973). The etiological agent of cytoplasmic incompatibility in Culex pipiens. Journal. Invertebrate Pathology, 22, 242-250.

Zabalou, S., Riegler, M., Theodorakopoulou, M., Stauffer, C., Savakis, C., \& Bourtzis, K. (2004). Wolbachia-induced cytoplasmic incompatibility as a means for insect pest population control. Proceedings of the National Academy of Sciences of the United States of America, 101(42), 15042-5. http://doi.org/10.1073/pnas.0403853101

Zhou, W., Rousset, F., \& O’Neil, S. (1998). Phylogeny and PCR-based classification of Wolbachia strains using wsp gene sequences. Proceedings. Biological Sciences / The Royal Society, 265(1395), 509-515. http://doi.org/10.1098/rspb.1998.0324 
Zielin, S. B., Littlejohn, J., de Rivera, C. E., Smith, W. P., \& Jacobson, S. L. (2016). Ecological investigations to select mitigation options to reduce vehicle-caused mortality of a threatened butterfly. Journal of Insect Conservation, 20(5), 845-854. http://doi.org/10.1007/s10841-016-9916-4

Zug, R., \& Hammerstein, P. (2012). Still a host of hosts for Wolbachia: analysis of recent data suggests that $40 \%$ of terrestrial arthropod species are infected. PloS One, 7(6), e38544. http://doi.org/10.1371/journal.pone.0038544

Zug, R., \& Hammerstein, P. (2014). Bad guys turned nice? A critical assessment of Wolbachia mutualisms in arthropod hosts. Biological Reviews of the Cambridge Philosophical Society, 49. http://doi.org/10.1111/brv.12098 


\section{APPENDIX A: Chapter 1 supplemental tables and figures}

Table A.1: Using values across 100 iterations, this table shows ANOVA results comparing the number of individuals at the time point representing the lowest population size for each of the single release models (1) no supplementation, (2) uninfected 300 butterflies, (3) uninfected 1000 butterflies, (4) Wolbachiainfected 50, (5) Wolbachia-infected 300, (6) Wolbachia-infected 1000.

\begin{tabular}{llllll}
\hline ANOVA table & SS & DF & MS & F(DFn,DFd $)$ & P values \\
\hline Treatment & $4.595 \mathrm{e}+006$ & 5 & 918912 & $\mathrm{~F}(5,593)=3349$ & $\mathrm{P}<0.0001$ \\
Residual & 162726 & 593 & 274.4 & & \\
Total & $4.757 \mathrm{e}+006$ & 598 & & & \\
\hline
\end{tabular}

ANOVA results: $\mathrm{F}(5,593)=3349 \mathrm{P}<0.0001, \mathrm{r}^{2}=0.9658$

Table A.2: Using values across 100 iterations, this table shows Tukey's multiple comparisons results comparing the number of individuals at the time point representing the lowest population size for each of the single release models to each other - (1) no supplementation, (2) uninfected 300 butterflies, (3) uninfected 1000 butterflies, (4) Wolbachia-infected 50, (5) Wolbachia-infected 300, (6) Wolbachia-infected 1000.

\begin{tabular}{llllll}
\hline $\begin{array}{l}\text { Tukey's } \\
\text { Post-hoc }\end{array}$ & $\begin{array}{l}\text { Single CRR } \\
\text { no-W 300 }\end{array}$ & $\begin{array}{l}\text { Single CRR } \\
\text { no-W 1000 }\end{array}$ & $\begin{array}{l}\text { Single CRR } \\
\boldsymbol{W} \text { 50 }\end{array}$ & $\begin{array}{l}\text { Single CRR } \\
\boldsymbol{W ~ 3 0 0}\end{array}$ & $\begin{array}{l}\text { Single CRR } \\
\boldsymbol{W} \text { 1000 }\end{array}$ \\
\hline No CRR & $\mathrm{MD}=131.3$ & $\mathrm{MD}=-39.45$ & $\mathrm{MD}=166.5$ & $\mathrm{MD}=25.70$ & $\mathrm{MD}=-45.61$ \\
& $\mathrm{P}<0.0001$ & $\mathrm{P}<0.0001$ & $\mathrm{P}<0.0001$ & $\mathrm{P}<0.0001$ & $\mathrm{P}<0.0001$ \\
& & $\mathrm{MD}=170.8$ & $\mathrm{MD}=35.24$ & $\mathrm{MD}=-0.4786$ & $\mathrm{MD}=176.9$ \\
$\begin{array}{l}\text { Single CRR } \\
\text { no-W 300 }\end{array}$ & & $\mathrm{P}<0.0001$ & $\mathrm{P}<0.0001$ & $\mathrm{P}<0.0001$ & $\mathrm{P}<0.0001$ \\
& & & $\mathrm{MD}=206.0$ & $\mathrm{MD}=170.3$ & $\mathrm{MD}=6.16$ \\
$\begin{array}{l}\text { Single CRR } \\
\text { no-W 1000 }\end{array}$ & & $\mathrm{P}<0.0001$ & $\mathrm{P}<0.0001$ & $\mathrm{P}=0.0826$ \\
& & & $\mathrm{MD}=35.72$ & $\mathrm{MD}=212.2$ \\
$\begin{array}{l}\text { Single CRR } \\
\text { W 50 }\end{array}$ & & & & $\mathrm{P}<0.0001$ & $\mathrm{P}<0.0001$ \\
& & & & & $\mathrm{MD}=176.4$ \\
Single CRR & & & & & $\mathrm{P}<0.0001$ \\
$W$ 300 & & & & & \\
\hline
\end{tabular}


Table A.3: Using values across 100 iterations, this table shows ANOVA results comparing the number of individuals at the 50-year time point for each of the single release models - (1) no supplementation, (2) uninfected 300 butterflies, (3) uninfected 1000 butterflies, (4) Wolbachia-infected 50, (5) Wolbachiainfected 300, (6) Wolbachia-infected 1000.

\begin{tabular}{llllll}
\hline ANOVA table & SS & DF & MS & F(DFn,DFd $)$ & P values \\
\hline Treatment & $3.162 \mathrm{e}+006$ & 5 & 632474 & $\mathrm{~F}(5,593)=1526$ & $\mathrm{P}<0.0001$ \\
Residual & 245717 & 593 & 414.4 & \\
Total & $3.408 \mathrm{e}+006$ & 598 & & \\
\hline
\end{tabular}

ANOVA results: $\mathrm{F}(5,593)=1526, \mathrm{P}<0.0001, \mathrm{r}^{2}=0.9279$

Table A.4: Using values across 100 iterations, this table shows Tukey's multiple comparisons results comparing the number of individuals at the 50-year time point for each of the single release models to each other - (1) no supplementation, (2) uninfected 300 butterflies, (3) uninfected 1000 butterflies, (4) Wolbachia-infected 50, (5) Wolbachia-infected 300, (6) Wolbachia-infected 1000.

\begin{tabular}{llllll}
\hline $\begin{array}{l}\text { Tukey's } \\
\text { Post-hoc }\end{array}$ & $\begin{array}{l}\text { Single CRR } \\
\text { no-W 300 }\end{array}$ & $\begin{array}{l}\text { Single CRR } \\
\text { no-W 1000 }\end{array}$ & $\begin{array}{l}\text { Single CRR } \\
\boldsymbol{W} \text { 50 }\end{array}$ & $\begin{array}{l}\text { Single CRR } \\
\boldsymbol{W} \text { 300 }\end{array}$ & $\begin{array}{l}\text { Single CRR } \\
\boldsymbol{W} \mathbf{1 0 0 0}\end{array}$ \\
\hline No CRR & $\mathrm{MD}=-21.77$ & $\mathrm{MD}=-34.10$ & $\mathrm{MD}=67.37$ & $\mathrm{MD}=153.4$ & $\mathrm{MD}=127.3$ \\
& $\mathrm{P}<0.0001$ & $\mathrm{P}<0.0001$ & $\mathrm{P}<0.0001$ & $\mathrm{P}<0.0001$ & $\mathrm{P}<0.0001$ \\
& & $\mathrm{MD}=12.33$ & $\mathrm{MD}=89.15$ & $\mathrm{MD}=175.2$ & $\mathrm{MD}=-149.1$ \\
Single CRR & & $\mathrm{P}=0.0003$ & $\mathrm{P}<0.0001$ & $\mathrm{P}<0.0001$ & $\mathrm{P}<0.0001$ \\
no-W 300 & & & $\mathrm{MD}=101.5$ & $\mathrm{MD}=187.5$ & $\mathrm{MD}=-161.4$ \\
Single CRR & & $\mathrm{P}<0.0001$ & $\mathrm{P}=0.0001$ & $\mathrm{P}<0.0001$ \\
no-W 1000 & & & $\mathrm{MD}=-86.04$ & $\mathrm{MD}=-59.97$ \\
Single CRR & & & & $\mathrm{P}<0.0001$ & $\mathrm{P}<0.0001$ \\
W 50 & & & & & $\mathrm{MD}=26.07$ \\
& & & & $\mathrm{P}<0.0001$ \\
\hline $\begin{array}{l}\text { Single CRR } \\
\text { W300 }\end{array}$ & & & & & \\
\hline
\end{tabular}


Table A.5: Using values across 100 iterations, this table shows ANOVA results comparing the number of individuals at the lowest population size time point for each of the multiple release models - (1) no supplementation, (2) uninfected 300, (3) Wolbachia-infected 300, (4) uninfected 300, Wolbachia-infected 50, (5) uninfected 50, Wolbachia-infected 300.

\begin{tabular}{llllll}
\hline ANOVA table & SS & DF & MS & F(DFn,DFd) & P values \\
\hline Treatment & $2.057 \mathrm{e}+006$ & 4 & 514202 & $\mathrm{~F}(4,524)=1891$ & $\mathrm{P}<0.0001$ \\
Residual & 142469 & 524 & 271.9 & & \\
Total & $2.199 \mathrm{e}+006$ & 528 & & & \\
& & & & & \\
\hline
\end{tabular}

ANOVA results: $\mathrm{F}(4,524)=1891, \mathrm{P}<0.0001, \mathrm{r}^{2}=0.94$

Table A.6: Using values across 100 iterations, this table shows Tukey's multiple comparisons results comparing the number of individuals at the lowest population size time point for each of the multiple release models - (1) no supplementation, (2) uninfected 300, (3) Wolbachia-infected 300, (4) uninfected 300, Wolbachia-infected 50, (5) uninfected 50, Wolbachia-infected 300.

\begin{tabular}{lllll}
\hline $\begin{array}{l}\text { Tukey's } \\
\text { Post-hoc }\end{array}$ & $\begin{array}{l}\text { Multiple } \\
\text { CRR no-W } \\
\text { 300 }\end{array}$ & $\begin{array}{l}\text { Mulltpile } \\
\text { CRR } \boldsymbol{W} 300\end{array}$ & $\begin{array}{l}\text { Combined } \\
\text { CRR 300 } \\
\text { no-W, 50 } \boldsymbol{W}\end{array}$ & $\begin{array}{l}\text { Combined CRR } \\
\mathbf{5 0} \text { no-W, 300 } \boldsymbol{W}\end{array}$ \\
\hline No CRR & $\mathrm{MD}=-$ & $\mathrm{MD}=18.29$ & $\mathrm{MD}=123.8$ & $\mathrm{MD}=105.9$ \\
& $\begin{array}{l}43.60 \\
\mathrm{P}<0.0001\end{array}$ & $\mathrm{P}<0.0001$ & $\mathrm{P}<0.0001$ & $\mathrm{P}<0.0001$ \\
$\begin{array}{l}\text { Multiple CRR } \\
\text { no-W 300 }\end{array}$ & & $\mathrm{MD}=61.88$ & $\mathrm{MD}=167.4$ & $\mathrm{MD}=149.5$ \\
& $\mathrm{P}<0.0001$ & $\mathrm{P}<0.0001$ & $\mathrm{P}<0.0001$ \\
$\begin{array}{l}\text { Multiple CRR } \\
\boldsymbol{W} \text { 300 }\end{array}$ & & $\mathrm{MD}=-105.5$ & $\mathrm{MD}=87.64$ \\
$\begin{array}{l}\text { Combined CRR 300 } \\
\text { no-W, 50 } W\end{array}$ & & & $\mathrm{P}<0.0001$ & $\mathrm{P}<0.0001$ \\
\hline
\end{tabular}


Table A.7: Using values across 100 iterations, this table shows ANOVA results comparing the number of individuals at the 50-year time point for each of the multiple release models - (1) no supplementation, (2) uninfected 300, (3) Wolbachia-infected 300, (4) uninfected 300, Wolbachia-infected 50, (5) uninfected 50, Wolbachia-infected 300.

\begin{tabular}{llllll}
\hline $\begin{array}{l}\text { ANOVA } \\
\text { table }\end{array}$ & SS & DF & MS & F(DFn,DFd) & P values \\
\hline Treatment & $\begin{array}{l}2.623 \mathrm{e}+ \\
006\end{array}$ & 4 & 655629 & $\mathrm{~F}(5,623)=1559$ & $\mathrm{P}<0.0001$ \\
Residual & 220414 & 524 & 420.6 .3 & & \\
& & & & & \\
Total & $2.843 \mathrm{e}+006$ & 528 & & & \\
\hline
\end{tabular}

ANOVA results: $\mathrm{F}(4,524)=1559, \mathrm{P}<0.0001, \mathrm{r}^{2}=0.92$

Table A.8: Using values across 100 iterations, this table shows Tukey's multiple comparisons results comparing the number of individuals at the 50-year time point for each of the multiple release models - (1) no supplementation, (2) uninfected 300, (3) Wolbachia-infected 300, (4) uninfected 300, Wolbachiainfected 50, (5) uninfected 50, Wolbachia-infected 300.

\begin{tabular}{|c|c|c|c|c|}
\hline $\begin{array}{l}\text { Tukey's } \\
\text { Post-hoc }\end{array}$ & $\begin{array}{l}\text { Multiple CRR } \\
\text { no-W } 300\end{array}$ & $\begin{array}{l}\text { Multiple CRR } \\
W 300\end{array}$ & $\begin{array}{l}\text { Combined CRR } \\
300 \text { no-W, } 50 \text { W }\end{array}$ & $\begin{array}{l}\text { Combined CRR } \\
50 \text { no-W, } 300 \mathrm{~W}\end{array}$ \\
\hline No CRR & $\begin{array}{l}\mathrm{MD}=-79.52 \\
\mathrm{P}<0.0001\end{array}$ & $\begin{array}{l}M D=22.64 \\
P<0.0001\end{array}$ & $\begin{array}{l}\mathrm{MD}=146.2 \\
\mathrm{P}<0.0001\end{array}$ & $\begin{array}{l}\mathrm{MD}=21.07 \\
\mathrm{P}<0.0001\end{array}$ \\
\hline $\begin{array}{l}\text { Multiple CRR } \\
\text { no-W } 300\end{array}$ & & $\begin{array}{l}\mathrm{MD}=102.2 \\
\mathrm{P}<0.0001\end{array}$ & $\begin{array}{l}\mathrm{MD}=225.8 \\
\mathrm{P}<0.0001\end{array}$ & $\begin{array}{l}\mathrm{MD}=100.6 \\
\mathrm{P}<0.0001\end{array}$ \\
\hline $\begin{array}{l}\text { Multiple CRR } \\
W 300\end{array}$ & & & $\begin{array}{l}\mathrm{MD}=-222.1 \\
\mathrm{P}<0.0001\end{array}$ & $\begin{array}{l}M D=-1.565 \\
P=0.9927\end{array}$ \\
\hline $\begin{array}{l}\text { Combined CRR } \\
300 \text { no-W, } 50 \mathrm{~W}\end{array}$ & & & & $\begin{array}{l}\mathrm{MD}=-125.2 \\
\mathrm{P}<0.0001\end{array}$ \\
\hline
\end{tabular}


$\boldsymbol{R}$ script A.1: R script for the Generalized linear mixed effects R script model, which was produced using "Ime4" and fit by maximum likelihood

$$
\begin{aligned}
& \text { glmer (cbind (Number.Eggs.Hatch, Number.Eggs.Unhatched }) \sim \text { Wolbachia.treatment + } \\
& (1 \mid \text { site/Year), data }=\text { data, family }=\text { binomial },+ \text { control }=\text { glmerControl } \\
& (\text { optimizer }=\text { "bobyqa", optCtrl = list }(\operatorname{maxfun}=100000)))
\end{aligned}
$$

Table A.9: Scaled residuals from general linear mixed-effects model.

\begin{tabular}{ccccc}
\hline Min & 1Q & Median & 3Q & Max \\
\hline-28.350 & -6.788 & 0 & 4.596 & 17.937 \\
\hline
\end{tabular}

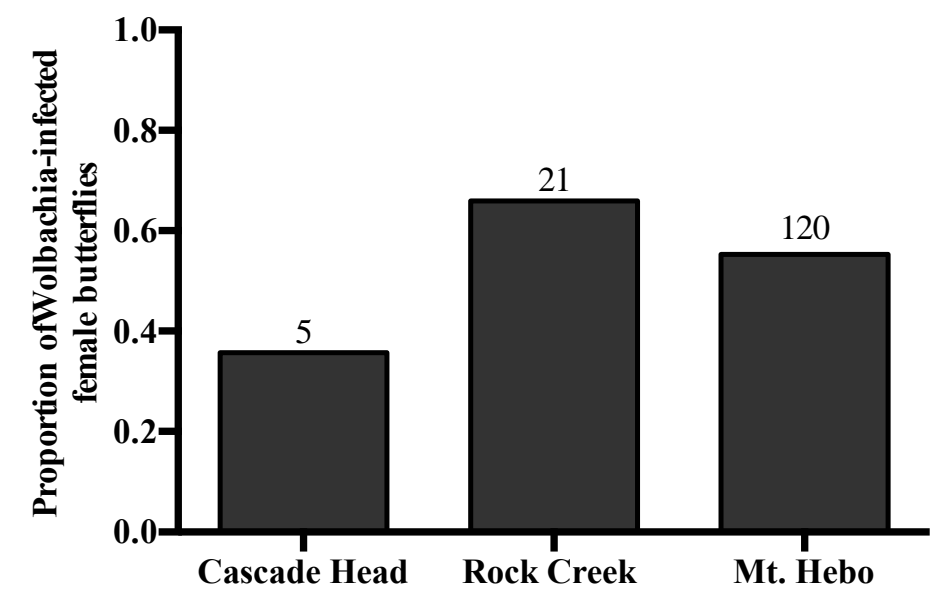

Figure A.1: Proportion of female Wolbachia-infected butterflies from each site sampled. Numbers above bars represents sample size for each site. 


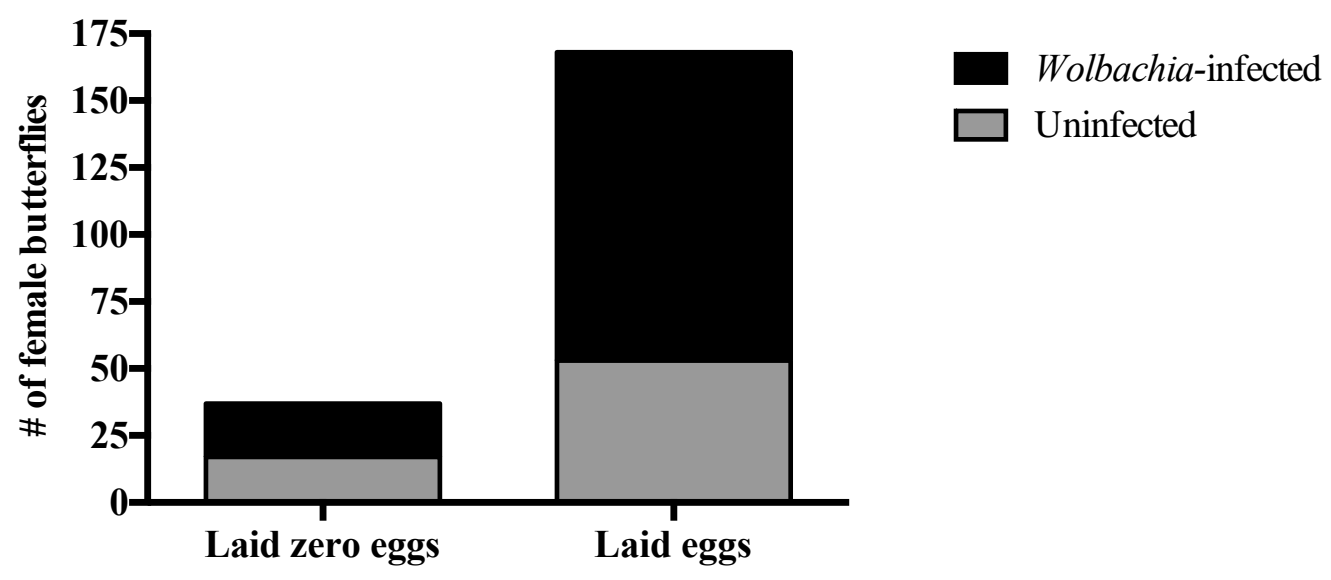

Figure A.2: Comparison of the number of Wolbachia-infected and uninfected female butterflies that did not lay eggs. 


\section{APPENDIX B: Chapter 3 supplemental tables and figures}

\begin{tabular}{|c|c|c|c|c|}
\hline $\mathrm{W}-26^{\circ} \mathrm{C}$ & Mean Difference & $95 \%$ CI of difference & & $\mathrm{P}$ values \\
\hline $\mathrm{W}-: 26$ vs. W-:18 & -0.2224 & -0.3165 to -0.1283 & $* * * *$ & $<0.0001$ \\
\hline $\mathrm{W}-: 26$ vs. $\mathrm{W}-: 20$ & -0.2517 & -0.3458 to -0.1576 & $* * * *$ & $<0.0001$ \\
\hline $\mathrm{W}-: 26$ vs $\mathrm{W}-: 22$ & -0.163 & -0.2571 to -0.06889 & $* * * *$ & $<0.0001$ \\
\hline $\mathrm{W}-: 26$ vs. $\mathrm{W}-: 24$ & -0.1333 & -0.2274 to -0.03917 & $* * * *$ & $<0.0001$ \\
\hline $\mathrm{W}-: 26$ vs. $\mathrm{w}-: 28$ & 0.2584 & 0.1643 to 0.3524 & $* * * *$ & $<0.0001$ \\
\hline $\mathrm{w}-: 26$ vs. $\mathrm{w}-: 30$ & 0.3056 & 0.2115 to 0.3997 & $* * * *$ & $<0.0001$ \\
\hline $\mathrm{w}-: 26$ vs. $\mathrm{w}-: 32$ & 0.3254 & 0.2313 to 0.4195 & $* * * *$ & $<0.0001$ \\
\hline
\end{tabular}

a.

\begin{tabular}{|l|c|l|l|l|}
\hline wMel $24^{\circ} \mathrm{C}$ & Mean Difference & \multicolumn{2}{|l|}{$95 \%$ CI of difference } & P values \\
\hline wMel:24 vs. wMel:18 & -0.1983 & -0.2924 to -0.1042 & $* * * *$ & $<0.0001$ \\
\hline wMel:24 vs. wMel:20 & -0.1658 & -0.2599 to -0.07169 & $* * * *$ & $<0.0001$ \\
\hline wMel:24 vs. wMel:22 & -0.1472 & -0.2413 to -0.05307 & $* * * *$ & $<0.0001$ \\
\hline wMel:24 vs. wMel:26 & 0.2111 & 0.1170 to 0.3052 & $* * * *$ & $<0.0001$ \\
\hline wMel:24 vs. wMel:28 & 0.2935 & 0.1994 to 0.3876 & $* * * *$ & $<0.0001$ \\
\hline wMel:24 vs. wMel:30 & 0.3197 & 0.2256 to 0.4137 & $* * * *$ & $<0.0001$ \\
\hline wMel:24 vs. wMel:32 & 0.3332 & 0.2391 to 0.4273 & $* * * *$ & $<0.0001$ \\
\hline
\end{tabular}

b.

\begin{tabular}{|l|r|l|l|l|}
\hline wMelCS $18^{\circ} \mathrm{C}$ & Mean Difference & \multicolumn{1}{|l|}{ 95\% CI of difference } & P values \\
\hline wMelCS: 18 vs. wMelCS:20 & 0.3479 & 0.2539 to 0.4420 & $* * * *$ & $<0.0001$ \\
\hline wMelCS: 18 vs. wMelCS:22 & 0.4371 & 0.3430 to 0.5312 & $* * * *$ & $<0.0001$ \\
\hline wMelCS: 18 vs. wMelCS:24 & 0.4456 & 0.3515 to 0.5397 & $* * * *$ & $<0.0001$ \\
\hline wMelCS: 18 vs. wMelCS:26 & 0.483 & 0.3889 to 0.5770 & $* * * *$ & $<0.0001$ \\
\hline wMelCS: 18 vs. wMelCS:28 & 0.4884 & 0.3943 to 0.5825 & $* * * *$ & $<0.0001$ \\
\hline wMelCS: 18 vs. wMelCS:30 & 0.517 & 0.4229 to 0.6111 & $* * * *$ & $<0.0001$ \\
\hline wMelCS: 18 vs. wMelCS:32 & 0.5252 & 0.4311 to 0.6193 & $* * * *$ & $<0.0001$ \\
\hline
\end{tabular}

c.

\begin{tabular}{|l|c|l|l|l|}
\hline wMelPop $18^{\circ} \mathrm{C}$ & Mean Difference & \multicolumn{2}{|l|}{$95 \%$ CI of difference } & P values \\
\hline wMelPop:18 vs. wMelPop:20 & 0.4268 & 0.3327 to 0.5208 & $* * * *$ & $<0.0001$ \\
\hline wMelPop:18 vs. wMelPop:22 & 0.4092 & 0.3151 to 0.5033 & $* * * *$ & $<0.0001$ \\
\hline wMelPop:18 vs. wMelPop:24 & 0.4681 & 0.3740 to 0.5622 & $* * * *$ & $<0.0001$ \\
\hline wMelPop:18 vs. wMelPop:26 & 0.5099 & 0.4158 to 0.6040 & $* * * *$ & $<0.0001$ \\
\hline wMelPop:18 vs. wMelPop:28 & 0.5208 & 0.4267 to 0.6149 & $* * * *$ & $<0.0001$ \\
\hline wMelPop:18 vs. wMelPop:30 & 0.5354 & 0.4413 to 0.6295 & $* * * *$ & $<0.0001$ \\
\hline wMelPop:18 vs. wMelPop:32 & 0.5488 & 0.4547 to 0.6429 & $* * * *$ & $<0.0001$ \\
\hline
\end{tabular}

Table B.1: Results from Tukey's multiple comparison post-hoc tests showing significant temperature preferences for each D. melanogaster - Wolbachia combination and w- flies. 


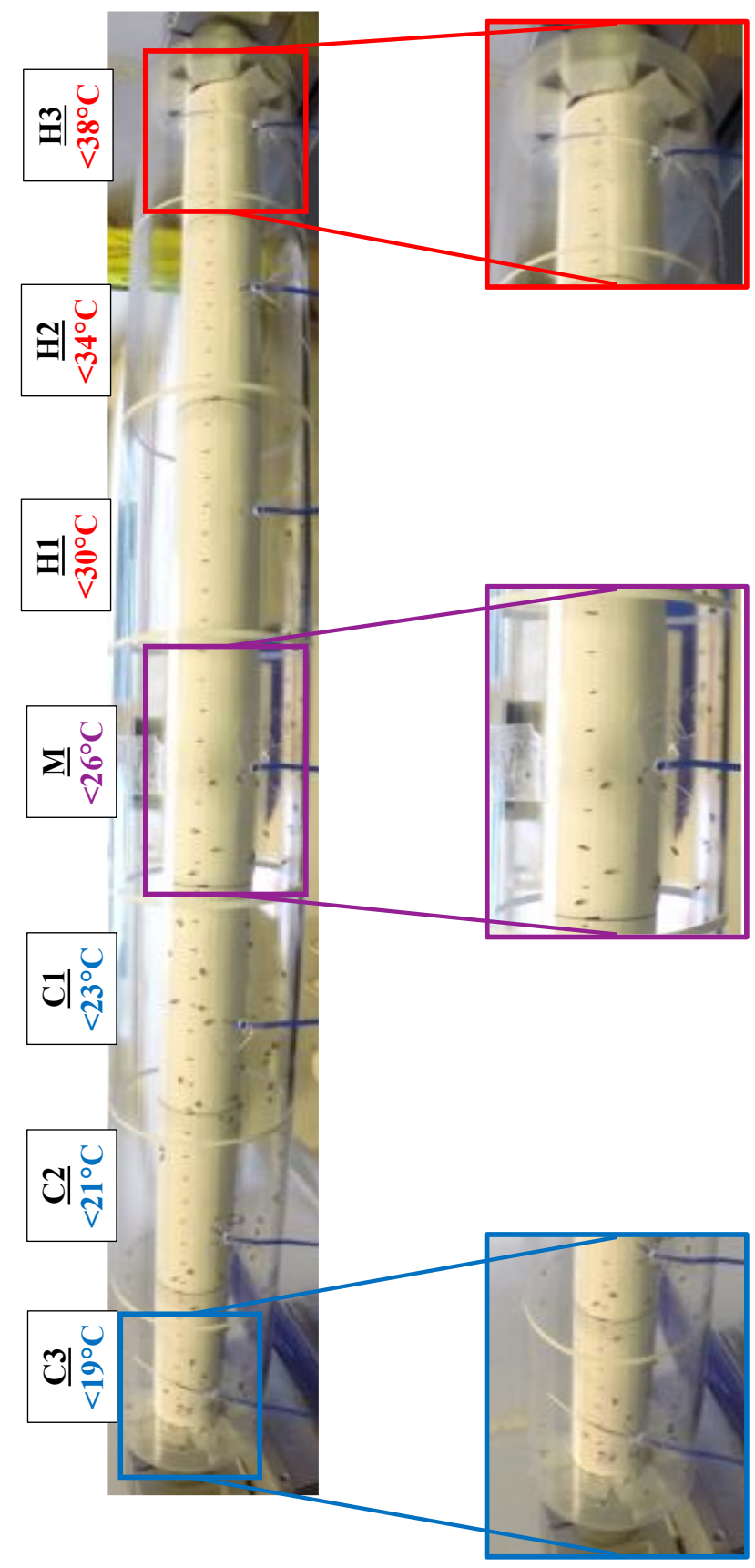

Figure B.1 Thermal gradient apparatus gradient depicting different temperature zones and fly dispersion ( $w$ MelPop). 


\section{$\underline{\mathbf{W}-}$}

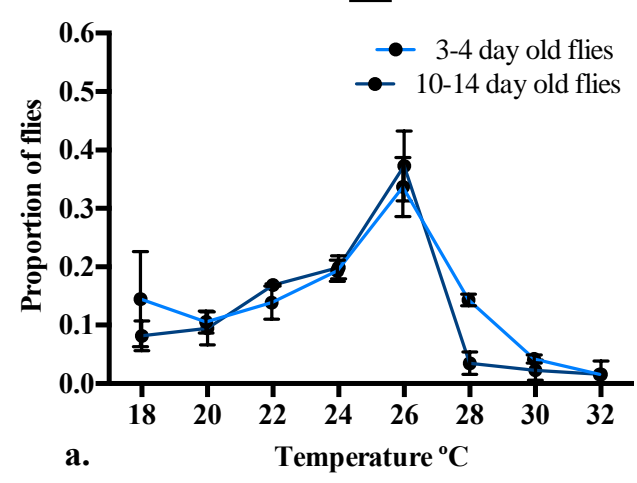

wMelCS

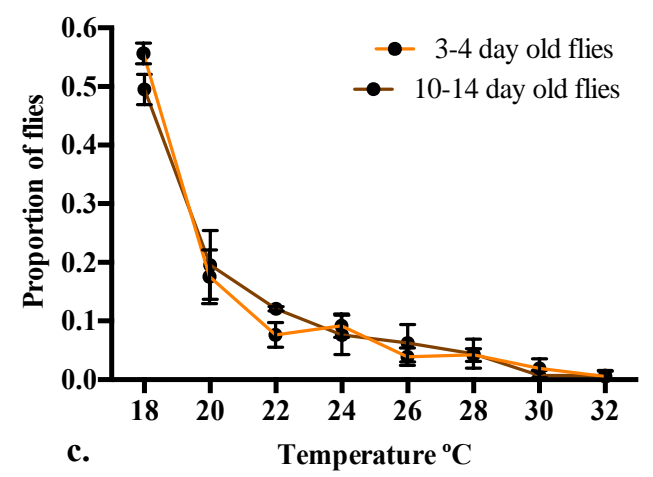

wMel

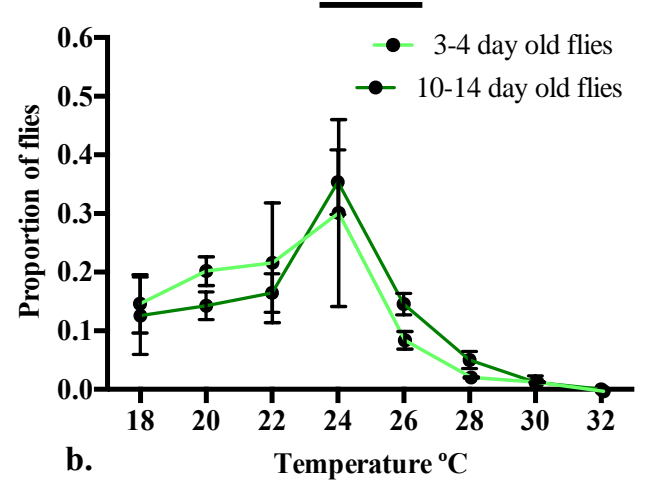

wMelPop.

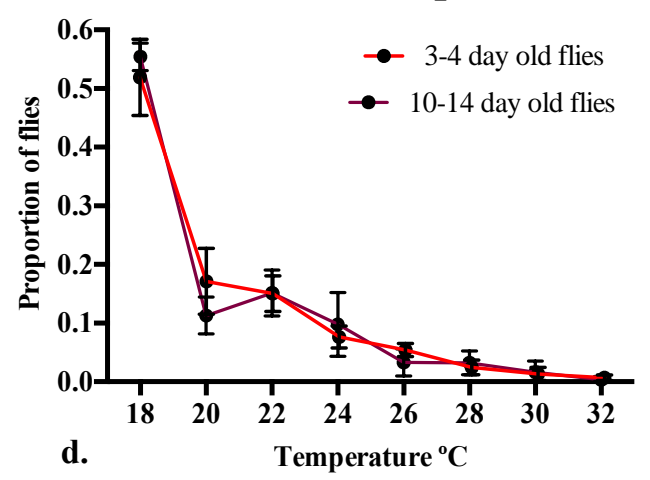

Figure B.2: Results from assays comparing temperature preferences of 3-4 day old flies to 10-14 day old flies. Graphs showing that age did not influence temperature preference of the flies. 
w-

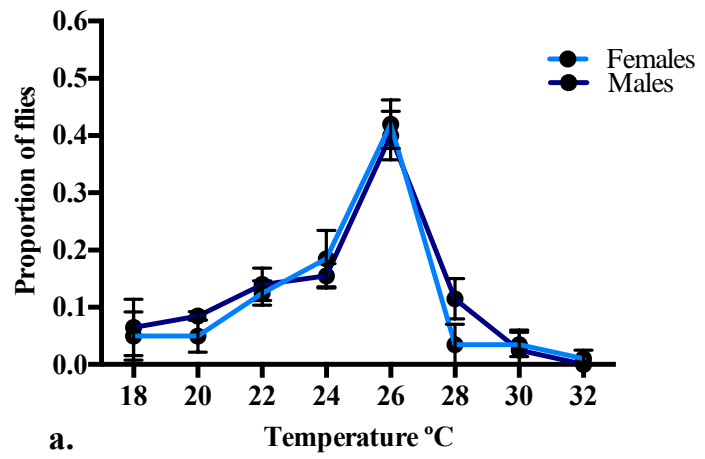

$\underline{w \text { MelCS }}$

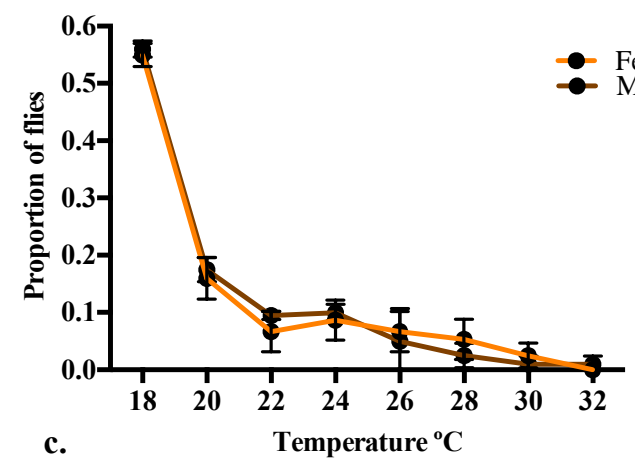

$\underline{w \text { Mel }}$

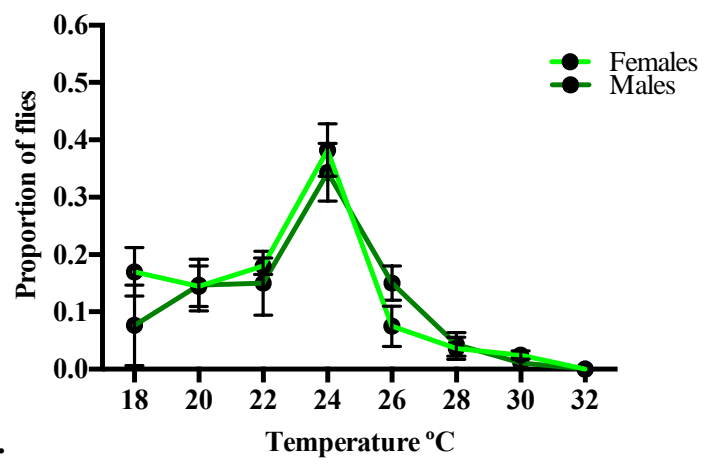

wMelPop

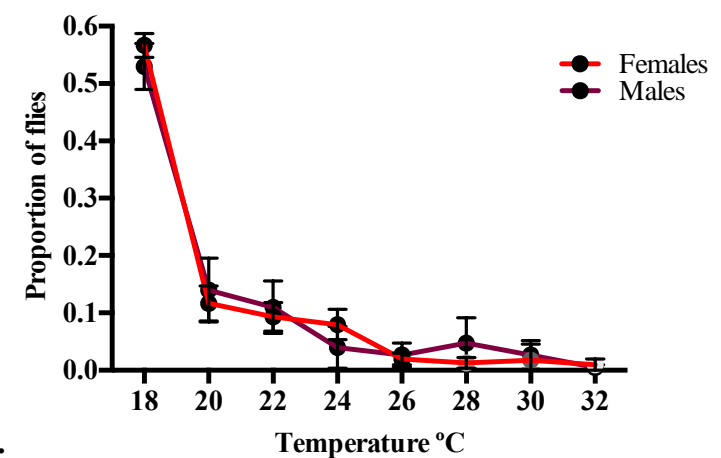

Figure B.3: Results from assays comparing temperature preferences of females and males. Graphs showing that sex did not influence temperature preference of the flies. 


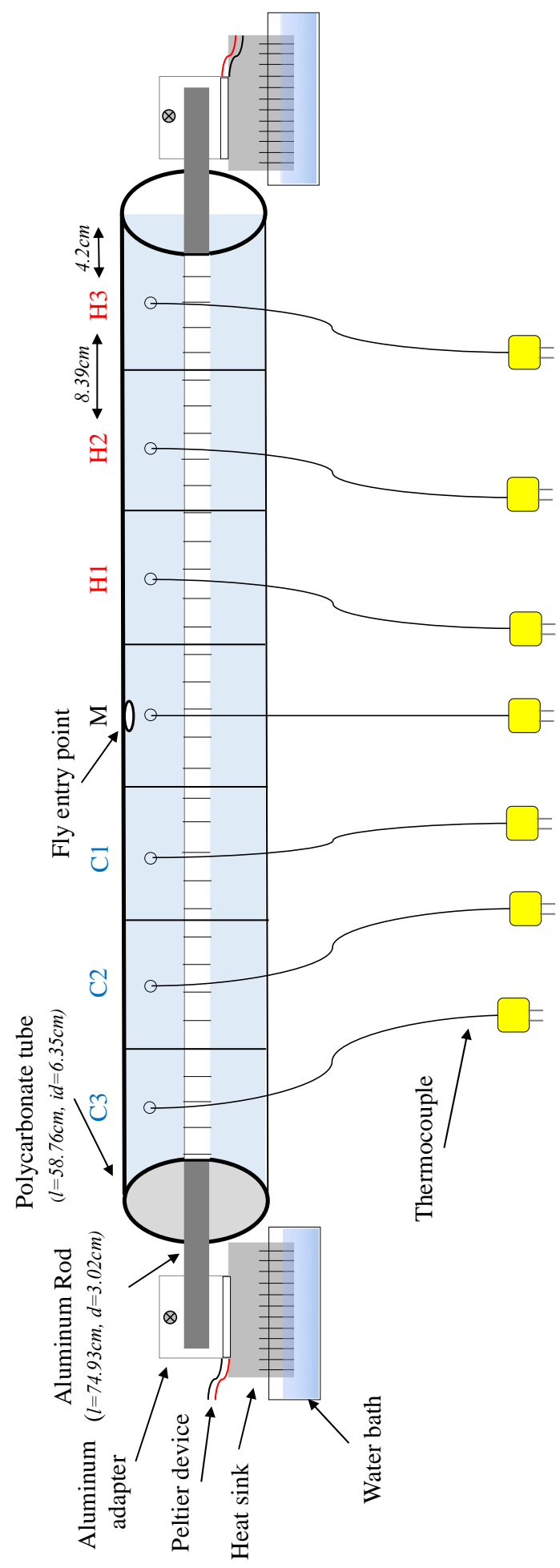

Figure B.4: Schematic of the thermal gradient apparatus used for thermal gradient assays as adapted from Rajpurohit \& Schmidt (2016). The polycarbonate tube and length of aluminum gradient with the tube were $58.76 \mathrm{~cm}$ and temperature was recorded 


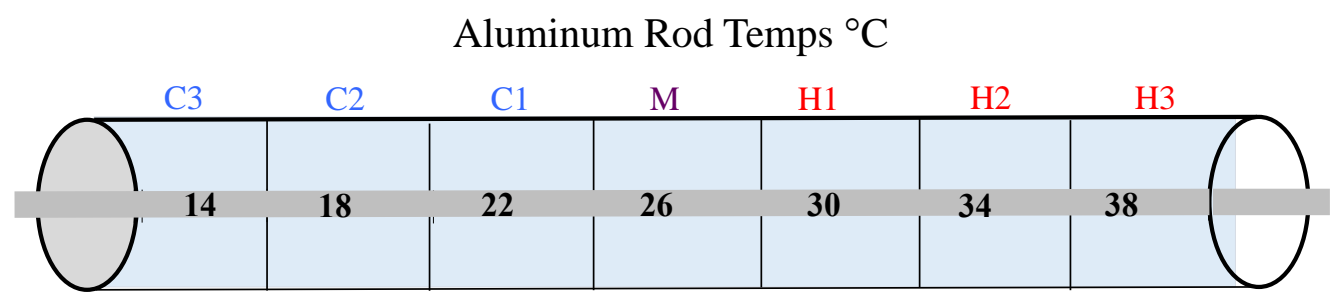

Polycarbonate Tube Temp ${ }^{\circ} \mathrm{C}$

\begin{tabular}{|c|c|c|c|c|c|c|c|}
\hline & C3 & $\mathrm{C} 2$ & $\mathrm{C} 1$ & $\mathrm{M}$ & H1 & $\mathrm{H} 2$ & $\mathrm{H} 3$ \\
\hline Top & & 21 & 23 & 25 & 27 & 29 & 31 \\
\hline Mid-point & 18 & 20 & 22 & 24 & 26 & 28 & 30 \\
\hline Bottom & 17 & 19 & 21 & 23 & 25 & 27 & 29 \\
\hline
\end{tabular}

Figure B.5: Average $+0.5^{\circ} \mathrm{C}$ (SD) temperatures from 18 runs that were recorded at each surface measured using k-type thermocouples. There was a linear increase in temperature from cold to hot as measured at each of seven evenly spaced $(8.39 \mathrm{~cm})$ 


\section{APPENDIX C: Cascades to Coast GK-12 Curriculum}

\section{CASCADES TO COAST

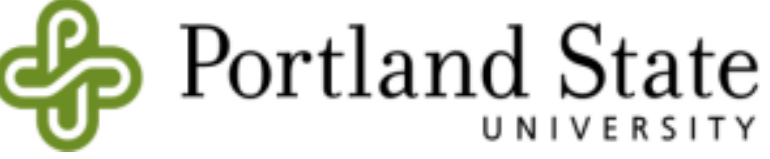

\section{Exploring Variation: Diversity Within and Between Species}

Fellows: Amy Truitt and Monica Mogilewsky (Environmental Science and Resources)

Teachers: Linda Wolf (Glencoe High School, Hillsboro, OR) and Jennie Richard

(Gresham

High School, Gresham, OR)

Advisers: Dr. Catherine E. de Rivera (Environmental Science) and Dr. Natalie Vasey (Anthropology)

\section{Learning Goal}

Students will learn to recognize variation between individuals of a species and distinguish it from variation between closely related species (species within the same order). Students will learn that variation within species arises from both genetic and environmental factors. They will also learn how scientists examine phylogenetic variation within and between species. Students will be introduced to some key terms for understanding the theory of evolution. 


\section{Students' Learning Objectives}

To recognize that all species exhibit individual variation

To learn the causes of individual variation within species

To recognize distinguish between within and between species variation

To relate the causes of individual variation to variation between species

$\square$ To learn vocabulary pertinent to the theory of evolution Target Grade: 10th Grade biology or integrated science

\section{Next Generation Science Standards}

HS.LS3.1 Ask questions to clarify relationships about the role of DNA and chromosomes in coding the instructions for characteristic traits passed from parents to offspring.

HS.LS3.2 Make and defend a claim based on evidence that inheritable genetic variations may result from: (1) new genetic combinations through meiosis, (2) viable errors occurring during replication, and/or (3) mutations caused by environmental factors. Exploring Variation_GK12 Curriculum

HS.LS3.3 Apply concepts of statistics and probability to explain the variation and distribution of expressed traits in a population.

\section{Unit Summary}

This unit will introduce students to the sources of individual variation and the vocabulary that scientists use to discuss that variation. Students will learn the two sources of variation and will practice distinguishing within species variation from between species variation. They will learn the foundations for how scientists distinguish between species. 


\section{Required Knowledge/Skills}

Students should be familiar with the hierarchical Linnaean system of classification and how to use an identification guide. Previous work with identification is helpful but not necessary.

\section{Activity Plan}

This activity is designed to be completed in two 50-60 minute class periods.

\section{Part I}

\section{Scaffolding - Sources of variation}

Instructor will introduce the definition of variation, types of variation, and sources of variation, preferably using local examples. Materials provided with this lesson plan use at least some local examples from Level III ecoregions (Cascade Mountains, Willamette Valley, and Coast Range Mountains). The instructor will compare within species variation with between species variation, preparing students to distinguish within species variation from between species variation in the hands-on exercise.

\section{Activity}

Materials needed

Exploring Variation presentation

Exploring Variation student worksheet

$\square$ An Inventory of a Few Human Traits student worksheet 


\section{Methods}

1. As a class define each trait on "An Inventory of a Few Human Traits" student worksheet.

2. Divide the class into groups of 4-5 students.

3. Working in groups, have each student complete the inventory for themselves and then

4. compare their answers to that of their group members.

5. Once students have finished their inventories, have students report their results to the class. For example, the first group might report that 2 of 4 members have pierced ears. In the interest of time, the instructor may wish to limit the number of traits report.

6. The instructor should record each group's results on the board and calculate the total number of students displaying each trait. If time allows, instructor should make histograms for two or three of the traits.

7. Use Exploring Variation power point presentation to formally introduce the primary concepts of biological variation. Have students fill out the worksheet while watching the presentation; be sure to cue them so that they know which slides will help them answer worksheet questions. Connect the concepts in the power point to traits from the Inventory of Human Traits activity.

8. After the presentation, have students again work in groups to prepare a list of traits for butterflies.

9. As a class, compile a master list of potential butterfly traits. 
10. If there is time, have students determine which of the butterfly traits are continuous and

11. which are discontinuous. Have students predict which traits would be most useful for distinguishing species and which traits would be most useful for distinguishing individuals.

\section{Part 2}

\section{Scaffolding}

The instructor should remind students of the definition of variation and should make the master list of potential butterfly traits available - either on the board or on handouts.

\section{$\underline{\text { Activity }}$}

Materials Needed

Exploring Variation student worksheet

$\square$ A collection of diverse specimen within a single order; for example, 30-50 butterflies (Order Insecta) representing 8-15 species. Collections may be created by the instructor by capturing local insects or by ordering specimen from online sources (see Credits). Alternatively, collections may be available for loan from local zoos and/or natural history museums.

$\square$ Foam core

$\checkmark$ Mounting pins

$\checkmark$ Identification guides (for the collection of specimen) Exploring Variation Student Instruction Sheet 


\section{Method}

Prepare prior to class:

1. For each student group, prepare a tray with foam core, mounting pins, masking tape and

2. 5-10 individual specimen. Number of specimen provided will depend on total number

3. of specimen available and number of student groups. Include in each group multiple representatives of 2-4 different species. Create a key for each group, so that you know the number and identity of species provided to each group.

4. During class:

5. Start by asking students for examples of variation in humans - have them first talk in

6. groups and then call on groups to contribute examples to the entire classroom.

7. Use power point presentation to introduce the following definitions: variation,

8. continuous variation, discontinuous variation, genetic variation, and environmental variation. Have students fill out the worksheet while watching the presentation; be sure to cue them so that they know which slides will help them answer worksheet questions.

9. Divide students into groups of 4-5 and give each group an identification tray.

10. Each student group should sort their specimen into species.

11. Species should be identified using the identification guide provided.

12. Specimen should be mounted to the foam core in the following manner: 
a. Butterflies should be pinned to foam core using mounting pins through the wings to help preserve the butterflies for long term use.

b. Each species should have its own row on the foam core.

c. Individual specimen of the same species should be mounted in a single line.

d. Below each row (one row per species), students should record the species

13. identification on a piece of masking tape.

14. Students should then answer the reflection questions on the Exploring Variation student

15. worksheet.

16. If time allows, have groups share their answers to the reflection questions with each

17. other.

\section{Credits}

- Power point presentation modified from www.skinnerscience.com/Biology/variation.ppt Retrieved 6 December 2014

- An Inventory of a Few Human Traits student worksheet: http://science.education.nih.gov/supplements/nihl/Genetic/guide/pdfs.htm Retrieved 9 December 2014

- *Online sources for insect collections: 


\section{http://www.insectdesigns.com/}

http://landing.carolina.com/insects?s_cid=ppc_gl_insects_ion\&gclid=CM3bxaGNssICF RFafgo duosACwhttp://www.insects 4 sale.com/

*Website addresses valid as of 6 December 2014

\section{Attachments}

$\square$ Exploring Variation presentation

$\square$ Exploring Variation student worksheet

$\square$ An Inventory of a Few Human Traits student worksheet

a Exploring Variation Student Instruction Sheet 